NBER WORKING PAPER SERIES

\title{
MARKETS FOR FINANCIAL INNOVATION
}

\author{
Ana Babus \\ Kinda Cheryl Hachem \\ Working Paper 25477 \\ http://www.nber.org/papers/w25477 \\ NATIONAL BUREAU OF ECONOMIC RESEARCH \\ 1050 Massachusetts Avenue \\ Cambridge, MA 02138 \\ January 2019, Revised January 2023
}

We thank the editor, Xavier Vives, and three anonymous referees for insightful suggestions that improved the paper. We are grateful to Paul Glasserman, John Kuong, and Pierre-Olivier Weill for thoughtful discussions. We also thank Doug Diamond, Veronica Guerrieri, Ben Hébert, Anil Kashyap, Stavros Panageas, Alireza Tahbaz-Salehi, Victoria Vanasco, and numerous seminar and conference participants for helpful comments.

NBER working papers are circulated for discussion and comment purposes. They have not been peerreviewed or been subject to the review by the NBER Board of Directors that accompanies official NBER publications.

(C) 2019 by Ana Babus and Kinda Cheryl Hachem. All rights reserved. Short sections of text, not to exceed two paragraphs, may be quoted without explicit permission provided that full credit, including (C) notice, is given to the source. 
Markets for Financial Innovation

Ana Babus and Kinda Cheryl Hachem

NBER Working Paper No. 25477

January 2019, Revised January 2023

JEL No. D47,D86,G23

\begin{abstract}
$\underline{\text { ABSTRACT }}$
We develop a theory of financial innovation in which both market structure and the payoffs of the claims being traded are determined endogenously. Intermediaries use the cash flows of an underlying asset to design securities for investors. Demand for securities arises as investors choose markets then trade using strategies represented by quantity-price schedules. We show that intermediaries create increasingly riskier asset-backed securities when facing deeper markets in which investors trade more competitively. In turn, investors elicit less risky securities when they choose thinner markets, revealing a novel role for market fragmentation in the creation of safer securities.
\end{abstract}

\author{
Ana Babus \\ Washington University in St. Louis \\ One Brookings Dr. \\ St. Louis, MS 63130 \\ anababus@gmail.com \\ Kinda Cheryl Hachem \\ University of Virginia \\ Darden School of Business \\ 100 Darden Boulevard \\ Charlottesville, VA 22906 \\ and NBER \\ hachemk@darden.virginia.edu
}




\section{Introduction}

It has long been acknowledged that non-financial firms adjust product design in response to market structure. ${ }^{1}$ Financial firms that mediate security issuances have the opportunity to do the same, and anecdotally they do. However, little is known about the theoretical forces that shape the relationship between the design of a financial claim and the market in which it trades. This is especially so when it comes to standardized securities whose payoffs are not commissioned by any one investor. What are financial intermediaries' incentives to adjust product design in response to market structure when creating securities to connect investors with markets? What are investors' incentives to participate in markets for certain securities?

We build a tractable model in which both security design and market structure are endogenously determined to study these questions. We then use the model to speak to the intricate relationship between the safety and liquidity of a security, which has recently received renewed interest in the literature. Our environment is one where financial intermediaries use the cash flows of an underlying asset to design standardized securities for investors to trade. A security specifies a payoff for every realization of the underlying asset. As in Ross (1976) and Allen and Gale (1994), we consider that financial innovation arises in response to investors' demand. However, key to our model is that the demand for securities is itself endogenous. This demand is modeled in two steps. First, investors choose a market in which to trade, which determines the market structure. Second, once markets open and investors can trade, their trading strategies are represented by quantity-price schedules, with each investor understanding the impact of her trade on the price of the security. Markets can be thinner and more fragmented with investors trading more strategically, or deeper and less fragmented with investors trading more competitively.

Financial intermediaries design securities knowing the depth of the markets they face. They do so strategically, taking into account how the payoffs of the security they design will affect the price at which investors ultimately trade the security in the market. Each investor chooses a market, and thus commits to a financial intermediary, before intermediaries design securities. ${ }^{2}$ Investors are rational and internalize how their choices will affect the market structure faced by financial intermediaries and thus the design of the securities that will be traded.

There are two implicit frictions in the environment that are worth making explicit here. First,

\footnotetext{
${ }^{1}$ See Johnson and Myatt (2003), Johnson and Myatt (2006), and Bar-Isaac, Caruana, and Cuñat (2012).

${ }^{2}$ Various extensions are possible here, including one where intermediaries design securities before each investor picks a market, which we explore as a robustness exercise.
} 
investors cannot directly invest in the same assets as financial intermediaries. This is realistic as financial intermediaries frequently create asset-backed securities that give investors exposure to markets that they could not otherwise invest in. Mortgage-backed securities are one such example. ${ }^{3}$ Second, intermediaries design securities bounded by limited liability. That is, a security's payoff cannot exceed the payoff of the asset that backs it in any given state of the world. In practice, most securities are implicitly designed to respect this constraint. In our set-up, limited liability is equivalent to the spanning constraint in the financial innovation literature (Duffie and Rahi (1995)) which requires that the securities a financial intermediary issues span the payoff of the asset that backs them.

We obtain two major sets of results. The first set of results characterizes the security that an intermediary finds optimal to offer taking as given the market structure. We show that this security depends monotonically on the depth of the intermediary's market. In particular, we show (i) that the optimal security belongs to the family of debt contracts, paying the lesser of a flat payoff and the full value of the underlying asset in every state of the world, and (ii) that the state in which the security starts paying the flat payoff is higher in markets with more investors. In other words, financial intermediaries design progressively riskier asset-backed securities when facing investors that trade more competitively. In the limit, the security approaches the payoff of the underlying asset in all states, which we refer to simply as selling "equity" to the investor.

The intuition for this first set of results is as follows. When choosing how to design a security, the intermediary's main incentive is to obtain a high price for it. Investors naturally like high expected payoffs but dislike risk, captured most simply as having mean-variance preferences. The equilibrium price at which a security is traded is therefore increasing in its mean payoff and decreasing in the variance of its payoffs across states. The intermediary thus faces a trade-off between the mean and the variance of the security he designs, making a debt contract optimal as debt has the least variance among all limited liability securities with the same expected value. Importantly, though, the equilibrium price decreases less with the variance of the security in deeper markets where investors have a lower price impact. Thus, the strength of the mean-variance trade-off faced by the intermediary (and hence where on the spectrum of debt contracts the security lies) depends on the depth of the market. The deeper the market, the less pronounced the trade-off and the more equity-like the intermediary makes his security.

\footnotetext{
${ }^{3}$ Naturally, there are derivative securities, such as equity options, for which the investors can acquire both the underlying asset (the equity security) and the derivative security (the equity option). These securities are therefore not subject to the first friction in our environment.
} 
The second set of results focuses on the equilibrium market structure. This is crucial to ensure that the securities intermediaries design in a given market structure can indeed be supported in equilibrium. If no investor benefits from trading in a particular market structure, then we should not expect the corresponding securities to arise in equilibrium.

When choosing which market to trade in, an investor weighs the gains from trade with other investors against the ability to influence the security that the intermediary designs. An investor who trades in a thinner market will have a larger price impact. On one hand, this amplifies the meanvariance trade-off in the intermediary's security design problem and delivers a less risky security. On the other hand, it also amplifies the extent to which the investor will move the price of the security against herself when trading with other investors.

Investors benefit from trading with each other because their valuations of any given security are subject to idiosyncratic preference shocks as markets open. When investors expect to be relatively homogeneous in their valuations of the same security, they anticipate limited benefits from trading with each other and are therefore willing to accept a larger price impact in order to elicit a less variable security from the intermediary. In contrast, when investors expect to be relatively heterogeneous, they understand that they may want to engage in large trades with each other so they seek to limit their price impact by choosing to trade in a large market, albeit with a riskier security.

At the core of our theoretical model is the market power that investors have relative to the financial intermediary that designs the security they trade, where market power is captured by price impact. When investors trade in thin markets, they have more market power relative to the intermediary. In this case, investors use their market power to obtain a security that is most favorable to them. In contrast, when investors trade in a deep market, the intermediary uses its relatively superior market power to design a security that is more favorable to it. These patterns are supported by emerging empirical evidence that links market power to certain aspects of bond design (e.g., Adelino, Frame, and Gerardi (2017) and Brancaccio and Kang (2022)). Our model thus elucidates a theoretical mechanism through which market power affects security design when market structure is endogenous.

By shedding light on the interaction between security design and market structure, our paper can contribute to an important agenda that studies the relationship between the safety and liquidity of a security. It is often assumed that safer securities are at least as liquid as riskier ones, but in practice the relationship between safety and liquidity is complex (e.g., Friewald, Jankowitsch, and 
Subrahmanyam (2017) and Geromichalos, Herrenbrueck, and Lee (2022)). Our baseline model predicts that less variable asset-backed securities are traded in thinner, more fragmented markets while more variable asset-backed securities are traded in deeper, less fragmented markets when securities are backed by the same underlying asset and every investor can freely choose a market in which to trade. Introducing constraints on the market choice of investors generates asymmetric equilibria where securities with different payoff profiles co-exist in markets of different sizes. If, in addition, intermediaries differ in the underlying assets they use to design asset-backed securities, then less variable securities may trade in deeper markets while more variable securities trade in thinner markets. These results highlight that multiple factors contribute to the relationship between the safety and the liquidity of a security.

A planner who chooses across market structures but is constrained to satisfy the equilibrium security design of intermediaries and the trading equilibrium among investors (when the latter can freely choose markets) would choose deeper markets, even though the security that emerges in these markets has more variable payoffs. Intermediaries are always better off designing a security for a large market than for a small market. Investors thus benefit at the expense of intermediaries in any equilibrium where debt is traded. In aggregate, however, the benefits to investors in an equilibrium where debt is traded are outweighed by the losses to intermediaries, such that total welfare is higher when markets are deeper. If the planner could decouple the security design choice from the market structure choice, then he could achieve the highest welfare by designing a debt security for risk averse investors and having them all trade this security in one large market in order to maximize the gains from trade. The problem is that security design cannot be decoupled from market structure in equilibrium. This result is at the heart of our paper. Intermediaries respond to market-based incentives when designing a security for investors to trade. These incentives come from the price of the security, which is endogenously less sensitive to investors' risk aversion in a large market because the price impact of an individual investor is decreasing in market size.

Related Literature This paper relates to several strands of literature. The most relevant studies are those on security design and endogenous market structure.

The literature on security design has been very prolific over recent decades. The classic problem explored in these papers is that of a firm needing to raise funds from an investor to finance an investment project. In exchange, the firm proposes a security to the investor. A common result in this literature is that debt is the optimal security in the presence of asymmetric information 
or moral hazard (e.g., Gale and Hellwig (1985), Gorton and Pennacchi (1990), Nachman and Noe (1994), DeMarzo and Duffie (1999), Biais and Mariotti (2005), Yang (2020), Hébert (2018), Asriyan and Vanasco (2018)). ${ }^{4}$ We explore a variant of the typical set-up. In particular, financial intermediaries issue securities which allow investors to have exposure to assets in which they cannot directly invest. The family of debt contracts is optimal even absent informational asymmetries, and, more importantly, financial intermediaries offer low-variance debt only when investors trade in a thin market. As the market gets deeper, the optimal security becomes equity. Our paper thus isolates investor market power as a force that disciplines the incentives of intermediaries in security design. Isolating this force is important as investor market power can have unique policy implications; see Babus and Hachem (2021) for an application of our model to regulatory debates about centralized trading, specifically the introduction of a centralized exchange to improve market access and increase liquidity.

Parallel to the literature on security design, there is a body of work on financial innovation that studies the role of security issuances in completing markets. From the seminal paper of Allen and Gale (1991) to the more recent contribution of Carvajal, Rostek, and Weretka (2012), the main focus of this line of research is to analyze whether competition among asset-holders affects their incentives to introduce new securities. Complementarily to this literature, we study a model in which a financial intermediary's decision to issue securities is affected by the strategic competition between investors when trading the securities they are offered.

There is a young but growing literature on endogenous market structure. Babus and Parlatore (2022), Cespa and Vives (2022), Dugast, Üslü, and Weill (2022), Lee and Wang (2018), and Yoon (2018) provide models that seek to explain why trade takes places in a variety of venues, centralized or decentralized. However, in these papers, the asset traded is taken to be exogenous. We endogenize both the security design and the market participation decision, which allows us to study the relationship between the type of security and the market structure in which it is traded.

A small number of papers study the effect of market structure on security design. In a set-up which assumes that investors are better informed about the prospects of the issuer than the issuer himself, Axelson (2007) shows that debt is optimal if the degree of competition among investors is low. Rostek and Yoon (2022) analyze the role of market structure for introducing non-redundant

\footnotetext{
${ }^{4}$ In Malenko and Tsoy (2018), a mixture of debt and equity can be optimal when the investor faces Knightian uncertainty about the underlying project's returns. Other models of endogenous capital structure instead assume transaction costs of security issuance as in Allen and Gale (1988); see, for example, Corbae and Quintin (2019) on the cyclical properties of safe debt.
} 
derivatives. In both of these papers, however, the market structure is taken to be exogenous. In our paper, the market structure is endogenously determined. This is important, as it ensures that the securities traded in a given market structure can indeed be supported in equilibrium.

The rest of the paper proceeds as follows: Section 2 introduces the model environment; Section 3 defines and characterizes the equilibrium; Section 4 connects some predictions of the model to real world markets; Section 5 discusses aggregate welfare; and Section 6 concludes. All proofs are collected in Appendix A.

\section{The Model Set-Up}

Our analysis focuses on how financial firms adjust the design of their securities in response to the demand they face from investors. To capture the interactions between investors and financial intermediaries in a simple setting, we adopt a standard security design framework in which we allow investors to trade the security that intermediaries design. To this, we add a market formation stage to capture how investors' demand arises. This is a key step to ensure that the securities intermediaries design in response to investors' demand can indeed be supported in equilibrium.

We consider an economy with three dates, $t=0,1,2$, and two types of agents, financial intermediaries and investors.

Intermediaries There are $M \geq 2$ risk neutral, impatient financial intermediaries indexed by $m=1, \ldots, M$. Each intermediary has access to a risky asset $Z$ at $t=0$. The asset can be interpreted as loans originated to firms or mortgages extended to households. Each unit of the

asset $Z$ yields a payoff $z(s) \geq 0$ if the aggregate state $s \in[0, S]$ is realized at date $t=2$. The cumulative distribution function for states is $F(s)$, with $F(\cdot)$ continuous and differentiable, and the probability density function is $f(s)$. Without loss of generality, we assume $z^{\prime}(\cdot)>0$.

A local market $m$ is associated with each intermediary $m$. At $t=0$ in each market $m$, the intermediary sells claims to the payoff of asset $Z$ to investors by issuing a security $W_{m}$ that pays $w_{m}(s) \geq 0$ in state $s$ at date $t=2$. The intermediary is the residual claimant on $Z$. Thus he is effectively designing two securities, one that he offers to investors and one that he keeps for himself, so that the two securities exhaust the payoff of asset $Z$, as is commonly assumed in the financial innovation spanning literature (Duffie and Rahi (1995)). Formally, this implies that the payoff of 
the security $W_{m}$ is subject to a feasibility constraint of the form

$$
w_{m}(s) \leq \alpha_{m} z(s), \forall s \in[0, S]
$$

where $\alpha_{m}>0$ allows for the possibility that the quantity of the underlying asset $Z$ available to intermediary $m$ differs from the quantity of $W_{m}$ that he issues to investors. In the simplest case, $\alpha_{m}=1$ which simplifies (1) to

$$
w_{m}(s) \leq z(s), \forall s \in[0, S] .
$$

We use feasibility constraint (2) in our main set-up and study the more general case with constraint (1) and $\alpha_{m}$ endogenous in Online Appendix B.1. The simplified feasibility constraint in (2) is consistent with an interpretation in which each intermediary issues an asset-backed security based on a representative loan that he previously originated. The more general constraint studied in Online Appendix B.1 is consistent with an interpretation in which each intermediary buys loans from a loan originator in order to issue an asset-backed security.

Investors There are $N \geq 3$ risk averse, patient investors, indexed by $i=1, \ldots, N$, who have mean-variance preferences. ${ }^{5}$ Investors do not have access to the asset $Z$. However, an investor who wants exposure to $Z$ can choose a local market $m$ in which she can acquire some quantity of the security $W_{m}$ that intermediary $m$ designs.

We model how investors' demand for securities arises in two steps. First, investors choose markets at date $t=0$. An investor can choose at most one market, but multiple investors can choose the same market. These choices determine a market structure $\mathcal{M}$, which remains fixed for the remaining periods. Second, markets open for trade at $t=1$ and each security $W_{m}$ is traded by investors in market $m$. Investors are subject to idiosyncratic preference shocks between the time they choose markets at $t=0$ and the time they trade with each other at $t=1$. These shocks introduce a reason for investors to trade with each other at $t=1$, as we will see below. Preference shocks are I.I.D. across investors and independent of the realization of the state $s$.

When an investor $i$ chooses a market $m$ at $t=0$, we say that $i \in m$. We denote by $n_{m}$ the number of investors that choose market $m$. We consider a market $m$ to be active if and only if

\footnotetext{
${ }^{5}$ The extensive use of mean-variance preferences in portfolio selection models sparked a debate about the utility theoretic foundations of these preferences. Several solutions have been proposed for a general distribution of shocks. One is to rationalize the mean-variance representation from a second-order Taylor approximation of a generic utility function. Another is to derive mean-variance exactly from a quadratic utility function. The quadratic functional form has been used widely in models with strategic competition, e.g., Vives (2011) and Rostek and Weretka (2012).
} 
$n_{m}>2$, as in Kyle (1989). In this case, we say that $m \in \mathcal{M}$. A market structure $\mathcal{M}$ is characterized by the number of active markets and by the number of investors in each active market. We define a market structure to be symmetric if each active market $m$ has the same number of investors $n_{m}=n$.

We model investors' trading strategies at $t=1$ as quantity-price schedules, as in Kyle (1989) and Vives (2011). In particular, the strategy of an investor is a map from her information set to the space of demand functions, as follows. The demand function of an investor $i \in m$ with preference shock $\theta^{i}$ is a continuous function $Q_{m}^{i}: \mathbb{R} \rightarrow \mathbb{R}$ which maps the price $p_{m}$ of the security $W_{m}$ in market $m$ into a quantity $q_{m}^{i}$ she wishes to trade

$$
Q_{m}^{i}\left(p_{m} ; \theta^{i}\right)=q_{m}^{i}
$$

An investor $i$ who trades $q_{m}^{i} \in \mathbb{R}$ units of security $W_{m}$ in market $m$ at date $t=1$ consumes $C_{m}^{i}$ at date $t=2$, where

$$
c_{m}^{i}(s)=q_{m}^{i} w_{m}(s)
$$

for each state $s$.

Timing To summarize, the timing of events in the model is as follows. At date $t=0$, each investor chooses a market $m$ in which to trade. The intermediary in market $m$ then designs the security $W_{m}$. At date $t=1$, each investor $i$ learns her preference shock $\theta^{i}$. All markets then open and investors in each market $m$ trade the security $W_{m}$. At date $t=2$, the state $s$ is realized. Investors receive payoffs according their final holdings of the security. Consumption takes place.

In line with Ross (1976) and Allen and Gale (1994), we have taken the approach that financial innovation is driven by investors' demand. For this, we have assumed that intermediaries design securities after investors choose markets. At the same time, our focus is on studying the issuance of standardized securities. For this, we have assumed that intermediaries design securities before the preference shocks, $\theta^{i}$, are realized. Thus, a security cannot be customized to address the specific requirements of any particular investor.

Payoffs and Market Clearing We now formalize the payoffs of investors and intermediaries. Given a market structure $\mathcal{M}$ and a security $W_{m}$ that intermediary $m$ designs at date $t=0$, the 
expected payoff of an investor $i$ in market $m$ at date $t=1$ as she engages in trade is

$$
V_{m}^{i}=\theta^{i} E_{1}\left(C_{m}^{i}\right)-\frac{\gamma}{2} \mathcal{V}_{1}\left(C_{m}^{i}\right)-p_{m} q_{m}^{i}
$$

where the parameter $\gamma>0$ controls the degree of risk aversion and $\mathcal{V}(\cdot)$ is the variance operator. We use $E_{1}(\cdot)$ and $\mathcal{V}_{1}(\cdot)$ to denote that expectations are being taken over the state $s$, which is the only unknown at date $t=1$. The preference shock $\theta^{i}$ is modeled as shifting the intercept of the marginal utility of consumption of investor $i$, as in Rostek and Weretka (2012). It is conceptually similar to an opposite shift in the investor's risk aversion parameter but analytically simpler to work with. The shock $\theta^{i}$ is independently distributed across investors according to a distribution $G(\cdot)$ with mean $\mu_{\theta}$ and standard deviation $\sigma_{\theta}$ and is also independent of the realization of the state $s$.

Substituting Eq. (3) into Eq. (4), we obtain that investor $i$ 's objective function at date $t=1$, before the uncertainty about the state of the world $s$ has been resolved, is

$$
V_{m}^{i}=\left[\theta^{i} E_{1}\left(W_{m}\right)-p_{m}\right] q_{m}^{i}-\frac{\gamma}{2} \mathcal{V}_{1}\left(W_{m}\right)\left(q_{m}^{i}\right)^{2}
$$

where $E_{1}\left(W_{m}\right) \equiv \int_{0}^{S} w_{m}(s) d F(s)$ and $\mathcal{V}_{1}\left(W_{m}\right) \equiv \int_{0}^{S}\left[w_{m}(s)-E_{1}\left(W_{m}\right)\right]^{2} d F(s)$. In this reformulation, the preference shock $\theta^{i}$ captures investor $i$ 's valuation of the payoff she expects to obtain from one unit of the security $W_{m}$. The heterogeneity that $\theta^{i}$ introduces across investors can be interpreted as differences in liquidity needs, in the use of securities as collateral, in technologies to repackage and resell cash flows, or in risk-management constraints, for example.

The price $p_{m}$ in Eq. (5) is the price at which local market $m$ clears, given the supply of the security $W_{m}$ by intermediary $m$. To reduce notation, we assume that each intermediary $m$ supplies one unit per capita of the security $W_{m}$ in his market. ${ }^{6}$ That is, intermediary $m$ supplies $n_{m}$ units of the security $W_{m}$. Then, the market clearing price $p_{m}$ is such that

$$
\sum_{i \in m} Q_{m}^{i}\left(p_{m} ; \theta^{i}\right)=n_{m}
$$

\footnotetext{
${ }^{6}$ If the intermediary is instead assumed to supply a fixed amount of $W_{m}$ to his market, then we would obtain results that mechanically go in the same direction as those in our main set-up while carrying additional notation. Alternatively, if the intermediary could choose the total supply of $W_{m}$ along with the state-by-state payoffs of $W_{m}$, then he would have enough instruments to offset the impact of investors' market power on the price of $W_{m}$ provided he is subject to the feasibility constraint (2) and does not face any issuance costs. If, however, issuance costs are introduced or the intermediary faces the more general feasibility constraint (1), then investors still have market power relative to the intermediary, even if the intermediary can choose the supply of $W_{m}$.
} 
Turn now to the payoffs of intermediaries. An intermediary $m$ supplies $n_{m}$ units of the security $W_{m}$ to investors in market $m$, and for each unit of the security, he receives the price $p_{m}$ implied by Eq. (6) at date $t=1$. Aside from supplying $W_{m}$ to the market, the intermediary does not take any position in this security. The intermediary is also the residual claimant on the payoff of asset $Z$, and under constraint (2), he receives $\left(Z-W_{m}\right)$ at date $t=2$ for each unit of $W_{m}$ that he supplied. ${ }^{7}$

The trading protocol through which investors in market $m$ acquire the security $W_{m}$ corresponds to a share auction as described by Wilson (1979). ${ }^{8}$ Given a market structure $\mathcal{M}$ and a security $W_{m}$ that the intermediary designs in a market $m$ with $n_{m}$ investors at date $t=0$, intermediary $m$ 's expected payoff at date $t=1$ is

$$
V_{m}=\left[p_{m}+\beta E_{1}\left(Z-W_{m}\right)\right] \times n_{m},
$$

where $\beta \in[0,1]$ is a discount factor that captures the impatience of intermediaries relative to investors.

\section{Equilibrium}

In this section, we define and characterize the equilibrium. We start by solving for the trading equilibrium in each market $m$ at date $t=1$, given a market structure $\mathcal{M}$ and the securities $W_{m}$ that intermediaries design at date $t=0$. We then characterize the security that each intermediary designs in equilibrium for his market $m$ at date $t=0$, given a market structure $\mathcal{M}$. Lastly, we analyze the market formation game which determines the equilibrium market structure $\mathcal{M}$ at $t=0$.

Definition 1 A subgame perfect equilibrium is a market structure $\mathcal{M}$, a set of securities $\left\{W_{m}\right\}_{m \in \mathcal{M}}$, and a set of demand functions $\left\{Q_{m}^{i}\right\}_{i \in m}$ for investors in each active market $m$ such that:

\footnotetext{
${ }^{7}$ We give intermediaries access to a sufficiently large pool of the asset $Z$ so that constraint (2) is satisfied. An alternative would be to fix the quantity of $Z$ available to intermediary $m$ at some exogenous value. As we explain in Online Appendix B.1, this alternative would generate mechanical effects that only reinforce our results.

${ }^{8}$ In particular, our set-up is consistent with the interpretation that at date $t=1$ each intermediary $m$ functions as a central counterparty and places the $n_{m}$ units of the security $W_{m}$ with investors in his market by running the following auction. Each investor $i$ in market $m$ is a bidder that submits a schedule indicating the quantity of the security she demands at each price. The supply of the security is perfectly divisible and, in each market $m$, the security is allocated at the clearing price, $p_{m}$, which is the solution to the market clearing condition (6). Each investor $i$ receives a share $q_{m}^{i}$ of the security for which she pays $p_{m} q_{m}^{i}$.
} 
1. $Q_{m}^{i}$ solves each investor $i$ 's problem at date $t=1$

$$
\max _{Q_{m}^{i}}\left\{\left[\theta^{i} E_{1}\left(W_{m}\right)-p_{m}\right] Q_{m}^{i}\left(p_{m} ; \theta^{i}\right)-\frac{\gamma}{2}\left(Q_{m}^{i}\left(p_{m} ; \theta^{i}\right)\right)^{2} \mathcal{V}_{1}\left(W_{m}\right)\right\}
$$

where the price $p_{m}$ satisfies market clearing, Eq. (6);

2. $W_{m}$ solves each financial intermediary $m$ 's problem at date $t=0$

$$
\max _{W_{m}} E_{0}\left\{p_{m}+\beta\left[E_{1}(Z)-E_{1}\left(W_{m}\right)\right]\right\} \times n_{m}
$$

subject to the feasibility constraint (2);

3. The market structure $\mathcal{M}$ is $\ell$-stable at date $t=0$. That is, for any group $\mathcal{L}=\left\{i_{1}, \ldots, i_{\ell}\right\}$ of investors, there is no subset in $\mathcal{L}$ that benefits from deviating and joining a different local market.

Our notion of equilibrium market structure, described in the third bullet of Definition 1, allows for multiple investors, not necessarily all in the same local market, to coordinate and jointly deviate to another local market, $m^{\prime}$. For a market structure $\mathcal{M}$ to be $\ell$-stable, the expected payoff any investor $i_{j} \in \mathcal{L}$ receives in her local market $m$ must be at least as large as the expected payoff from deviating to any other market $m^{\prime}$, that is,

$$
E_{0}\left(V_{m}^{i_{j}}\right) \geq E_{0}\left(V_{m^{\prime}}^{i_{j}}\right) \text { for all } m^{\prime} \neq m
$$

including those markets $m^{\prime} \notin \mathcal{M}$. Thus, there is no group of up to $\ell$ investors that can benefit from exiting their local markets and all joining an inactive market $m^{\prime}$ (i.e., a market with $n_{m^{\prime}} \leq 2$ ) under the market structure $\mathcal{M}$. Similarly, there is no group of up to $\ell$ investors that can benefit from exiting their local markets and all joining an active market $m^{\prime} \in \mathcal{M}$. Notice that $\ell=1$ corresponds to the case where investors cannot coordinate and can only consider unilateral deviations. The ability of investors to coordinate, as captured by $\ell>1$, can be the result of a financial intermediary poaching investors to join his local market rather than explicit cross-market coordination by investors. Our notion of an $\ell$-stable equilibrium market structure is related to the concept of group/strong stability defined in Roth and Sotomayor (1990) and used more recently by Farboodi (2021).

It is important to note that all agents act strategically. This implies that each investor $i \in m$ takes into account her price impact in market $m$ when submitting her demand. Similarly, an 
intermediary understands how the security he designs at date $t=0$ affects the price at which investors trade it at date $t=1$. At the market formation stage, each investor also takes into account how her market choice shapes the security that the intermediaries design, as well as the price at which trade takes place at date $t=1$. To streamline the exposition, we restrict our attention to equilibria in which the market structure is symmetric, intermediaries design the same security, and agents have linear trading strategies.

The rest of this section characterizes the equilibrium. As mentioned earlier, we solve first for the trading equilibrium conditional on a market structure and a set of securities (Section 3.1), then for the equilibrium security conditional on a market structure (Section 3.2), and finally for the equilibrium market structure (Section 3.3).

\subsection{The Trading Equilibrium}

At date $t=1$, after each investor $i$ learns her preference shock $\theta^{i}$, all active markets open and trade takes place. In each market $m$, an investor chooses her trading strategy in order to maximize her expected payoff, understanding that she has impact on the price $p_{m}$. As is standard in similar models, we simplify the optimization problem (7), which is defined over a function space, to finding the functions $Q_{m}^{i}\left(p_{m} ; \theta^{i}\right)$ pointwise; see Vives (2008) for a comprehensive treatment. For this, we fix a realization of the set of preference shocks, $\left\{\theta^{i}\right\}_{i=1}^{N}$. Then, we solve for the optimal quantity $q_{m}^{i}$ that each investor $i \in m$ demands in market $m$ when she takes as given the demand functions of the other investors in market $m$. Thus, we obtain investor $i$ 's best response quantity $q_{m}^{i}$ in market $m$ for each realization of the preference shocks of the other investors in market $m$. This gives us a map from prices to quantities, or the investor's optimal demand function point by point. We describe the procedure in detail below.

The first order condition for an investor $i$ in market $m$ is

$$
\theta^{i} E_{1}\left(W_{m}\right)-p_{m}-\left(\frac{\partial p_{m,-i}}{\partial q_{m}^{i}}+\gamma \mathcal{V}_{1}\left(W_{m}\right)\right) q_{m}^{i}=0
$$

where $p_{m,-i}$ is the residual inverse demand of investor $i$ implied by

$$
q_{m}^{i}+\sum_{j \in m, j \neq i} Q_{m}^{j}\left(p_{m} ; \theta^{j}\right)=n_{m}
$$

An investor $i \in m$ chooses to trade a quantity $q_{m}^{i}$ of the security $W_{m}$ so that her marginal 
benefit equalizes her marginal cost of trading. The first term in the first order condition (10) is the marginal benefit of increasing the final holdings of the security $W_{m}$ for investor $i$, which is given by the expected value of the security scaled by the investor's preference shock $\theta^{i}$. The remaining terms in Eq. (10) represent investor $i$ 's marginal cost of increasing her demand. The second term represents the price that the investor pays to acquire one unit of the security $W_{m}$. Investors also incur indirect costs, captured in the last term in Eq. (10). First, since the investors trade strategically, increasing the quantity demanded has an impact on the market clearing price. Note that the price impact implied by Eq. (11) will be non-stochastic, and hence independent of the realization of the preference shocks $\left\{\theta^{i}\right\}_{i \in m}$, when the demands of the other investors in market $m$ are linear. Second, investors are risk averse, which maps into a holding cost of the security that increases proportionally to the variance of $W_{m}$ as the quantity demanded increases. Eq. (10) implies that investor $i$ 's best response demand function is linear when the demands of the other investors in market $m$ are linear. The following proposition characterizes the trading equilibrium in a market $m$.

Proposition 1 Given a market structure $\mathcal{M}$ and a set of securities $\left\{W_{m}\right\}_{m \in \mathcal{M}}$, there exists a unique symmetric linear equilibrium that characterizes investors' trading strategies in each market $m$, as follows. The equilibrium demand function of an investor $i$ in market $m$ is

$$
Q_{m}^{i}\left(p_{m} ; \theta^{i}\right)=\frac{1}{\left(1+\lambda_{m}\right) \gamma \mathcal{V}_{1}\left(W_{m}\right)}\left[\theta^{i} E_{1}\left(W_{m}\right)-p_{m}\right]
$$

where $\lambda_{m}^{-1} \equiv\left(n_{m}-2\right)$ is an index of market depth. The equilibrium price in market $m$ is

$$
p_{m}=\left(\frac{1}{n_{m}} \sum_{i \in m} \theta^{i}\right) E_{1}\left(W_{m}\right)-\left(1+\lambda_{m}\right) \gamma \mathcal{V}_{1}\left(W_{m}\right)
$$

Proposition 1 shows that investor $i$ buys or sells the security $W_{m}$ depending on whether her valuation $\theta^{i} E_{1}\left(W_{m}\right)$ of the security's expected payoff is above or below the price $p_{m}$ at which she can trade. However, as can be seen from the denominator of Eq. (12), the investor will restrict the size of her trade for two reasons. First, she is risk averse and the security is risky. Thus, the more risk averse the investor is (as proxied by a higher $\gamma$ ), the less she will trade. Similarly, the more risky the security is (as reflected in a higher variance of payoffs across states), the less of it the investor trades, everything else constant. Second, the investor has a price impact, $\partial p_{m,-i} / \partial q_{m}^{i}=\lambda_{m} \gamma \mathcal{V}_{1}\left(W_{m}\right)$, that decreases with market depth, $\lambda_{m}^{-1}$. In other words, the larger the market is, the more the investor 
can trade without moving the price against herself.

The equilibrium price in market $m$, characterized by Eq. (13), is the expected payoff of the security $W_{m}$, scaled by the average valuation of the investors in market $m$, minus a risk premium. The risk premium exists because investors are risk averse and have exposure to a risky security that is in positive fixed supply.

Given a realization of investors' preference shocks, $\left\{\theta^{i}\right\}_{i=1}^{N}$, it follows from Eq. (13) that the price of the security $W_{m}$ is lower in a thinner market. The price of the security also decreases with the variance of the security, everything else constant. However, the price decreases less with the variance of the security as the market becomes deeper. ${ }^{9}$ These effects arise because investors are strategic and dislike risk. In a smaller market, changes in the demand of an individual investor have a larger impact on the price of the security. Furthermore, the riskier the security is, the less of it a risk averse investor will demand. If an investor demands less of the security, more will be available to other investors. The price will then have to fall so that, on average, other investors are content with holding more of the security. As the size of the market increases, the price impact of any one investor falls. An increase in riskiness is thus met with a smaller decrease in price compared to a smaller market where a strategic decrease in demand by one investor leads to a bigger price drop.

The effects of market depth and the variance of the security on the price are typical of models in which investors strategically trade risky assets in positive net supply by submitting demand functions. In contrast to standard models, however, in our model both the variance of the security and the market depth are endogenous. In particular, the security is the choice of the intermediaries, while the market structure, and implicitly the market depth, is the outcome of investors' choices. Our paper seeks to understand how these forces interact.

\subsection{The Equilibrium Security}

At the end of date $t=0$, after the market structure is determined, each active intermediary $m$ designs a security $W_{m}$ in response to investors' demand in his market. In particular, an intermediary chooses the payoff $w_{m}(s)$ of the security for each state $s$ to maximize his expected profit in (8), subject to the feasibility constraint (2). The constraint (2) restricts the intermediary to offer investors a security with a payoff that does not exceed what the intermediary realizes on the asset

\footnotetext{
${ }^{9}$ To verify this, consider the cross-partial derivative of the price $p_{m}$ with respect to the variance of the security $W_{m}$ and the number of investors in market $m$, holding everything else constant. This derivative is given by $\left.\frac{\partial}{\partial n_{m}} \frac{\partial p_{m}}{\partial \mathcal{V}_{1}\left(W_{m}\right)}\right|_{E_{1}\left(W_{m}\right)=c s t}=-\gamma \frac{\partial \lambda_{m}}{\partial n_{m}}>0$.
} 


\section{$Z$ in any state $s$.}

Taking the expectation at date $t=0$ of the price $p_{m}$ at which investors in market $m$ trade the security $W_{m}$ (i.e., the price in Eq. (13)) and substituting it into (8), we obtain that intermediary $m$ designs the security $W_{m}$ to maximize the following objective function:

$$
E_{0}\left(V_{m}\right)=\left[\beta E_{1}(Z)+\left(\mu_{\theta}-\beta\right) E_{1}\left(W_{m}\right)-\left(1+\lambda_{m}\right) \gamma \mathcal{V}_{1}\left(W_{m}\right)\right] \times n_{m}
$$

It is transparent that the intermediary benefits from offering a security that pays well in expectation, as the expected price at which investors trade is increasing in $E_{1}\left(W_{m}\right) .{ }^{10}$ At the same time, the intermediary increases his expected profit if he offers a security with low variance, as the expected price at which investors trade is decreasing in $\mathcal{V}_{1}\left(W_{m}\right)$. In fact, if he were unconstrained, the intermediary would offer a security with infinite mean and zero variance. However, because the payoff of the security $W_{m}$ cannot exceed the payoff of the asset $Z$, the intermediary faces a trade-off between the mean and the variance of the security he designs. Since the weight on the variance in the intermediary's expected profit in Eq. (14) depends on the depth $\lambda_{m}^{-1}$ of the market in which the security is traded, how exactly this trade-off is resolved will depend on the market structure, as characterized in the following proposition.

Proposition 2 Suppose $\mu_{\theta}>\beta$ so that intermediaries find it profitable to design securities for investors. In any market $m$ with $n_{m}$ investors, intermediary $m$ designs a security $W_{m}$ with payoffs

$$
w_{m}(s)= \begin{cases}z(s) & \text { if } s<\bar{s}_{m} \\ E_{1}\left(W_{m}\right)+\frac{\mu_{\theta}-\beta}{2 \gamma} \frac{n_{m}-2}{n_{m}-1} & \text { if } s \geq \bar{s}_{m}\end{cases}
$$

where the threshold state $\bar{s}_{m} \in[0, S]$ is defined by

$$
\bar{s}_{m}= \begin{cases}z^{-1}\left(E_{1}\left(W_{m}\right)+\frac{\mu_{\theta}-\beta}{2 \gamma} \frac{n_{m}-2}{n_{m}-1}\right), & \forall n_{m}<n_{S} \\ S, & \forall n_{m} \geq n_{S}\end{cases}
$$

and $n_{S}$ is finite if and only if the equation

$$
\frac{n_{S}-2}{n_{S}-1}=\frac{2 \gamma}{\mu_{\theta}-\beta}\left[z(S)-E_{1}(Z)\right]
$$

\footnotetext{
${ }^{10}$ Notice that $E_{0}\left(W_{m}\right)=E_{0}\left(E_{1}\left(W_{m}\right)\right)$ is the law of iterated expectations and, since there is no information being revealed between $t=0$ and $t=1$, it follows that $E_{0}\left(W_{m}\right)=E_{1}\left(W_{m}\right)$.
} 
has a solution $n_{S} \geq 3$.

Proposition 2 shows that intermediary $m$ finds it optimal to design a security that will pay the lesser of a flat payoff and the full value of the asset $Z$ in every state of the world. The security payoff depends on the market structure, the distribution of the underlying asset $Z$, and the preferences of investors and intermediaries. We say that the security is debt if it pays the flat payoff in at least some states (i.e., the security is debt if $\bar{s}_{m}<S$ ). The flat payoff that is paid in states $s \geq \bar{s}_{m}$ represents the face value of the security. If the security replicates the payoff of the asset $Z$ in all states, then the intermediary sells everything to the investors and passes through the payoffs of the underlying asset $Z$. For convenience, we refer to the security that replicates the payoff of the asset $Z$ in all states as equity. ${ }^{11}$ In our model, equity is the limiting case of a debt security where the threshold state above which the security pays a flat payoff is $\bar{s}_{m}=S$.

We have the following three cases from the characterization of $n_{S}$ in Proposition 2. If $\frac{2 \gamma}{\mu_{\theta}-\beta}\left[z(S)-E_{1}(Z)\right] \leq \frac{1}{2}$, then the intermediary finds it optimal to sell everything and offer equity in any market structure. If $\frac{2 \gamma}{\mu_{\theta}-\beta}\left[z(S)-E_{1}(Z)\right] \geq 1$, then the intermediary finds it optimal to design a debt security in any market structure, including in markets with infinitely many investors. These two cases represent corner solutions of the intermediary's optimization problem. If instead $\frac{2 \gamma}{\mu_{\theta}-\beta}\left[z(S)-E_{1}(Z)\right] \in\left(\frac{1}{2}, 1\right)$, then intermediary $m$ offers a debt security if the number of investors $n_{m}$ in market $m$ is below a threshold $n_{S}$, otherwise he offers equity.

Figure 1 illustrates the optimal security for different values of $n_{m}$ in the last case where the solution to the intermediary's optimization problem can be either debt or equity. The rest of this section expounds the properties depicted in the figure.

The rationale for why debt is the security that the intermediary chooses from the set of all possible security profiles stems from the following property of a debt security: there are no two states $s^{\prime}$ and $s^{\prime \prime}$ such that $w_{m}\left(s^{\prime}\right)<z\left(s^{\prime}\right)$ and $w_{m}\left(s^{\prime}\right)<w_{m}\left(s^{\prime \prime}\right)$. In other words, if the feasibility constraint (2) does not bind in either state $s^{\prime}$ or state $s^{\prime \prime}$, the debt security yields the same payoff in both states, and if constraint (2) binds only in one of the two states, the payoff in that state must be smaller than the payoff on the flat part of the debt contract. Suppose intermediary $m$ chooses a security that does not have this property. Then a deviation which increases the payoff of the security in state $s^{\prime}$ by $\varepsilon_{s^{\prime}}>0$ and decreases the payoff of the security in state $s^{\prime \prime}$ by $\varepsilon_{s^{\prime \prime}}=\frac{f\left(s^{\prime}\right)}{f\left(s^{\prime \prime}\right)} \varepsilon_{s^{\prime}}$ decreases the variance of the security without changing its mean. Since the intermediary's expected profit in

\footnotetext{
${ }^{11}$ Typically, in the literature on security design, an equity security has a payoff that yields a fraction of the underlying asset. We extend this definition to accommodate a fraction of 1 .
} 


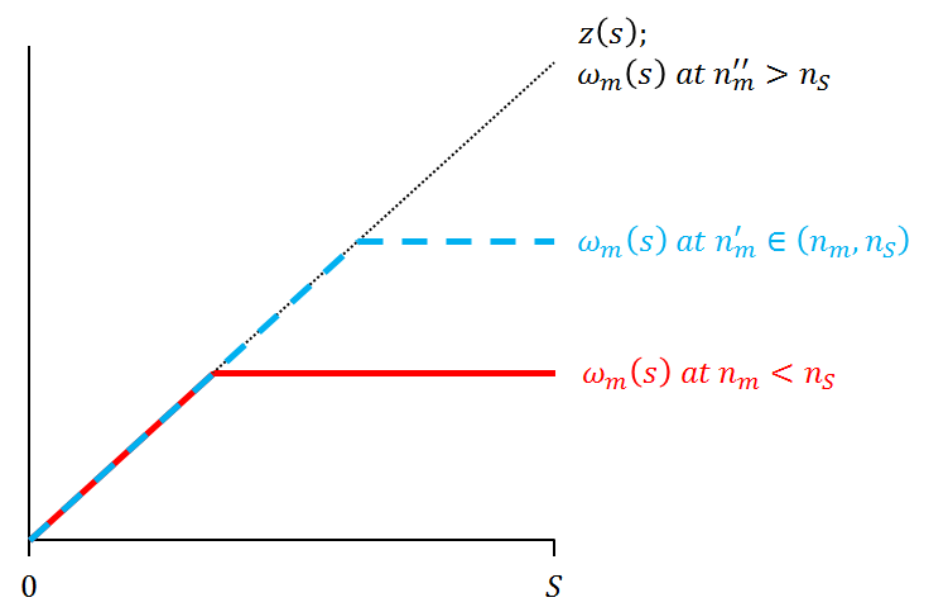

Figure 1: Dependence of optimal security on market size.

Eq. (14) is decreasing in the variance of the security, it follows that such a deviation is profitable. Therefore, it cannot be optimal for the intermediary to choose any security other than debt. This argument is similar to the one Hébert (2018) uses to show that debt is the optimal contract in the presence of moral hazard. Novel to our framework, however, is how the equilibrium security depends on the market structure in which it is traded. The following proposition characterizes the relationship between the market structure and the debt contract that the intermediary chooses.

Proposition 3 Suppose $\frac{2 \gamma}{\mu_{\theta}-\beta}\left[z(S)-E_{1}(Z)\right]>\frac{1}{2}$ so that $n_{S} \geq 3$. Then the threshold state $\bar{s}_{m}$ defined by (16) is increasing in the number of investors $n_{m}$ in market $m$ as long as $n_{m} \leq n_{S}$.

Proposition 3 shows that when the intermediary designs a debt security, he will adjust its payoff depending on the market in which the security is traded. In particular, the lowest state in which a security $W_{m}$ pays the flat payoff increases with the number of investors in market $m$, as depicted in Figure 1. In other words, conditional on designing a debt security, the intermediary offers a higher face value in a larger market. At the same time, the larger the market, the more variable the security that the intermediary designs. This property of the equilibrium security extends automatically to the case when Eq. (17) does not have a finite solution and the intermediary offers debt in markets of any size.

To understand Proposition 3, we appeal to the intuition developed at the end of Section 3.1 about the forces that affect the price of a security $W_{m}$. To start, consider a state $s$ where the security that intermediary $m$ designs pays $w_{m}(s)<z(s)$. If the intermediary increases $w_{m}(s)$ slightly, holding constant the payoffs in all other states, then he increases both the mean and 
the variance of the security $W_{m}$. The increase in the mean of the security works in favor of the intermediary because it increases the price he expects to receive, whereas the increase in the variance of the security decreases the intermediary's expected profit. However, as we explained in Section 3.1, a higher variance has a greater impact on the expected price in a small market than in a large market. In contrast, as we can see from Eq. (13), the impact of a higher mean on the expected price does not depend on the size of the market. Therefore, the marginal benefit to the intermediary of an increase in $w_{m}(s)$ is independent of $n_{m}$, while the marginal cost is decreasing in $n_{m}$. Since a profit-maximizing intermediary sets $w_{m}(s)$ to equate marginal benefit and marginal cost, it follows that he will increase $w_{m}(s)$ by more in a large market than in a small market. Given that the intermediary finds it optimal to issue a debt security, he can accomplish this by increasing the threshold state above which the security pays a flat payoff. The next corollary formalizes this discussion and follows immediately from Proposition 3.

Corollary 1 Suppose that Eq. (17) has a finite solution $n_{S} \geq 3$. The security $W_{m}$ that the intermediary designs in market $m$ has the following properties:

$$
\begin{aligned}
& \text { 1. } \frac{\partial E_{1}\left(W_{m}\right)}{\partial n_{m}}>0 \text { for any } n_{m} \leq n_{S} \text {; } \\
& \text { 2. } \frac{\partial \mathcal{V}_{1}\left(W_{m}\right)}{\partial n_{m}}>0 \text { for any } n_{m} \leq n_{S} \text {. }
\end{aligned}
$$

Two polar securities can be of interest: riskless debt, which is a security that has a flat payoff in all states of the world, and equity, which replicates the payoff of the asset $Z$ in every state. Proposition 2 allows us to understand whether these securities can be offered by intermediaries in equilibrium. The results are collected in the following corollary.

\section{Corollary 2 Fix a market structure $\mathcal{M}$.}

1. In any market $m \in \mathcal{M}$ with $n_{m} \geq n_{S}$ investors, where $n_{S} \in[3, \infty)$ and satisfies Eq. (17), the intermediary offers a security that pays the payoff of the asset $Z$ in every state.

2. There is no market $m \in \mathcal{M}$ in which the intermediary offers a security that pays a flat payoff in all states of the world.

The first part of Corollary 2 is a direct implication of Proposition 2 and the discussion that follows it. Any intermediary with at least $n_{S}$ investors will find it optimal to sell everything and offer equity. The second part of Corollary 2 says that intermediaries will never offer riskless debt. 
Suppose to the contrary that there is a market size $n_{m} \geq 3$ for which an intermediary would find it optimal to offer riskless debt. The variance of riskless debt is zero so, from Eq. (14), it must be the case that the intermediary finds it optimal to offer riskless debt for any market size, including in markets with at least $n_{S}$ investors. This contradicts the first part of Corollary 2, hence the intermediary never finds it optimal to offer riskless debt.

\subsection{The Equilibrium Market Structure}

The results so far have characterized the security that an intermediary chooses to design, taking as given the market structure. Our results revealed an important role for the relative market power between investors and intermediaries. However, investors have a tool - their market choice - that can affect this relative market power. Thus, to draw the stronger conclusion that a particular security exists in equilibrium, we need to verify that the market structure in which it trades exists. We address this question now.

To understand the incentives of investor $i$ at date $t=0$ when she chooses a market in which to trade, we need to first evaluate her expected payoff $E_{0}\left(V_{m}^{i}\right)$ from being in market $m$, given a market structure $\mathcal{M}$. The expression for $E_{0}\left(V_{m}^{i}\right)$ is obtained by substituting the equilibrium

demand function $Q_{m}^{i}\left(p_{m} ; \theta^{i}\right)$ from Eq. (12) and the equilibrium price $p_{m}$ from Eq. (13) into the expression for $V_{m}^{i}$ in Eq. (5) then taking expectations at date $t=0$, before the realization of $\theta^{i}$ is known. This delivers investor $i$ 's expected payoff as

$E_{0}\left(V_{m}^{i}\right)=\frac{\sigma_{\theta}^{2}}{2 \gamma} \frac{n_{m}-1}{n_{m}}\left(1-\frac{1}{\left(1+\lambda_{m}^{-1}\right)^{2}}\right) \frac{\left[E_{1}\left(W_{m}\right)\right]^{2}}{\mathcal{V}_{1}\left(W_{m}\right)}+\frac{\gamma}{2}\left(1+\frac{1}{\lambda_{m}^{-1}}\right)^{2}\left(1-\frac{1}{\left(1+\lambda_{m}^{-1}\right)^{2}}\right) \mathcal{V}_{1}\left(W_{m}\right)$

which simplifies to

$$
E_{0}\left(V_{m}^{i}\right)=\frac{\sigma_{\theta}^{2}}{2 \gamma} \frac{n_{m}-2}{n_{m}-1} \frac{\left[E_{1}\left(W_{m}\right)\right]^{2}}{\mathcal{V}_{1}\left(W_{m}\right)}+\frac{\gamma}{2} \frac{n_{m}}{n_{m}-2} \mathcal{V}_{1}\left(W_{m}\right)
$$

after further substituting the index of market depth $\lambda_{m}^{-1}=n_{m}-2$.

The expected payoff at date $t=0$ of an investor who will trade the security $W_{m}$ at date $t=1$ in a market with $n_{m}$ investors has two components. The first term in Eq. (18) is proportional to the variance of investor preference shocks, $\sigma_{\theta}^{2}$, and captures the gains from trade with other investors. The larger $\sigma_{\theta}^{2}$ is, the more heterogeneous investors are in how they value the mean payoff of the same security and the more they benefit from trading with each other, as reflected in more 
heterogenous equilibrium holdings of the security $W_{m}$. For smaller $\sigma_{\theta}^{2}$, investors are more similar in their valuation of the security and the equilibrium holdings of each investor approaches 1 , which is the per capita supply offered by the intermediary in market $m$. In this case, an investor's payoff is mainly driven by the risk premium that she commands as compensation for holding a risky security. The second term in Eq. (18) captures the part of the investor's expected payoff that comes from this compensation for risk.

Lemma 1 Suppose the payoffs of the underlying asset $Z$ satisfy $\frac{z(k)-E_{1}(Z \mid s \leq k)}{\sqrt{\mathcal{V}_{1}(Z \mid s \leq k)}}<\sqrt{2}+\varepsilon$ for all $k \in(0, S]$, where $\varepsilon \geq 0$ is a scalar that (weakly) increases with $\frac{\mu_{\theta}-\beta}{\gamma}$. Then the compensation for risk term $\frac{n_{m}}{n_{m}-2} \mathcal{V}_{1}\left(W_{m}\right)$ in the investor's expected payoff $E_{0}\left(V_{m}^{i}\right)$ is decreasing in $n_{m}$ when $W_{m}$ is evaluated at the optimal security in Proposition 2.

Both the gains from trade and the compensation for risk depend directly and indirectly on the depth of the market in which the investor trades. For a given security $W_{m}$, the gains from trade term in Eq. (18) increases directly with $n_{m}$, both because the fundamental gains from trade, as measured by $\frac{n_{m}-1}{n_{m}} \sigma_{\theta}^{2}$, are increasing in the number of market participants (even though the asset supply scales up linearly with the size of the market) and because the price impact of an investor is smaller in a larger market. In contrast, the compensation for risk term decreases directly with $n_{m}$ because the investor's price impact falls with the size of the market. At the same time, the security that intermediary $m$ finds optimal to offer in Proposition 2 changes with $n_{m}$, indirectly affecting both terms in Eq. (18) through $W_{m}$. The compensation for risk term is dominated by the direct effect of the market size $n_{m}$ when the payoffs of the underlying asset $Z$ satisfy the condition in Lemma 1. Intuitively, the condition requires the realizations of $Z$ to be sufficiently variable. We carry this condition through the rest of the analysis.

There can be a wide variety of market structures whose stability may be interesting to explore. When organized on a spectrum, most market structures can be classified as either more fragmented or more centralized in nature. Fragmentation is most severe when all intermediaries are active and investors are equally divided across them. Centralization is most severe when only one intermediary is active and all investors trade in a single market. We explore conditions under which these two benchmark cases emerge as the unique equilibrium market structure to get insight into the forces that drive investors' market choice. 


\subsubsection{Symmetric Fragmented Markets}

With a discrete number of investors and intermediaries, a symmetric market structure in which each active market contains exactly $n$ investors may not exist for every value of $n \in \mathbb{N}^{+}$. We therefore extend the definition of a symmetric market structure to allow for a distribution of investors across markets such that there are $n$ investors in some markets and $(n+1)$ investors in others. Mathematically, a generalized symmetric market structure $\mathcal{M}$ is characterized by the number of active markets, $M_{1}+M_{2} \leq M$ with $M_{1} \in \mathbb{N}^{+}$and $M_{2} \in \mathbb{N}^{0}$, and by the number of investors in each market, $n$ or $(n+1)$, where

$$
M_{1} \times n+M_{2} \times(n+1)=N,
$$

with $n \in[3, N] \cap \mathbb{N}^{+}$. If all intermediaries are active, i.e., $M_{1}+M_{2}=M$, then Eq. (19) implies that $M_{1}$ intermediaries are each getting $\left\lfloor\frac{N}{M}\right\rfloor$ investors and $M_{2}$ intermediaries are each getting $\left\lfloor\frac{N}{M}\right\rfloor+1$ investors, where the notation $\lfloor X\rfloor$ means $X$ is rounded down to the nearest integer. Throughout, we assume $N$ and $M$ such that $\left\lfloor\frac{N}{M}\right\rfloor \geq 3$.

The following proposition establishes that small $\sigma_{\theta}^{2}$ is sufficient for the existence and uniqueness of a symmetric equilibrium where securities are traded in fragmented markets:

Proposition 4 There exists $\bar{\sigma}>0$ such that, for any $\sigma_{\theta}^{2} \leq \bar{\sigma}$, the market structure in which all intermediaries are active is the unique $\ell$-stable generalized symmetric market structure for any $\ell \geq 3$.

The intuition for Proposition 4 is as follows. When $\sigma_{\theta}^{2} \leq \bar{\sigma}$, the investor's expected payoff $E_{0}\left(V_{m}^{i}\right)$ is driven by the compensation for risk term, $\frac{n_{m}}{n_{m}-2} \mathcal{V}_{1}\left(W_{m}\right)$, which by Lemma 1 is decreasing in the size of the investor's local market. Thus, investors will seek to trade in the smallest possible markets. At least three investors are necessary in a market for there to exist a linear equilibrium with trade when investor preference shocks are independent; see also Wilson (1979) and Kyle (1989). When investors can jointly deviate in groups of three or more $(\ell \geq 3)$, they will distribute themselves across all financial intermediaries. It may appear that fragmented markets can only ever have three investors per market. This need not be the case because the number of available intermediaries is what pins down the size of each market when investors want to trade in the smallest possible markets. In particular, the smallest possible market will have more than three investors if $M$ is small enough that $\left\lfloor\frac{N}{M}\right\rfloor>3$. While it is beyond the scope of the paper to model 
intermediary entry, we note here that varying the number of intermediaries will change the size of each market and hence the degree of market fragmentation.

By influencing which market structures can be supported in equilibrium, the variance of investor preference shocks, $\sigma_{\theta}^{2}$, also affects which securities are designed in equilibrium. When $\sigma_{\theta}^{2}$ is small, investors will not differ much in their valuations of the same security. The gains from trade are therefore low and investors anticipate that they will trade little with each other. Given this, they are willing to trade in smaller markets, where they can use their larger price impact to obtain from intermediaries a less variable security, as per Proposition 2. While the larger price impact also hurts the investor when she trades the security with other investors in the same market, this concern is muted because she anticipates trading little with other investors. Thus, debt securities are traded in fragmented markets. The following corollary formalizes these implications:

Corollary 3 In the symmetric equilibrium of Proposition 4, all intermediaries offer a debt security if $\left\lfloor\frac{N}{M}\right\rfloor+1<n_{S}$. They instead sell everything, i.e., offer equity, if $\left\lfloor\frac{N}{M}\right\rfloor \geq n_{S}$.

Corollary 3 shows that as the degree of market fragmentation changes, so does the security that is offered in equilibrium. Recall that when $\sigma_{\theta}^{2}$ is low the degree of market fragmentation is pinned down by the total number of intermediaries since there is a unique market structure that is $\ell$-stable for any given number $M$. Thus, the equilibrium security $W_{m}$ need not be the one associated with $n_{m}=3$ in Proposition 2. As the number of intermediaries decreases, the degree of market fragmentation decreases and the security can change from low-variance debt to high-variance debt or even equity.

The discussion so far has focused on market stability for any $\ell \geq 3$. When only unilateral or bilateral deviations of investors are allowed, i.e. $\ell \in\{1,2\}$, there can be multiple market structures that are stable for a given number of intermediaries $M$. Without the ability to coordinate in larger groups, an investor remains isolated if she joins an inactive market $m$ with $n_{m}<2$. If an investor were to deviate to such a market she would not trade and therefore receives a payoff of zero. Thus, while the investor's expected payoff is still decreasing in the size of her local market, she no longer benefits from exiting her market and joining the market of an inactive intermediary. In this case, the symmetric market structure with $M$ active intermediaries in Proposition 4 is only one of many possible equilibria; any symmetric market structure with fewer than $M$ active intermediaries is also an $\ell$-stable market structure when $\ell \in\{1,2\}$ and $\sigma_{\theta}^{2} \leq \bar{\sigma}$. 


\subsubsection{Fully Centralized Market}

We now establish conditions under which a highly centralized market structure can be supported in equilibrium.

Proposition 5 Suppose the distribution function $F(\cdot)$ for the state $s \in[0, S]$ is such that the investor's expected payoff $E_{0}\left(V_{m}^{i}\right)$ evaluated at the optimal security in Proposition 2 has at most one critical point over the range $n \geq\left\lfloor\frac{N}{M}\right\rfloor$, where $\left\lfloor\frac{N}{M}\right\rfloor<n_{S} \in(3, \infty)$. Then the unique $\ell$-stable equilibrium for $\ell=N$ has all investors trading in one market if and only if both $\sigma_{\theta}^{2}$ and $\frac{E_{1}(Z)}{\sqrt{\mathcal{V}_{1}(Z)}}$ are sufficiently large.

An example of a distribution that delivers an investor value function with at most one critical point is $F(s)=\frac{s}{S}$ with $S$ within some bounds, i.e., a (moderately disperse) uniform distribution. ${ }^{12}$

Proposition 5 reinforces that the variance of investor preference shocks, $\sigma_{\theta}^{2}$, helps determine which market structures - and thus which securities - can be supported in equilibrium. The intuition for $\sigma_{\theta}^{2}$ small was discussed in Section 3.3.1. When $\sigma_{\theta}^{2}$ is instead large, the gains from trade are also large. Investors understand that they may want to make large trades with each other in order to reap these gains, hence they seek to minimize their price impact by trading in a large market, albeit with a riskier security, provided this security is not too bad, i.e., $\frac{E_{1}(Z)}{\sqrt{\mathcal{V}_{1}(Z)}}$ sufficiently high. Proposition 5 focuses on $\ell=N$, which allows all investors to coordinate. An alternative interpretation is that any inactive intermediary can seek out investors to form a new market, or any active intermediary can seek out investors to form a larger market. This form of "poaching" by intermediaries achieves the same allocations as cross-market coalitions of investors without requiring that investors themselves coordinate. Either way, $\ell=N$ allows investors to pursue any profitable deviations if they exist. Equity securities are then traded in a centralized market under the conditions in Proposition 5.

\subsubsection{The Importance of Endogenous Market Structure}

The interplay between endogenous security design and endogenous market structure determines which securities will exist in equilibrium given a set of structural parameters (e.g., $\mu_{\theta}, \sigma_{\theta}^{2}$, the properties of the underlying asset $Z$, etc.). The following thought experiment demonstrates why allowing investors to choose a market structure plays an important role. Suppose markets are exogenously fragmented. In Proposition 2, we showed that investors will have the market power to

\footnotetext{
${ }^{12}$ See the end of the proof of Proposition 5 for an analysis of this example.
} 
elicit debt securities from intermediaries. The trading of debt securities in fragmented markets will then always be observed if investors do not have the option to choose the market structure in which they trade. However, we know from the discussion of the investor value function that investors will want to trade in a single market in order to lessen their price impact when the variance of their preference shocks, $\sigma_{\theta}^{2}$, is sufficiently large. In a single market, though, the market power shifts to the intermediary, who then delivers a pass-through security, not a debt security. Whether a debt security is actually observed in equilibrium thus depends on what market structure investors want to trade in when they understand that security design is endogenous. Predictions about the equilibrium security therefore require a characterization of the equilibrium market structure.

To better appreciate how endogenizing the market structure changes the securities that prevail for a given set of structural parameters, we return to the investor's expected payoff and deconstruct it in more detail. Consider specifically Eq. (18), which represents investor $i$ 's expected profit when Eq. (5) is evaluated at both the equilibrium demand function $Q_{m}^{i}\left(p_{m} ; \theta^{i}\right)$ and the equilibrium price $p_{m}$ derived in Proposition 1. Given a market depth $\lambda_{m}^{-1}$, Eq. (18) implies that, among all securities with the same mean payoff $E_{1}\left(W_{m}\right)$, an investor $i$ would be better off with the security with the least variance $\mathcal{V}_{1}\left(W_{m}\right)$ if she expects investors to have very disperse valuations. In other words, investor $i$ would be better off with debt if $\sigma_{\theta}^{2}$ is high but equity if $\sigma_{\theta}^{2}$ is low, for a fixed market structure.

The endogeneity of market depth and its effect on security design reverses this ordering. A key feature of the equilibrium in our model is that investors take into account that their market choice affects market depth and hence the payoffs of the securities that intermediaries design. Thus, an investor's expected profit in Eq. (18) depends on the depth of the market both directly and indirectly, with the indirect effect coming through the equilibrium security $W_{m}$ derived in Proposition 2. The two terms in Eq. (18) - the gains from trade term and the compensation for risk term - can move in opposite directions as the market becomes deeper; see the proof of Lemma 1 for a formalization. Thus, consistent with Proposition 5 and its discussion, investors will prefer equity if $\sigma_{\theta}^{2}$ is high but debt if $\sigma_{\theta}^{2}$ is low. This constitutes a reversal in the securities that make investors better off (as a function of the expected dispersion in their valuations) relative to the case where investors only take into account the price impact of their trades for a given market depth.

It is important to notice that investors' preferences shape the payoffs of the security traded in equilibrium both directly and indirectly. First, because the expected price at which a security $W_{m}$ trades is increasing in the mean $\mu_{\theta}$ of the investor preference shocks, $\mu_{\theta}$ directly enters the 
optimization problem of intermediary $m$ and thus directly affects the payoffs of the security that he finds optimal to design. Second, although the variance of the investor preference shocks does not appear directly in the payoffs of the security derived in Proposition $2, \sigma_{\theta}^{2}$ plays an important role in determining which securities are traded in equilibrium. The payoffs of the equilibrium security in market $m$ depend directly on the number of investors $n_{m}$, and $\sigma_{\theta}^{2}$ affects an investor's decision about which market to trade in. Thus, as we discussed above, when $\sigma_{\theta}^{2}$ is high, investors value trading in deeper markets, which induces the intermediary to offer riskier securities, while, when $\sigma_{\theta}^{2}$ is low, investors prefer trading in thinner markets, which induces the intermediary to offer less variable securities.

\section{Discussion}

Investment banks perform three functions which may be of value to an issuer of new securities: designing the security, underwriting, and distributing the security to investors (Baron (1982)). A substantial body of research over the past few decades has contributed to understanding the security design problem. However, the interaction between design and distribution remains understudied, despite being at the forefront of the security issuance process in practice. Consider, for example, a negotiated issuance of municipal bonds, as described in industry materials. ${ }^{13}$ The underwriter advertises a tentative security to investors, before the terms of the security have been fully set. Depending on the incoming flow of orders, the underwriter may recommend changes in the structure and payoffs of the security to the issuer. The underwriter then allocates the bonds to investors, once the terms of the security have been finalized. A similar process exists for negotiated issuances of other types of securities.

Our model sheds light on the strategic interactions that can arise in this process to shape the security that ultimately comes to market. The key mechanism behind our theoretical predictions is that security design is shaped by the market power that investors have relative to the financial intermediary in local markets. This mechanism gives rise to an equilibrium association between market depth and security design that is robust to several alternative formulations of our environment, as we show in Online Appendix B. ${ }^{14}$ Furthermore, there is emerging empirical evidence that

\footnotetext{
${ }^{13}$ E.g., "The Municipal Underwriting Process" by the investment bank Piper Jaffray in 2005.

${ }^{14}$ Specifically, we consider the following extensions in Online Appendix B: allowing the intermediary to choose how many units of the underlying asset back each unit of the security designed for investors; allowing investors to choose markets after securities are designed; allowing investors to choose more than one market in which to trade; and allowing more than one security to be designed for investors in each market.
} 
supports the mechanism behind our results. When investors trade in thin markets, they have more market power relative to the intermediary. In this case, investors use their market power to obtain a security that is most favorable to them, as in Adelino, Frame, and Gerardi (2017). In contrast, when investors trade in a deep market, the intermediary uses its relatively superior market power to design a security that is more favorable to it, as in Brancaccio and Kang (2022).

By shedding light on the interaction between security design and market structure, our paper can contribute to an important agenda that studies the relationship between asset safety and liquidity. While it is often assumed that safer securities are at least as liquid as riskier ones, in practice the relationship between safety and liquidity is complex. For instance, Friewald, Jankowitsch, and Subrahmanyam (2017) find that mortgage-backed securities are more liquid than collateralized mortgage obligations despite being pass-through securities, with only part of the liquidity difference attributable to differences in government guarantees. As another example, in well-known work on U.S. Treasuries, Krishnamurthy and Vissing-Jorgensen (2012) identify the safety premium assuming that Aaa and Baa corporate bonds are equally liquid. More recently, however, Geromichalos, Herrenbrueck, and Lee (2022) demonstrate that certain assets may carry different liquidity premia precisely because they have different risks.

Our model allows us to highlight the importance of the underlying asset for interpreting safety versus liquidity premia. We accomplish this by undertaking two exercises. First, we consider an extension of the model that allows the co-existence of securities with different safety profiles issued on the same underlying asset. Second, we discuss how changes in the riskiness of the underlying asset affect the relationship between market liquidity and the riskiness of the asset-backed security designed by the intermediary. All supporting derivations are collected in Online Appendix C.

\subsection{Liquidity and Safety for a Common Underlying Asset}

To draw implications about the relationship between safety and liquidity through the lens of our model, we need to be able to compare different security profiles backed by the same underlying asset. Our characterization of equilibrium has so far focused on the stability of either symmetric fragmented markets (Section 3.3.1) or a single centralized market (Section 3.3.2), leading to one security profile being issued in each equilibrium. Thus, we now need to shift our attention to the existence of asymmetric equilibria in which markets of different size co-exist. Such equilibria ensure the co-existence of securities with different safety profiles that are backed by the same underlying asset. 
Asymmetric equilibria that are $\ell$-stable under Definition 1 exist for $\ell=N$ if the investor value function achieves a global maximum at more than one point or if there is a restriction on the total number of intermediaries in the economy. ${ }^{15}$ Alternatively, one can consider restrictions on only the number of intermediaries that a given investor can interact with, instead of restricting the total number of intermediaries in the economy. In particular, suppose that every investor has preexisting relationships with a subset of intermediaries formed from interactions outside the model. Intermediaries are heterogeneous in the number of investors they have relationships with, with some intermediaries having more and others having less. As in our main set-up, each investor chooses an intermediary in whose market to trade from the subset of intermediaries that she has a relationship with. Lemma C.1 in Online Appendix C establishes that this setting with pre-existing relationships supports asymmetric equilibria where debt and equity co-exist. That is, large markets in which investors trade more variable securities co-exist with small markets in which investors trade less variable securities.

Market size in our model aligns closely to a natural measure of liquidity captured by the price impact of an individual investor. Recall from Section 3.1 that the price impact of investor $i$ in market $m$ is $\partial p_{m,-i} / \partial q_{m}^{i}=\lambda_{m} \gamma \mathcal{V}_{1}\left(W_{m}\right)$, where $\lambda_{m}^{-1} \equiv\left(n_{m}-2\right)$ and, in equilibrium, $W_{m}$ depends on $n_{m}$ as demonstrated in Proposition 2. Under the conditions stated in Lemma 1, the total derivative of $\partial p_{m,-i} / \partial q_{m}^{i}$ with respect to $n_{m}$ is negative. Since a market is liquid if the security can be traded with little impact on its price, a larger market in our model is also a more liquid market. ${ }^{16}$

Thus, our model implies that a safer security with less variable payoffs will be less liquid than a riskier security with more variable payoffs when both securities are backed by the same underlying asset. This prediction suggests that factors other than market power are at play if riskier securities are observed to be less liquid than safer securities in such environments. For instance, a riskier security may be more customized to fit the needs of specialized investors, as in Brancaccio and Kang (2022). Alternatively, a safer security may have an associated priority structure that enhances its

\footnotetext{
${ }^{15}$ Consider, for illustration, an investor value function $E V(n)$ that achieves its global maximum uniquely at some market size $n^{*}$. An asymmetric equilibrium with $n_{A} \in\left(n^{*}, N-n^{*}\right)$ investors in one market and $n_{B}=N-n_{A}$ investors in another market is possible if the total number of intermediaries is restricted to $M=2$.

${ }^{16}$ At this stage it is worth noting that primary and secondary markets are one and the same in our model. We believe this to be a reasonable simplification. While in practice we distinguish between trade in primary and secondary markets, these markets are typically tightly linked. In particular, a more liquid secondary market makes the primary market more liquid as well. It would follow from our model that an individual investor has limited price impact against the intermediary in a liquid primary market. Hence, the intermediary can design a more variable security and investors will accept it (i.e., they will not leave the primary market) because the security can be re-traded in a liquid secondary market after the realization of preference shocks. In this way, liquidity of the secondary market supports liquidity of the primary market.
} 
liquidity, as is the case with more senior tranches in structured securitization (Friewald, Hennessy, and Jankowitsch (2016)).

\subsection{Liquidity and Safety for Different Underlying Assets}

In practice, many of the securities we observe are not backed by the same underlying asset. We now explore how differences in the riskiness of the underlying asset $Z$ affect the relationship between market liquidity and the riskiness of the asset-backed security designed by the intermediary in our model.

To fix ideas, consider the specification $z(s)=\kappa s$ for the payoffs of the underlying asset $Z$, where $s \in[0,1]$ is uniformly distributed. Notice that $\kappa$ affects both the mean and the variance of the underlying asset $Z$. Specifically, the higher is $\kappa$, the higher are both the mean $E_{1}(Z)$ and variance $\mathcal{V}_{1}(Z)$ of $Z$. However, by keeping the ratio $\frac{E_{1}(Z)}{\sqrt{\mathcal{V}_{1}(Z)}}$ independent of $\kappa$ we control for the quality, i.e., the expected payoff per unit of risk, of the underlying asset.

We modify our main set-up to allow for a subset $M^{\prime}$ of intermediaries to have access to an underlying asset characterized by $\kappa^{\prime}$ while the remaining subset of intermediaries, $M^{\prime \prime} \equiv M-M^{\prime}$, have access to an underlying asset characterized by $\kappa^{\prime \prime}>\kappa^{\prime}$. An intermediary who uses the underlying asset $\kappa^{\prime \prime}$ will design an asset-backed security with a higher variance than an intermediary who uses the underlying asset $\kappa^{\prime}$ when both face markets of the same size. ${ }^{17}$ However, as investors choose a market in which to trade, markets of different sizes can co-exist in equilibrium. As we show in Online Appendix C, an asymmetric market structure in which each of the $M^{\prime}$ intermediaries has $n_{m^{\prime}}$ investors and each of the $M^{\prime \prime}$ intermediaries has $n_{m^{\prime \prime}}$ investors, with $n_{m^{\prime}}<n_{m^{\prime \prime}}$ and $N=M^{\prime} \times n_{m^{\prime}}+M^{\prime \prime} \times n_{m^{\prime \prime}}$, can be supported in equilibrium. Thus, a safer security with less variable payoffs can be less liquid than a riskier security with more variable payoffs, even when intermediaries differ in the underlying assets they use, provided investors can choose freely between the different intermediaries.

In reality, though, not all investors are unconstrained when choosing a market in which to trade. As we argued above, investors often have long-term relationships with a handful of intermediaries. Alternatively, some investors may be subject to regulation that allows them to participate only in certain markets. To capture this in our model, we consider that a subset $N^{\prime}$ of investors are restricted to have relationships only with the $M^{\prime}$ intermediaries who have access to the underlying

\footnotetext{
${ }^{17}$ Intuitively, flattening out the payoff profile of the security to overcome the higher variability of the underlying asset would involve too steep a drop in the mean payoff of the security (and thus its price) to be profitable for the intermediary.
} 
asset characterized by $\kappa^{\prime}$ while the remaining subset of investors, $N^{\prime \prime} \equiv N-N^{\prime}$, can choose to trade in any market, including those associated with intermediaries $M^{\prime \prime}$ who have access to the underlying asset characterized by $\kappa^{\prime \prime}$. We explore this environment in Online Appendix C and demonstrate that a safer security with less variable payoffs can be more liquid, not less liquid, than a riskier security with more variable payoffs.

The examples in this section highlight the complexity of the relationship between the safety and the liquidity of a security and suggest that one needs to cautiously disentangle the various factors that contribute to patterns documented empirically.

\section{Aggregate Welfare}

We now study aggregate welfare in the model, taking into account the expected payoffs of both investors and intermediaries, to better understand the potential tradeoffs that a social planner would face when designing policy.

We consider equilibrium market structures with $M_{1}$ intermediaries each getting $n$ investors and $M_{2}$ intermediaries each getting $(n+1)$ investors, such that Eq. (19) is satisfied. In each active market, an investor obtains an expected profit $E_{0}\left(V_{m}^{i}\right)$ given by Eq. (18), while the intermediary receives an expected profit $E_{0}\left(V_{m}\right)$ given by Eq. (14). Aggregate welfare can then be defined as

$$
\begin{aligned}
\mathcal{W}= & n \times M_{1} \times E_{0}\left(\left.V_{m}^{i}\right|_{n_{m}=n}\right)+(n+1) \times M_{2} \times E_{0}\left(\left.V_{m}^{i}\right|_{n_{m}=n+1}\right) \\
& +M_{1} \times E_{0}\left(\left.V_{m}\right|_{n_{m}=n}\right)+M_{2} \times E_{0}\left(\left.V_{m}\right|_{n_{m}=n+1}\right) .
\end{aligned}
$$

The following proposition characterizes the dependence of aggregate welfare on market depth for a given specification of the payoffs of the underlying asset $Z$.

Proposition 6 Consider $z(s)=z(0)+\kappa s$ and $s \in[0, S]$ uniformly distributed according to $F(s)=$ $\frac{s}{S}$. Also suppose $N>n_{S}$ with $n_{S} \in[3, \infty)$. It follows that:

1. An active intermediary's expected profit $E_{0}\left(V_{m}\right)$ in Eq. (14) is increasing in $n_{m}$ when $W_{m}$ is the equilibrium security derived in Proposition 2.

2. If $z(0)$ is not too large, then for any value of $\sigma_{\theta}^{2}$, the equilibrium in which all investors trade in a single market and the intermediary sells everything (i.e., offers equity) achieves the highest aggregate welfare. 
The first part of Proposition 6 says that an intermediary is always better off designing a security for a large market than for a small market. Investors have less price impact in large markets, so the intermediary is able to command a higher price for whatever security he designs. Recall from Propositions 4 and 5 that an investor will be worse off in a large market than in a small market when $\sigma_{\theta}^{2}$ is sufficiently low. Therefore, investors benefit at the expense of intermediaries in any equilibrium where debt is traded.

The second part of Proposition 6 says that the benefits to investors of an equilibrium in which intermediaries offer debt are outweighed by the losses to intermediaries, at least in environments where it is impossible to design a security that has high returns in all states of the world (i.e., environments where $z(0)$ is low). First, the expected, per-capita profit of an active intermediary increases more quickly with $n_{m}$ than the expected profit of an investor may decrease with $n_{m}$. Second, the non-linear relationship between market size and the price impact of investors means that total welfare across intermediaries is maximized when there is only one active intermediary.

The results in the second part of Proposition 6 characterize the solution to the problem of a social planner who chooses a market structure, a set of securities, and a set of demand functions to maximize aggregate welfare subject to the equilibrium conditions in the first and second bullets of Definition 1. We can then draw two conclusions from the results on equilibrium market structure in Section 3.3. First, if investors choose market structure as per the third bullet of Definition 1 with $\ell=1$, i.e., only unilateral deviations must be ruled out, there will be a decentralized equilibrium that coincides with the planner's solution. All investors trading in one market is a stable market structure whenever investors consider only unilateral deviations, hence we can interpret the second part of Proposition 6 as saying that the planner will open a single market if constrained to choose among solutions that arise as a decentralized equilibrium in Definition 1 with $\ell=1$. Second, if investors choose market structure as per the third bullet of Definition 1 with $\ell=N$, i.e., all unilateral and multilateral deviations must be ruled out, the decentralized equilibrium will only coincide with the planner's solution when both $\sigma_{\theta}^{2}$ and $\frac{E_{1}(Z)}{\sqrt{\mathcal{V}_{1}(Z)}}$ are large enough (Proposition 5).

What would the planner do if not constrained to choose among solutions that arise as a decentralized equilibrium in Definition 1? It is straightforward to show that he would open a single market in which all investors trade a zero-variance security (i.e., riskless debt). ${ }^{18}$ Intuitively, a

\footnotetext{
${ }^{18}$ We omit the proof for brevity. It is simply welfare maximization by a planner who: (i) opens $M_{1}$ markets each with $n$ investors and $M_{2}$ markets each with $n+1$ investors such that Eq. (19) holds; (ii) designs a security $W_{m}$ subject only to the feasibility condition (2); (iii) allocates to investor $i$ in market $m$ a quantity $q_{m}^{i}$ of the security $W_{m}$ after the realization of investor preference shocks, where $\sum_{i \in m} q_{m}^{i}=n_{m}$ for each market $m$; and (iv) allocates to the intermediary in each market $m$ a quantity $n_{m}$ of the security $\left(Z-W_{m}\right)$.
} 
security with zero variance neutralizes the risk aversion of investors. Maximum aggregate welfare can then be achieved by allocating unboundedly positive positions $q_{m}^{i}$ to investors whose realization of $\theta^{i}$ exceeds the market average and unboundedly negative positions to the rest to satisfy market clearing, $\sum_{i \in N} q_{m}^{i}=N$. If the planner is restricted to design a positive-variance security, then he will open a single market in which investors take large but finite positions on the closest possible security to riskless debt. Key here is that the planner can achieve higher welfare by decoupling the security design choice from the market structure choice: he would like to design a debt security for risk averse investors and he would like all investors to trade this security in the same market in order to maximize the gains from trade.

The problem is that security design cannot be decoupled from market structure in equilibrium. This result is at the heart of our paper. Intermediaries respond to market-based incentives when designing a security for investors to trade. These incentives come from the price of the security, which is endogenously less sensitive to investors' risk aversion in a large market because the price impact of an individual investor is decreasing in market size. Policy interventions that overlook the implications of market structure for security design can lead to unintended consequences; see Babus and Hachem (2021) for one application.

\section{Conclusion}

This paper has developed a tractable model of financial innovation to address a critical question: what is the relationship between the types of securities offered and the market structures in which they trade? A central finding of our paper is that financial intermediaries design progressively riskier securities when facing deeper, less fragmented markets in which investors trade more competitively. Market fragmentation thus plays an important role in the creation of safer securities.

The methodological novelty in our paper is that both security design and market structure are endogenously determined. This is important, as it ensures the securities created for a given market structure are indeed supported in equilibrium. Financial intermediaries design asset-backed securities taking into account investors' demand in the markets in which the securities will be traded. Investors choose markets understanding that their choices will affect market depth and thus the design of the securities that will be available for trade.

When choosing how to design a security, an intermediary's main incentive is to obtain a high price for it. As usual, the equilibrium price at which the security is traded is increasing in its mean 
payoff and decreasing in the variance of its payoffs across states. The intermediary thus faces a trade-off between the mean and the variance of the security he designs, making a debt contract the optimal one. Importantly, we show that the equilibrium price decreases less with the variance of the security in deeper markets where investors have a lower price impact. Thus, the strength of the mean-variance trade-off faced by the intermediary depends on the depth of the market. The deeper the market, the less pronounced the trade-off and the higher the face value of the debt contract offered.

When choosing a market in which to trade, an investor weighs the gains from trade with other investors against the ability to influence the security that the financial intermediary designs. An investor who trades in a thinner, more fragmented market will have a larger price impact. On one hand, this amplifies the mean-variance trade-off in the intermediary's security design problem and delivers a less risky security. On the other hand, it also amplifies the extent to which the investor will move the price of the security against herself when trading with other investors.

In Dugast, Üslü, and Weill (2022), investors' types play a key role in determining the market structure in which trade occurs. In our model, investors' preferences affect the security that will be traded, both directly through the payoffs that an intermediary offers for a given market structure and indirectly through the market structure that prevails as an equilibrium. When investors expect to be relatively heterogeneous in their valuations of the same security, they understand that they may want to engage in large trades with each other so they seek to limit their price impact by trading in a large market, albeit with a riskier security. In contrast, when investors expect to be relatively homogeneous in their valuations, they anticipate trading little with each other and are thus willing to accept a larger price impact in thinner, more fragmented markets in order to elicit less variable securities from financial intermediaries.

A key prediction of our model is that less variable asset-backed securities are traded in thinner, more fragmented markets while more variable asset-backed securities are traded in deeper, less fragmented markets when securities are backed by the same underlying asset and every investor can freely choose a market in which to trade. However, if intermediaries differ in their underlying assets and investors face constraints on their market choice, then less variable securities may trade in deeper markets while more variable securities trade in thinner markets. Having developed a parsimonious framework at the intersection of market structure and security design, our model provides a platform on which many extensions can be considered and offers fruitful avenues for future work. 


\section{References}

Adelino, M., S. Frame, and K. Gerardi. 2017. "The Effect of Large Investors on Asset Quality: Evidence from Subprime Mortgage Securities." Journal of Monetary Economics, 87, pp 34-51.

Allen, F. and D. Gale. 1988. "Optimal Security Design." Review of Financial Studies, 1(3), pp. 229-263.

Allen, F. and D. Gale. 1991. "Arbitrage, Short Sales, and Financial Innovation." Econometrica, 59(4), pp. 1041-1068.

Allen, F. and D. Gale. 1994. Financial Innovation and Risk Sharing. Cambridge, MA: MIT Press.

Asriyan, V. and V. Vanasco. 2018. "Security Design in Non-Exclusive Markets." Working Paper, CREI.

Axelson, U. 2007. "Security Design with Investor Private Information." Journal of Finance, 62(6), pp. $2587-2632$.

Babus, A. and K. Hachem. 2021. "Regulation and Security Design in Concentrated Markets." Journal of Monetary Economics, 121(1), pp. 139-151 (Carnegie-Rochester-NYU).

Babus, A. and C. Parlatore. 2022. "Strategic Fragmented Markets." Journal of Financial Economics, 145(3), pp. 876-908.

Bar-Isaac, H., G. Caruana, and V. Cuñat. 2012. "Search, Design, and Market Structure." American Economic Review, 102(2), pp. 1140-1160.

Baron, D. 1982. "A Model of the Demand for Investment Banking Advising and Distribution Services for New Issues." Journal of Finance, 37(4), pp. 955-976.

Biais, B. and R. Green. 2019. "The Microstructure of the Bond Market in the 20th Century." Review of Economic Dynamics, 33(1), pp. 250-271.

Biais, B. and T. Mariotti. 2005. "Strategic Liquidity Supply and Security Design." Review of Economic Studies, 72(3), pp. 615-649.

Boyarchenko, N., A. Costello, and O. Shachar. 2018. "Credit Market Choice." Federal Reserve Bank of New York, Staff Report No. 863. 
Brancaccio, G. and K. Kang. 2022. "Search Frictions and Product Design in the Municipal Bond Market." Working Paper, NYU.

Carvajal, A., M. Rostek, and M. Weretka. 2012. "Competition in Financial Innovation." Econometrica, 80(5), pp. 1895-1936.

Cespa, G. and X. Vives. 2022. "Exchange Competition, Entry, and Welfare." Review of Financial Studies, 35(5), pp. 2570-2624.

Corbae, D. and E. Quintin. 2019. "Asset Quality Dynamics.” Working Paper, UW-Madison.

DeMarzo, P. and D. Duffie. 1999. "A Liquidity-Based Model of Security Design." Econometrica, 67(1), pp. 65-99.

Duffie, D. and R. Rahi. 1995. "Financial Market Innovation and Security Design: An Introduction." Journal of Economic Theory, 65(1), pp. 1-42.

Dugast, J., S. Üslü, and P. O. Weill. 2022. "A Theory of Participation in OTC and Centralized Markets." Forthcoming in Review of Economic Studies.

Farboodi, M. 2021. "Intermediation and Voluntary Exposure to Counterparty Risk." Working Paper, MIT.

Friewald, N., C. Hennessy, and R. Jankowitsch. 2016. "Secondary Market Liquidity and Security Design: Theory and Evidence from ABS Markets.” Review of Financial Studies, 29(5), pp. 12541290.

Friewald, N., R. Jankowitsch, and M. Subrahmanyam. 2017. "Transparency and Liquidity in the Structured Product Market." Review of Asset Pricing Studies, 7(2), pp. 316-348.

Gale, D. and M. Hellwig. 1985. "Incentive-Compatible Debt Contracts: The One-Period Problem." Review of Economic Studies, 52(4), pp. 647-663.

Geromichalos, A., L. Herrenbrueck, and S. Lee. 2022. "Asset Safety versus Asset Liquidity." Forthcoming in Journal of Political Economy.

Gorton. G. and G. Pennacchi. 1990. "Financial Intermediaries and Liquidity Creation." Journal of Finance, 45(1), pp. 49-71. 
Hébert, B. 2018. "Moral Hazard and the Optimality of Debt." Review of Economic Studies, 85(4), pp. 2214-2252.

Johnson, J., and D. P. Myatt. 2003. "Multiproduct Quality Competition: Fighting Brands and Product Line Pruning." American Economic Review, 93(3) pp. 748-774.

Johnson, J., and D. P. Myatt. 2006. "On the Simple Economics of Advertising, Marketing, and Product Design." American Economic Review, 96(3) pp. 756-784.

Krishnamurthy, A. and A. Vissing-Jorgensen. 2012. "The Aggregate Demand for Treasury Debt." Journal of Political Economy, 120(2), pp. 233-267.

Kyle, A. 1989. "Informed Speculation with Imperfect Competition." Review of Economic Studies, 56(3), pp. 317-355.

Lee, T. and C. Wang. 2018. "Why Trade Over-the-Counter? When Investors Want Price Discrimination." Working Paper, Wharton.

Malenko, A. and A. Tsoy. 2018. "Asymmetric Information and Security Design Under Knightian Uncertainty." Working Paper, MIT.

Malamud, S. and M. Rostek. 2017. "Decentralized Exchange." American Economic Review, 107(11), pp. 3320-3362.

Nachman, D. and T. Noe. 1994. "Optimal Design of Securities under Asymmetric Information." Review of Financial Studies, 7(1), pp. 1-44.

Ross, S. 1976. "Options and Efficiency." Quarterly Journal of Economics, 90(1), pp. 75-89.

Roth, A. and M. Sotomayor. 1990. Two-Sided Matching: A Study in Game-Theoretic Modeling and Analysis. Cambridge University Press.

Rostek, M. and M. Weretka. 2012. "Price Inference in Small Markets." Econometrica, 80(2), pp. 687-711.

Rostek, M. and J. H. Yoon. 2022. "Design of Synthetic Financial Products in Decentralized Markets." Working Paper, University of Wisconsin.

Vives, X. 2008. Information and Learning in Markets. Princeton University Press. 
Vives, X. 2011. "Strategic Supply Function Competition with Private Information." Econometrica, 79(6), pp. 1919-1966.

Wilson, R. 1979. "Auctions of Shares." Quarterly Journal of Economics, 93(4), pp. 675-689.

Yang, M. 2020. "Optimality of Debt under Flexible Information Acquisition." Review of Economic Studies, 87(1), pp. 487-536.

Yoon, J. H. 2018. "Endogenous Market Structure: Over-the-Counter versus Exchange Trading." Working Paper, UCL. 


\section{Appendix A - Proofs}

\section{Proof of Proposition 1}

Rearrange the first order condition of investor $i$ in Eq. (10) to isolate:

$$
q_{m}^{i}=\frac{\theta^{i} E_{1}\left(W_{m}\right)-p_{m}}{\frac{\partial p_{m,-i}}{\partial q_{m}^{i}}+\gamma \mathcal{V}_{1}\left(W_{m}\right)}
$$

for any $i \in m$. Use this expression to substitute out $Q_{m}^{j}(\cdot)$ from Eq. (11) for all investors $j \neq i$ in market $m$ :

$$
q_{m}^{i}+\sum_{j \in m, j \neq i} \frac{\theta^{j} E_{1}\left(W_{m}\right)-p_{m}}{\frac{\partial p_{m,-j}}{\partial q_{m}^{j}}+\gamma \mathcal{V}_{1}\left(W_{m}\right)}=n_{m}
$$

We focus on symmetric linear equilibria in which the price impact $\frac{\partial p_{m,-j}}{\partial q_{m}^{j}}$ does not vary across investors within the same market. This permits rearranging Eq. (A.2) to isolate:

$$
p_{m}=\frac{\sum_{j \in m, j \neq i} \theta^{j}}{n_{m}-1} E_{1}\left(W_{m}\right)-\frac{n_{m}-q_{m}^{i}}{n_{m}-1}\left(\frac{\partial p_{m,-j}}{\partial q_{m}^{j}}+\gamma \mathcal{V}_{1}\left(W_{m}\right)\right)
$$

which then implies:

$$
\frac{\partial p_{m,-i}}{\partial q_{m}^{i}}=\frac{1}{n_{m}-1}\left(\frac{\partial p_{m,-j}}{\partial q_{m}^{j}}+\gamma \mathcal{V}_{1}\left(W_{m}\right)\right)
$$

Invoking symmetry $\left(\frac{\partial p_{m,-i}}{\partial q_{m}^{i}}=\frac{\partial p_{m,-j}}{\partial q_{m}^{j}}\right)$, we obtain:

$$
\frac{\partial p_{m,-i}}{\partial q_{m}^{i}}=\lambda_{m} \gamma \mathcal{V}_{1}\left(W_{m}\right)
$$

where $\lambda_{m} \equiv \frac{1}{n_{m}-2}$. Substituting Eq. (A.3) into Eq. (A.1) delivers the equilibrium demand function $Q_{m}^{i}\left(p_{m} ; \theta^{i}\right)$ in Eq. (12). Substituting Eq. (12) into the market clearing condition $\sum_{i \in m} Q_{m}^{i}\left(p_{m} ; \theta^{i}\right)=$ $n_{m}$ then delivers the equilibrium price $p_{m}$ in Eq. (13).

\section{Proof of Proposition 2}

Intermediary $m$ designs a security $W_{m}$ to maximize his expected payoff in Eq. (8), subject to the state-by-state feasibility constraint (2).

Letting $v(s) \geq 0$ denote the Lagrange multiplier on the feasibility constraint for state $s$, we can 
write the Lagrangian for intermediary $m$ 's optimization problem as:

$$
\mathcal{L}_{m}=E_{0}\left(V_{m}\right)+\int_{0}^{S} v(s)\left[z(s)-w_{m}(s)\right] d F(s)
$$

or, equivalently:

$$
\begin{aligned}
\mathcal{L}_{m}= & \beta E_{1}(Z) n_{m}+\left(\mu_{\theta}-\beta\right) n_{m} \int_{0}^{S} w_{m}(s) d F(s) \\
& -\gamma \frac{n_{m}\left(n_{m}-1\right)}{n_{m}-2}\left[\int_{0}^{S}\left(w_{m}(s)\right)^{2} d F(s)-\left(\int_{0}^{S} w_{m}(s) d F(s)\right)^{2}\right] \\
& +\int_{0}^{S} v(s)\left[z(s)-w_{m}(s)\right] d F(s)
\end{aligned}
$$

where the intermediary is choosing $w_{m}(s)$ for each state $s \in[0, S]$ taking as given the market size $n_{m}$. We restrict attention to $n_{m} \geq 3$ so that the trading equilibrium in Proposition 1 involves a well-defined equilibrium price for market $m$.

The first order condition with respect to $w_{m}(s)$ delivers:

$$
v(s) \stackrel{\text { sign }}{=} E_{1}\left(W_{m}\right)+\frac{\mu_{\theta}-\beta}{2 \gamma} \frac{n_{m}-2}{n_{m}-1}-w_{m}(s)
$$

where $v(s) \geq 0$ and $w_{m}(s) \leq z(s)$ hold with complementary slackness.

If $v(s)>0$, then:

$$
w_{m}(s)=z(s)
$$

and, invoking (A.4), we need:

$$
z(s)<E_{1}\left(W_{m}\right)+\frac{\mu_{\theta}-\beta}{2 \gamma} \frac{n_{m}-2}{n_{m}-1}
$$

to confirm $v(s)>0$.

If $v(s)=0$, then (A.4) pins down:

$$
w_{m}(s)=E_{1}\left(W_{m}\right)+\frac{\mu_{\theta}-\beta}{2 \gamma} \frac{n_{m}-2}{n_{m}-1}
$$

and we need:

$$
z(s) \geq E_{1}\left(W_{m}\right)+\frac{\mu_{\theta}-\beta}{2 \gamma} \frac{n_{m}-2}{n_{m}-1}
$$


to confirm $w_{m}(s) \leq z(s)$.

The payoffs of the equilibrium security are therefore:

$$
w_{m}(s)=\left\{\begin{array}{lll}
z(s) & \text { if } \quad z(s)<E_{1}\left(W_{m}\right)+\frac{\mu_{\theta}-\beta}{2 \gamma} \frac{n_{m}-2}{n_{m}-1} \\
E_{1}\left(W_{m}\right)+\frac{\mu_{\theta}-\beta}{2 \gamma} \frac{n_{m}-2}{n_{m}-1} & \text { if } \quad z(s) \geq E_{1}\left(W_{m}\right)+\frac{\mu_{\theta}-\beta}{2 \gamma} \frac{n_{m}-2}{n_{m}-1}
\end{array}\right.
$$

Suppose there exists an $\bar{s}_{m} \in(0, S)$ solving:

$$
z\left(\bar{s}_{m}\right) \equiv E_{1}\left(W_{m}\right)+\frac{\mu_{\theta}-\beta}{2 \gamma} \frac{n_{m}-2}{n_{m}-1}
$$

Then $z^{\prime}(\cdot)>0$ implies:

$$
E_{1}\left(W_{m}\right)=\int_{0}^{\bar{s}_{m}} z(s) d F(s)+\int_{\bar{s}_{m}}^{S} z\left(\bar{s}_{m}\right) d F(s)
$$

and we can rewrite Eq. (A.5) as:

$$
\int_{0}^{\bar{s}_{m}}\left[z\left(\bar{s}_{m}\right)-z(s)\right] d F(s) \equiv \frac{\mu_{\theta}-\beta}{2 \gamma} \frac{n_{m}-2}{n_{m}-1}
$$

The left-hand side of Eq. (A.7) is increasing in $\bar{s}_{m}$ so there will be a unique solution $\bar{s}_{m} \in(0, S)$ if and only if:

$$
z(S)-E_{1}(Z)>\frac{\mu_{\theta}-\beta}{2 \gamma} \frac{n_{m}-2}{n_{m}-1}
$$

The ratio $\frac{n_{m}-2}{n_{m}-1}$ is increasing in $n_{m}$ and asymptotes to 1 as $n_{m} \rightarrow \infty$.

If the parameters satisfy $z(S)-E_{1}(Z) \in\left[\frac{\mu_{\theta}-\beta}{4 \gamma}, \frac{\mu_{\theta}-\beta}{2 \gamma}\right)$, then Eq. (17) has a unique solution $n_{S} \in[3, \infty)$. For any $n_{m} \in\left[3, n_{S}\right)$, condition (A.8) holds and the equilibrium security is given by Eq. (15) with $\bar{s}_{m}$ as defined in Eq. (A.5). For any $n_{m} \in\left[n_{S}, \infty\right)$, condition (A.8) does not hold, meaning that there is no $\bar{s}_{m} \in(0, S)$ solving Eq. (A.5). The equilibrium security is still given by Eq. (15) but with $\bar{s}_{m}=S$ instead of Eq. (A.5).

If the parameters satisfy $z(S)-E_{1}(Z) \geq \frac{\mu_{\theta}-\beta}{2 \gamma}$, then condition (A.8) is true for any $n_{m} \in[3, \infty)$. The equilibrium security is thus given by Eq. (15) with $\bar{s}_{m}$ as defined in Eq. (A.5). Condition (A.8) being true for any $n_{m} \in[3, \infty)$ means that there is no solution $n_{S} \in[3, \infty)$ to Eq. (17). Assigning $n_{S}=\infty$ here recovers Eq. (A.5) from Eq. (16) for any $n_{m} \geq 3$.

If the parameters satisfy $z(S)-E_{1}(Z)<\frac{\mu_{\theta}-\beta}{4 \gamma}$, then condition (A.8) is false for any $n_{m} \in[3, \infty)$. The equilibrium security is thus given by Eq. (15) with $\bar{s}_{m}=S$ for all $n_{m} \in[3, \infty)$. Assigning 
$n_{S}=-\infty$ here recovers $\bar{s}_{m}=S$ from Eq. (16) for any $n_{m} \geq 3$.

We have now shown that the solution to the intermediary's F.O.C.s belongs to the family of debt securities: $W_{m}$ pays the entirety of the underlying asset $Z$ up to some threshold state $\bar{s}_{m}$, after which it pays a flat amount that does not vary with the state. A perturbation argument similar to Hébert (2018) can be used to confirm the optimality of debt securities in our environment. We sketch this argument in the main text (see the paragraph that follows Figure 1) so do not reproduce it here. Instead, we confirm that $\bar{s}_{m}$ as defined by Eq. (A.7) satisfies the S.O.C. for a maximum in an auxiliary problem where the intermediary chooses a threshold state $\widetilde{s}_{m}$ to maximize his expected profit within the family of debt securities.

The objective function for this auxiliary problem is:

$$
\begin{aligned}
\mathcal{L}_{m}^{(A)}= & \left(\mu_{\theta}-\beta\right)\left[z\left(\widetilde{s}_{m}\right)-\int_{0}^{\widetilde{s}_{m}}\left[z\left(\widetilde{s}_{m}\right)-z(s)\right] d F(s)\right] \\
& -\gamma \frac{n_{m}-1}{n_{m}-2}\left[\int_{0}^{\widetilde{s}_{m}}\left[z\left(\widetilde{s}_{m}\right)-z(s)\right]^{2} d F(s)-\left(\int_{0}^{\widetilde{s}_{m}}\left[z\left(\widetilde{s}_{m}\right)-z(s)\right] d F(s)\right)^{2}\right]
\end{aligned}
$$

The first derivative with respect to $\widetilde{s}_{m}$ is:

$$
\frac{\partial \mathcal{L}_{m}^{(A)}}{\partial \widetilde{s}_{m}}=\left[\mu_{\theta}-\beta-2 \gamma \frac{n_{m}-1}{n_{m}-2} \int_{0}^{\widetilde{s}_{m}}\left[z\left(\widetilde{s}_{m}\right)-z(s)\right] d F(s)\right]\left[1-F\left(\widetilde{s}_{m}\right)\right] z^{\prime}\left(\widetilde{s}_{m}\right)
$$

If $n_{m}<n_{S}$, then Eq. (A.7) has a unique interior solution $\bar{s}_{m} \in(0, S)$, which is also the unique interior solution to $\frac{\partial \mathcal{L}_{m}^{(A)}}{\partial \widetilde{s}_{m}}=0$. The second derivative evaluated at this solution is:

$$
\left.\frac{\partial^{2} \mathcal{L}_{m}^{(A)}}{\partial \widetilde{s}_{m}^{2}}\right|_{\widetilde{s}_{m}=\bar{s}_{m}}=-2 \gamma \frac{n_{m}-1}{n_{m}-2}\left(z^{\prime}\left(\bar{s}_{m}\right)\right)^{2} F\left(\bar{s}_{m}\right)\left[1-F\left(\bar{s}_{m}\right)\right]<0
$$

where the inequality follows from $\bar{s}_{m} \in(0, S)$. Eq. (A.7) thus defines a local maximum and, since there are no local minima, the local maximum is also the global maximum.

If $n_{m}>n_{S}$, then there is no solution $\bar{s}_{m}<S$ to Eq. (A.7). The only solution to $\frac{\partial \mathcal{L}_{m}^{(A)}}{\partial \widetilde{s}_{m}}=0$ is therefore $\widetilde{s}_{m}=S$, in which case the second derivative is:

$$
\left.\frac{\partial^{2} \mathcal{L}_{m}^{(A)}}{\partial \widetilde{s}_{m}^{2}}\right|_{\widetilde{s}_{m}=S}=-\left[\mu_{\theta}-\beta-2 \gamma \frac{n_{m}-1}{n_{m}-2}\left[z(S)-E_{1}(Z)\right]\right] f(S) z^{\prime}(S)
$$

This is negative if and only if $\frac{n_{m}-2}{n_{m}-1}>\frac{2 \gamma}{\mu_{\theta}-\beta}\left[z(S)-E_{1}(Z)\right]$ or, equivalently, $n_{m}>n_{S}$. 
Notice that Eq. (A.7) is only defined if $\mu_{\theta}>\beta$. We now demonstrate that $\mu_{\theta}>\beta$ is necessary and sufficient for the intermediary's participation constraint to be satisfied. The participation constraint requires that the intermediary's maximized expected profit, as given by $E_{0}\left(V_{m}\right)$ in Eq. (8) when evaluated at the equilibrium security, must be at least as large as $\beta E_{1}(Z) \times n_{m}$, which is what the intermediary could get by consuming $n_{m}$ units of $Z$ at date $t=2$ instead of using these units to design the security for market $m$.

If $n_{m} \geq n_{S}$, then the intermediary's maximization problem yields $W_{m}=Z$ and the participation constraint simplifies to:

$$
\left(\mu_{\theta}-\beta\right) E_{1}(Z) \geq \gamma \frac{n_{m}-1}{n_{m}-2} \mathcal{V}_{1}(Z)
$$

Assume $\mu_{\theta}>\beta$ so that the left-hand side of (A.9) is positive. The right hand side of (A.9) is decreasing in $n_{m}$ so (A.9) will hold for all $n_{m} \geq n_{S}$ if it holds for $n_{m}=n_{S}$. Evaluating (A.9) at the definition of $n_{S}$ in Eq. (17), we get:

$$
2 z(S) E_{1}(Z) \geq E\left(Z^{2}\right)+\left(E_{1}(Z)\right)^{2}
$$

which is true because $Z$ has the property $z^{\prime}(\cdot)>0$.

If $n_{m}<n_{S}$, then $\bar{s}_{m} \in(0, S)$ is defined by Eq. (A.7). The participation constraint requires:

$$
\left(\mu_{\theta}-\beta\right) E_{1}\left(W_{m}\right) \geq \gamma \frac{n_{m}-1}{n_{m}-2} \mathcal{V}_{1}\left(W_{m}\right)
$$

where $E_{1}\left(W_{m}\right)$ is given by Eq. (A.6) and:

$$
\mathcal{V}_{1}\left(W_{m}\right)=\int_{0}^{\bar{s}_{m}}\left[z\left(\bar{s}_{m}\right)-z(s)\right]^{2} d F(s)-\left(\int_{0}^{\bar{s}_{m}}\left[z\left(\bar{s}_{m}\right)-z(s)\right] d F(s)\right)^{2}
$$

Use Eq. (A.7) to rewrite (A.10) as:

$$
2 E_{1}\left(W_{m}\right) \int_{0}^{\bar{s}_{m}}\left[z\left(\bar{s}_{m}\right)-z(s)\right] d F(s) \geq \mathcal{V}_{1}\left(W_{m}\right)
$$

then substitute in for $E_{1}\left(W_{m}\right)$ and $\mathcal{V}_{1}\left(W_{m}\right)$ to get:

$$
\begin{aligned}
& 2 z\left(\bar{s}_{m}\right) \frac{1}{F\left(\bar{s}_{m}\right)} \int_{0}^{\bar{s}_{m}} z(s) d F(s)+\left(\frac{1}{F\left(\bar{s}_{m}\right)}-1\right)\left[\left(z\left(\bar{s}_{m}\right)\right)^{2}-\frac{1}{F\left(\bar{s}_{m}\right)} \int_{0}^{\bar{s}_{m}}(z(s))^{2} d F(s)\right] \\
\geq & \frac{1}{F\left(\bar{s}_{m}\right)} \int_{0}^{\bar{s}_{m}}(z(s))^{2} d F(s)+\left(\frac{1}{F\left(\bar{s}_{m}\right)} \int_{0}^{\bar{s}_{m}} z(s) d F(s)\right)^{2}
\end{aligned}
$$


which is again true because of $z^{\prime}(\cdot)>0$.

\section{Proof of Proposition 3}

For any $n_{m}<n_{S}$, Eq. (16) simplifies to Eq. (A.7) from the proof of Proposition 2. Differentiating Eq. (A.7) yields:

$$
\frac{d \bar{s}_{m}}{d n_{m}}=\frac{\mu_{\theta}-\beta}{2 \gamma} \frac{1}{\left(n_{m}-1\right)^{2}} \frac{1}{z^{\prime}\left(\bar{s}_{m}\right) F\left(\bar{s}_{m}\right)}>0
$$

Therefore, $\frac{d \bar{s}_{m}}{d n_{m}}>0$ for any $n_{m} \in\left[3, n_{S}\right)$ and $\lim _{n_{m} \rightarrow n_{S}^{-}} \frac{d \bar{s}_{m}}{d n_{m}}>0$.

A corollary is that the same properties hold for the mean and variance of the equilibrium security. To see why, differentiate Eq. (A.6) and (A.11) to get:

$$
\frac{d E_{1}\left(W_{m}\right)}{d \bar{s}_{m}}=z^{\prime}\left(\bar{s}_{m}\right)\left[1-F\left(\bar{s}_{m}\right)\right]
$$

and:

$$
\frac{d \mathcal{V}_{1}\left(W_{m}\right)}{d \bar{s}_{m}}=2 z^{\prime}\left(\bar{s}_{m}\right)\left[1-F\left(\bar{s}_{m}\right)\right] \int_{0}^{\bar{s}_{m}}\left[z\left(\bar{s}_{m}\right)-z(s)\right] d F(s)
$$

Both of these derivatives are strictly positive because $n_{m}<n_{S}$ implies $\bar{s}_{m} \in(0, S)$. It then follows immediately that $E_{1}\left(W_{m}\right)$ and $\mathcal{V}_{1}\left(W_{m}\right)$ increase with $n_{m}$ as $\bar{s}_{m}$ increases with $n_{m}$, up until the point where $n_{m}=n_{S}$.

\section{Proof of Lemma 1}

Write $\frac{n \mathcal{V}_{1}(W(n))}{n-2}$ to make explicit that we are evaluating $\mathcal{V}_{1}(\cdot)$ at the equilibrium security derived in Proposition 2, denoted here by $W(n)$ to make explicit its dependence on the market size $n$.

Taking derivatives:

$$
\frac{d}{d n}\left(\frac{n \mathcal{V}_{1}(W(n))}{n-2}\right)=-\frac{2 \mathcal{V}_{1}(W(n))}{(n-2)^{2}}+\frac{n}{n-2} \frac{d \mathcal{V}_{1}(W(n))}{d n}
$$

If $n \geq n_{S}$, then $W(n)=Z$ and this derivative is negative. If instead $n<n_{S}$, then we can use the derivatives in the proof of Proposition 3 to write:

$$
\frac{d}{d n}\left(\frac{n \mathcal{V}_{1}(W(n))}{n-2}\right) \stackrel{\text { sign }}{=}-\mathcal{V}_{1}(W(n))+\frac{\mu_{\theta}-\beta}{2 \gamma} \frac{n(n-2)}{(n-1)^{2}} \frac{1-F(\bar{s})}{F(\bar{s})} \int_{0}^{\bar{s}}[z(\bar{s})-z(s)] d F(s)
$$

Using Eq. (A.7) and the expression for $\mathcal{V}_{1}(W(n))$ in Eq. (A.11), we obtain the following necessary 
and sufficient condition for $\frac{d}{d n}\left(\frac{n \mathcal{V}_{1}(W(n))}{n-2}\right)<0$ when $n<n_{S}$ :

$$
\int_{0}^{\bar{s}}[z(\bar{s})-z(s)]^{2} d F(s)>\frac{1}{F(\bar{s})}\left(1+\frac{1-F(\bar{s})}{n-1}\right)\left(\int_{0}^{\bar{s}}[z(\bar{s})-z(s)] d F(s)\right)^{2}
$$

This rearranges to:

$$
\frac{z(\bar{s})-E_{1}(Z \mid s \leq \bar{s})}{\sqrt{\mathcal{V}_{1}(Z \mid s \leq \bar{s})}}<\sqrt{\frac{n-1}{1-F(\bar{s})}}
$$

where:

$$
E_{1}(Z \mid s \leq \bar{s}) \equiv \frac{1}{F(\bar{s})} \int_{0}^{\bar{s}} z(s) d F(s)
$$

and:

$$
\mathcal{V}_{1}(Z \mid s \leq \bar{s}) \equiv \frac{1}{F(\bar{s})} \int_{0}^{\bar{s}}(z(s))^{2} d F(s)-\left(\frac{1}{F(\bar{s})} \int_{0}^{\bar{s}} z(s) d F(s)\right)^{2}
$$

Since $n \geq 3$ and $F(\bar{s}) \in[0,1]$, a sufficient condition for (A.12) is:

$$
\frac{z(\bar{s})-E_{1}(Z \mid s \leq \bar{s})}{\sqrt{\mathcal{V}_{1}(Z \mid s \leq \bar{s})}}<\sqrt{2}+\varepsilon(\bar{s})
$$

where $\varepsilon(\bar{s}) \equiv \sqrt{2}\left(\frac{1}{\sqrt{1-F(\bar{s})}}-1\right) \geq 0$ and $\varepsilon^{\prime}(\bar{s})>0$. From Eq. (A.7), we know that $\bar{s}$ is (weakly) increasing in $\frac{\mu_{\theta}-\beta}{\gamma}$. The same is then true for $\varepsilon(\bar{s})$ and we can define the (sufficient) condition in the statement of Lemma 1 independently of a particular value of $\bar{s}$.

This completes the proof of Lemma 1. We next present a tractable example where the compensation for risk term is decreasing in $n_{m}$ while the gains from trade term is increasing in $n_{m}$; this example can be skipped without loss to the proof of Lemma 1. Consider an asset $Z$ with payoffs $z(s)=s$, where $s \in[0, S]$ is uniformly distributed according to $F(s)=\frac{s}{S}$. For ease of reference, we introduce the notation

$$
G\left(n_{m}\right) \equiv \frac{\sigma_{\theta}^{2}}{2 \gamma} \frac{n_{m}-2}{n_{m}-1} \frac{\left[E_{1}\left(W\left(n_{m}\right)\right)\right]^{2}}{\mathcal{V}_{1}\left(W\left(n_{m}\right)\right)}
$$

for the gains from trade term, and

$$
R\left(n_{m}\right) \equiv \frac{\gamma}{2} \frac{n_{m}}{n_{m}-2} \mathcal{V}_{1}\left(W\left(n_{m}\right)\right)
$$

for the compensation for risk term, both evaluated at the equilibrium security derived in Proposition 2. 
Taking derivatives:

$G^{\prime}\left(n_{m}\right)=\frac{\sigma_{\theta}^{2}}{2 \gamma} \frac{n_{m}-2}{n_{m}-1} \frac{E_{1}\left(W\left(n_{m}\right)\right)}{\mathcal{V}_{1}\left(W\left(n_{m}\right)\right)}\left[\frac{E_{1}\left(W\left(n_{m}\right)\right)}{\left(n_{m}-1\right)\left(n_{m}-2\right)}+2 \frac{d E_{1}\left(W\left(n_{m}\right)\right)}{d n_{m}}-\frac{E_{1}\left(W\left(n_{m}\right)\right)}{\mathcal{V}_{1}\left(W\left(n_{m}\right)\right)} \frac{d \mathcal{V}_{1}\left(W\left(n_{m}\right)\right)}{d n_{m}}\right]$

and:

$$
R^{\prime}\left(n_{m}\right)=-\frac{\gamma}{2} \frac{n_{m}}{n_{m}-2}\left[\frac{2 \mathcal{V}_{1}\left(W\left(n_{m}\right)\right)}{n_{m}\left(n_{m}-2\right)}-\frac{d \mathcal{V}_{1}\left(W\left(n_{m}\right)\right)}{d n_{m}}\right]
$$

If $n_{m}>n_{S}$, then $W\left(n_{m}\right)=Z$ and thus $\frac{d E_{1}\left(W\left(n_{m}\right)\right)}{d n_{m}}=\frac{d \mathcal{V}_{1}\left(W\left(n_{m}\right)\right)}{d n_{m}}=0$, which further implies $G^{\prime}\left(n_{m}\right)>0$ and $R^{\prime}\left(n_{m}\right)<0$.

If instead $n_{m} \leq n_{S}$, then Proposition 2 defines:

$$
z\left(\bar{s}_{m}\right)=E_{1}\left(W\left(n_{m}\right)\right)+\frac{\mu_{\theta}-\beta}{2 \gamma} \frac{n_{m}-2}{n_{m}-1}
$$

With $z(s)=s$ and $f(s)=\frac{1}{S}$, the equilibrium security has:

$$
E_{1}\left(W\left(n_{m}\right)\right)=\bar{s}_{m}\left(1-\frac{1}{2} \frac{\bar{s}_{m}}{S}\right)
$$

and:

$$
\mathcal{V}_{1}\left(W\left(n_{m}\right)\right)=\frac{\bar{s}_{m}^{3}}{S}\left(\frac{1}{3}-\frac{1}{4} \frac{\bar{s}_{m}}{S}\right)
$$

where:

$$
\frac{1}{2} \frac{\bar{s}_{m}^{2}}{S}=\frac{\mu_{\theta}-\beta}{2 \gamma} \frac{n_{m}-2}{n_{m}-1}
$$

The total derivatives of $E_{1}\left(W\left(n_{m}\right)\right)$ and $\mathcal{V}_{1}\left(W\left(n_{m}\right)\right)$ with respect to $n_{m}$ are therefore:

$$
\frac{d E_{1}\left(W\left(n_{m}\right)\right)}{d n_{m}}=\left(1-\frac{\bar{s}_{m}}{S}\right) \frac{\mu_{\theta}-\beta}{2 \gamma \frac{\bar{s}_{m}}{S}} \frac{1}{\left(n_{m}-1\right)^{2}}
$$

and:

$$
\frac{d \mathcal{V}_{1}\left(W\left(n_{m}\right)\right)}{d n_{m}}=\frac{\bar{s}_{m}^{2}}{S} \frac{d E_{1}\left(W\left(n_{m}\right)\right)}{d n_{m}}
$$

Substituting into the expressions for $G^{\prime}\left(n_{m}\right)$ and $R^{\prime}\left(n_{m}\right)$, we get:

$$
G^{\prime}\left(n_{m}\right)=\frac{\sigma_{\theta}^{2}}{4 \gamma} \frac{\bar{s}_{m}}{\left(n_{m}-1\right)^{2}} \frac{E_{1}\left(W\left(n_{m}\right)\right)}{\mathcal{V}_{1}\left(W\left(n_{m}\right)\right)} \frac{\frac{1}{3}+\left(1-\frac{\bar{s}_{m}}{S}\right)^{2}}{\frac{4}{3}-\frac{\bar{s}_{m}}{S}}>0
$$


and:

$$
R^{\prime}\left(n_{m}\right)=-\frac{\gamma}{4} \frac{\bar{s}_{m}^{3}}{S} \frac{\left(\frac{\mu_{\theta}-\beta}{\gamma S} \frac{n_{m}-2}{n_{m}-1}\right)^{\frac{1}{2}}-\frac{4-n_{m}}{3}}{\left(n_{m}-1\right)\left(n_{m}-2\right)^{2}}
$$

To help establish $R^{\prime}\left(n_{m}\right)<0$, notice that $R^{\prime}\left(n_{m}\right)<0$ for all $n_{m} \geq 3$ if and only if $R^{\prime}(3)<0$. Therefore, $\frac{\mu_{\theta}-\beta}{\gamma S}>\frac{2}{9}$ is sufficient for $R^{\prime}\left(n_{m}\right)<0$. This condition on $\frac{\mu_{\theta}-\beta}{\gamma}$ is consistent with the sufficient condition in Lemma 1; in fact, the condition derived here delivers an $\varepsilon$ that ensures the condition there holds.

\section{Proof of Proposition 4}

It will suffice to show that the investor's value function is decreasing in the number of investors in her market for $\sigma_{\theta}^{2}$ low.

From Eq. (18), the expected profit of an investor in a market of size $n$ is:

$$
E_{0}\left(V^{i}(n)\right)=\frac{\sigma_{\theta}^{2}}{2 \gamma} \frac{n-2}{n-1} \frac{\left[E_{1}(W(n))\right]^{2}}{\mathcal{V}_{1}(W(n))}+\frac{\gamma}{2} \frac{n}{n-2} \mathcal{V}_{1}(W(n))
$$

where we write $E_{0}\left(V^{i}(n)\right)$ to make explicit that we are evaluating the investor's expected profit at the equilibrium security derived in Proposition 2, denoted here by $W(n)$ to make explicit its dependence on the market size $n$.

Note that $E_{0}\left(V^{i}(n)\right)$ is continuous and differentiable in $n \in \mathbb{R}_{+}$. Taking the derivative with respect to $n$ in Eq. (A.16), we obtain

$$
\frac{d}{d n} E_{0}\left(V^{i}(n)\right)=\frac{\sigma_{\theta}^{2}}{2 \gamma} X(n)+\frac{\gamma}{2} \frac{d}{d n}\left(\frac{n \mathcal{V}_{1}(W(n))}{n-2}\right)
$$

where

$$
X(n) \equiv \frac{1}{(n-1)^{2}} \frac{\left[E_{1}(W(n))\right]^{2}}{\mathcal{V}_{1}(W(n))}+\frac{n-2}{n-1} \frac{d}{d n}\left(\frac{\left[E_{1}(W(n))\right]^{2}}{\mathcal{V}_{1}(W(n))}\right)
$$

and

$$
\frac{d}{d n}\left(\frac{\left[E_{1}(W(n))\right]^{2}}{\mathcal{V}_{1}(W(n))}\right)=\frac{E_{1}(W(n))}{\mathcal{V}_{1}(W(n))}\left[2 \frac{d E_{1}(W(n))}{d n}-\frac{E_{1}(W(n))}{\mathcal{V}_{1}(W(n))} \frac{d \mathcal{V}_{1}(W(n))}{d n}\right]
$$

If $\frac{d}{d n} E_{0}\left(V^{i}(n)\right)<0$, then investors want to be in the smallest possible markets, and as long as they can deviate in groups of three or more, i.e., $\ell \geq 3$ in Definition 1 , all intermediaries will be active.

From Lemma $1, \frac{d}{d n}\left(\frac{n \mathcal{V}_{1}(W(n))}{n-2}\right)<0$ when the payoffs of the asset $Z$ satisfy the condition in the 
lemma. The next step is to show that $X(n)$ is bounded. If $n \geq n_{S}$, then $W(n)=Z$ and

$$
\frac{d}{d n}\left(\frac{\left[E_{1}(W(n))\right]^{2}}{\mathcal{V}_{1}(W(n))}\right)=0
$$

If instead $n<n_{S}$, then we can use the derivatives in the proof of Proposition 3 to write

$$
\frac{d}{d n}\left(\frac{\left[E_{1}(W(n))\right]^{2}}{\mathcal{V}_{1}(W(n))}\right) \stackrel{\text { sign }}{=} 1-\frac{E_{1}(W(n))}{\mathcal{V}_{1}(W(n))} \int_{0}^{\bar{s}}[z(\bar{s})-z(s)] d F(s),
$$

which simplifies to

$$
\frac{d}{d n}\left(\frac{\left[E_{1}(W(n))\right]^{2}}{\mathcal{V}_{1}(W(n))}\right) \stackrel{\operatorname{sign}}{=}-\frac{\int_{0}^{\bar{s}} z(s)[z(\bar{s})-z(s)] d F(s)}{\mathcal{V}_{1}(W(n))}<0
$$

after substituting $E_{1}(W(n))$ as per Eq. (A.6) and $\mathcal{V}_{1}(W(n))$ as per Eq. (A.11). Thus,

$$
X(n) \leq \frac{1}{(n-1)^{2}} \frac{\left[E_{1}(W(n))\right]^{2}}{\mathcal{V}_{1}(W(n))} \leq \frac{1}{4} \frac{\left[E_{1}(W(3))\right]^{2}}{\mathcal{V}_{1}(W(3))}
$$

for all $n \geq 3$, where $n=3$ is the smallest market size for which there can be a well-defined equilibrium price in Eq. (13). If $n_{S}>3$, then Eq. (A.7) defines $\bar{s} \in(0, S)$ and hence $E_{1}(W(3)) \in$ $(0, \infty)$ and $\mathcal{V}_{1}(W(3)) \in(0, \infty)$. In other words, $\frac{\left[E_{1}(W(3))\right]^{2}}{\mathcal{V}_{1}(W(3))}$ is bounded. If instead $n_{S}=3$, then

$\frac{\left[E_{1}(W(3))\right]^{2}}{\mathcal{V}_{1}(W(3))}=\frac{\left[E_{1}(Z)\right]^{2}}{\mathcal{V}_{1}(Z)}$, which is also bounded. It follows then that $X(n)$ is bounded. Invoking the condition on $Z$ from Lemma 1, we can now conclude that there exists a bound $\bar{\sigma}>0$ such that $\frac{d E_{0}\left(V^{i}(n)\right)}{d n}<0$ for all $n \geq 3$ if $\sigma_{\theta}^{2} \leq \bar{\sigma}$.

\section{Proof of Proposition 5}

The first step is to consider what happens when the security is held fixed at $Z$. In this case, the investor's expected value is simply (proportional to):

$$
E U(n) \equiv\left[\left(\frac{\sigma_{\theta}}{\gamma}\right)^{2} \frac{n-2}{n-1}\left(\frac{E(Z)}{\mathcal{V}(Z)}\right)^{2}+\frac{n}{n-2}\right] \mathcal{V}(Z)
$$

where:

$$
\frac{\partial E U}{\partial n}=\left[\left(\frac{\sigma_{\theta}}{\gamma}\right)^{2} \frac{1}{(n-1)^{2}}\left(\frac{E(Z)}{\mathcal{V}(Z)}\right)^{2}-\frac{2}{(n-2)^{2}}\right] \mathcal{V}(Z)
$$


Therefore:

$$
\frac{\partial E U}{\partial n} \stackrel{\operatorname{sign}}{=} \frac{\sigma_{\theta}}{\sqrt{2} \gamma} \frac{E(Z)}{\mathcal{V}(Z)}-\frac{n-1}{n-2}
$$

where $\frac{n-1}{n-2}$ is a decreasing function of $n$ that takes on a minimum value of 1 as $n \rightarrow \infty$.

Lemma A.1 Consider a minimum market size of $n_{\min } \geq 3$. Then $E U(n)$ is maximized at $n=$ $n_{\min }$ if $\frac{\sigma_{\theta}}{\gamma} \frac{E(Z)}{\mathcal{V}(Z)}<\sqrt{\frac{2\left(n_{\min }-1\right)}{n_{\min }-2}}$ and at $n \rightarrow \infty$ otherwise.

Proof. There are three cases from Eq. (A.17):

1. If $\frac{\sigma_{\theta}}{\sqrt{2} \gamma} \frac{E(Z)}{\mathcal{V}(Z)} \leq 1$, then $\frac{\partial E U}{\partial n}<0$ for all $n$. Thus, $E U(n)$ is maximized at $n=n_{\min }$.

2. If $\frac{\sigma_{\theta}}{\sqrt{2} \gamma} \frac{E(Z)}{\mathcal{V}(Z)} \in\left(1, \frac{n_{\min }-1}{n_{\min }-2}\right)$, then there exists an $n \in\left(n_{\min }, \infty\right)$ such that $\frac{\partial E U}{\partial n}=0$ but it minimizes $E U(n)$, i.e., $\frac{\partial^{2} E U}{\partial n^{2}}>0$. Thus, $E U(n)$ is maximized at either $n=n_{\min }$ or $n \rightarrow \infty$. Note that $E U\left(n_{\min }\right)>E U(\infty)$ reduces to $\frac{\sigma_{\theta}}{\sqrt{2} \gamma} \frac{E(Z)}{\mathcal{V}(Z)}<\sqrt{\frac{n_{\min }-1}{n_{\min }-2}}$, where $\sqrt{\frac{n_{\min }-1}{n_{\min }-2}}<\frac{n_{\min }-1}{n_{\min }-2}$ is trivially true for any $n_{\min } \geq 3$.

3. If $\frac{\sigma_{\theta}}{\sqrt{2} \gamma} \frac{E(Z)}{\mathcal{V}(Z)} \geq \frac{n_{\min }-1}{n_{\min }-2}$, then $\frac{\partial E U}{\partial n}>0$ for all $n$. Thus, $E U(n)$ is maximized at $n \rightarrow \infty$.

Under $\ell$-stability for $\ell=N$ in Definition 1, Lemma A.1 implies fragmented markets if $\frac{E(Z)}{\mathcal{V}(Z)}<$ $\frac{\gamma}{\sigma_{\theta}} \sqrt{\frac{2\left(n_{\min }-1\right)}{n_{\min }-2}}$ (because investors want to have a price impact to get higher compensation for risk) and a centralized market if $\frac{E(Z)}{\mathcal{V}(Z)}>\frac{\gamma}{\sigma_{\theta}} \sqrt{\frac{2\left(n_{\min }-1\right)}{n_{\min }-2}}$ (because investors do not want to have a price impact in anticipation of taking large positions to get gains from trade).

The second step is to return to the model with an endogenous security, i.e., $W(n)$. For any $n \geq n_{S}$, the optimal security is $W(n)=Z$, where $Z$ is independent of $n$. Thus, the investor's expected value with endogenous security design, $E_{0}\left(V^{i}(n)\right)$, equals $E U(n)$ for any $n \geq n_{S}$.

Consider the three cases in the proof of Lemma A.1. In Case 1, we can immediately conclude that $E_{0}\left(V^{i}(n)\right)$ will be maximized at some $n<n_{S}$ given that $E U(n)$ is decreasing and convex for any $n \geq n_{S}$ (and $E_{0}\left(V^{i}(n)\right)$ is assumed continuously differentiable at all points, including $\left.n=n_{S}\right)$. Thus, in Case 1, we get that only fragmented markets survive in equilibrium. In Cases 2 and 3 , if $E_{0}\left(V^{i}(n)\right)$ has at most one critical point over $n \in\left(n_{\min }, \infty\right)$, then it will suffice to just check the endpoints because the properties of $E U(n)$ imply that $E_{0}\left(V^{i}(n)\right)$ is increasing and convex starting at some $n \in\left[n_{S}, \infty\right)$ and therefore that the critical point, if it exists, must be a minimum. Thus, in Cases 2 and 3, we get that only fragmented markets survive in equilibrium if and only if 
$E_{0}\left(V^{i}\left(n_{\min }\right)\right) \geq E_{0}\left(V^{i}(\infty)\right)$, or equivalently: ${ }^{19}$

$$
\left(\frac{\sigma_{\theta}}{\gamma}\right)^{2}\left[\left(\frac{E(Z)}{\sqrt{\mathcal{V}(Z)}}\right)^{2}-\left(\frac{E\left(W\left(n_{\min }\right)\right)}{\sqrt{\mathcal{V}\left(W\left(n_{\min }\right)\right)}}\right)^{2} \frac{n_{\min }-2}{n_{\min }-1}\right]<\frac{n_{\min }}{n_{\min }-2} \mathcal{V}\left(W\left(n_{\min }\right)\right)-\mathcal{V}(Z)
$$

Under the condition on the payoffs of $Z$ in Lemma $1, \frac{d}{d n}\left(\frac{n \mathcal{V}_{1}(W(n))}{n-2}\right)<0$ for all $n$. Thus, $\frac{n_{\min }}{n_{\min }-2} \mathcal{V}\left(W\left(n_{\min }\right)\right)>\mathcal{V}(Z)$. This means that a contradiction of $E_{0}\left(V^{i}\left(n_{\min }\right)\right) \geq E_{0}\left(V^{i}(\infty)\right)$ requires both $\frac{E(Z)}{\sqrt{\mathcal{V}(Z)}}>\frac{E\left(W\left(n_{\min }\right)\right)}{\sqrt{\mathcal{V}\left(W\left(n_{\min }\right)\right)}} \sqrt{\frac{n_{\min }-2}{n_{\min }-1}}$ and $\frac{\sigma_{\theta}}{\gamma}$ sufficiently large. Also recall that being in Case 2 or 3 requires $\frac{\sigma_{\theta}}{\sqrt{2} \gamma} \frac{E(Z)}{\mathcal{V}(Z)}>1$. Accordingly, only fragmented markets survive in equilibrium unless both $\frac{E(Z)}{\mathcal{V}(Z)}$ and $\frac{\sigma_{\theta}}{\gamma}$ are sufficiently large.

We now present an example of a distribution function $F(s)$ that delivers $E_{0}\left(V^{i}(n)\right)$ with at most one critical point over $n \in\left(n_{\min }, \infty\right)$.

Consider without loss of generality $z(s)=s$ for $s \in[0, S]$. If $s$ is uniformly distributed, i.e., $F(s)=\frac{s}{S}$, then Eq. (A.7) gives $\frac{\bar{s}}{S}=a \sqrt{\frac{n-2}{n-1}}$, where $a \equiv \sqrt{\frac{\mu_{\theta}-\beta}{\gamma S}}$. Thus, from Eq. (17), $n_{S}=2+\frac{1}{a^{2}-1} \in(3, \infty)$ if and only if $a \in(1, \sqrt{2})$. Impose this restriction on $a$ so that we can consider market structures where debt-like securities are traded, i.e., market structures where $n<n_{S}$ and thus $\frac{\bar{s}}{S} \in(0,1)$ from Proposition $2 .^{20}$

To obtain more compact expressions in what follows, define $y \equiv \sqrt{\frac{n-2}{n-1}}$ so that $\frac{\bar{s}}{S}=a y$ and $y \in\left[\frac{1}{\sqrt{2}}, \frac{1}{a}\right]$ for $n \in\left[3, n_{S}\right]$. The investor's expected payoff is then (proportional to):

$$
E V(y)=3\left(\frac{\sigma_{\theta}}{\gamma S}\right)^{2} \frac{y(2-a y)^{2}}{a(4-3 a y)}+\frac{1}{12}\left(\frac{2}{y^{2}}-1\right)(a y)^{3}(4-3 a y)
$$

for $y \leq \frac{1}{a}$. Given the properties of $E U(n)$ derived earlier for $n \geq n_{S}$, it will suffice to show that $E V^{\prime \prime}\left(y^{*}\right)>0$ at any point $y^{*} \leq \frac{1}{a}$ where $E V^{\prime}\left(y^{*}\right)=0$.

The first and second derivatives are

$$
E V^{\prime}(y)=6\left(\frac{\sigma_{\theta}}{\gamma S}\right)^{2} \frac{(2-a y)\left(4-6 a y+3 a^{2} y^{2}\right)}{a(4-3 a y)^{2}}-a^{3}\left(a y-\frac{2}{3}+y^{2}(1-a y)\right)
$$

and

$$
E V^{\prime \prime}(y)=6\left(\frac{\sigma_{\theta}}{\gamma S}\right)^{2}\left(\frac{6(2-a y)\left(4-6 a y+3 a^{2} y^{2}\right)}{(4-3 a y)^{3}}-1\right)-a^{3}\left(a+2 y-3 a y^{2}\right)
$$

\footnotetext{
${ }^{19}$ To accommodate the integer issue, also check for $n_{\min }+1$. Qualitatively, the conditions are the same as for $n_{\min }$.

${ }^{20}$ Recall from the proof of Proposition 2 that $a \geq \sqrt{2}$ would imply $W(n)=Z$ for all $n \geq 3$. Also recall that $a<1$ would imply $W(n) \neq Z$ even as $n \rightarrow \infty$.
} 
respectively. If there exists a $y^{*} \leq \frac{1}{a}$ such that $E V^{\prime}\left(y^{*}\right)=0$, then

$$
\frac{a^{4}\left(a y^{*}-\frac{2}{3}+y^{* 2}\left(1-a y^{*}\right)\right)\left(4-3 a y^{*}\right)^{2}}{\left(2-a y^{*}\right)\left(4-6 a y^{*}+3 a^{2} y^{* 2}\right)}=6\left(\frac{\sigma_{\theta}}{\gamma S}\right)^{2}
$$

and thus $E V^{\prime \prime}\left(y^{*}\right)>0$ if and only if

$$
a\left(a y^{*}-\frac{2}{3}+y^{* 2}\left(1-a y^{*}\right)\right)\left(\frac{6}{4-3 a y^{*}}-\frac{\left(4-3 a y^{*}\right)^{2}}{\left(2-a y^{*}\right)\left(4-6 a y^{*}+3 a^{2} y^{* 2}\right)}\right)>a+2 y^{*}-3 a y^{* 2}
$$

In the limiting case of $a=\sqrt{2}$, the range $y \in\left[\frac{1}{\sqrt{2}}, \frac{1}{a}\right]$ reduces to $y=\frac{1}{\sqrt{2}}$. It is straightforward to verify that (A.18) is satisfied if $y^{*}=\frac{1}{\sqrt{2}}$ does indeed solve $E V^{\prime}\left(y^{*}\right)=0$ at $a=\sqrt{2}$. Both sides of (A.18) are continuous in $a$ and $y^{*}$, hence there exists an $\underline{a} \in(1, \sqrt{2})$ such that (A.18) will be satisfied for any $y^{*} \in\left[\frac{1}{\sqrt{2}}, \frac{1}{a}\right]$ for any $a \in(\underline{a}, \sqrt{2})$. Note that $a \equiv \sqrt{\frac{\mu_{\theta}-\beta}{\gamma S}}$ and $a \in(\underline{a}, \sqrt{2})$ defines a non-empty set of $S$ for which the investor's expected payoff will have at most one critical point whenever the state $s$ is uniformly distributed over the interval $[0, S]$.

\section{Proof of Proposition 6}

Start with the intermediary's expected payoff, $E_{0}\left(V_{m}\right)$. Substituting $\lambda_{m}^{-1} \equiv\left(n_{m}-2\right)$ into Eq. (14):

$$
E_{0}\left(V_{m}\right)=\left[\beta E_{1}(Z)+\left(\mu_{\theta}-\beta\right) E_{1}\left(W\left(n_{m}\right)\right)-\frac{n_{m}-1}{n_{m}-2} \gamma \mathcal{V}_{1}\left(W\left(n_{m}\right)\right)\right] \times n_{m}
$$

This expression for $E_{0}\left(V_{m}\right)$ is increasing in $n_{m}$ holding constant the security $W_{m}$, implying that $E_{0}\left(V_{m}\right)$ is increasing in $n_{m}$ for $n_{m}>n_{S}$ since the equilibrium security for any $n_{m}>n_{S}$ is simply $W_{m}=Z$. It then remains to check that $E_{0}\left(V_{m}\right)$ is also increasing in $n_{m}$ for $n_{m} \leq n_{S}$ when evaluated at the equilibrium security $W\left(n_{m}\right)$.

$$
\begin{aligned}
& \text { With } z(s)=z(0)+\kappa s \text { and } f(s)=\frac{1}{S} \text { : } \\
& \qquad \begin{aligned}
E_{1}\left(W_{m}\right)=z(0)+\kappa \bar{s}_{m}\left(1-\frac{1}{2} \frac{\bar{s}_{m}}{S}\right) \\
\mathcal{V}_{1}\left(W_{m}\right)=\kappa^{2} \frac{\bar{s}_{m}^{3}}{S}\left(\frac{1}{3}-\frac{1}{4} \frac{\bar{s}_{m}}{S}\right) \\
\left(\frac{\bar{s}_{m}}{S}\right)^{2}=\frac{\mu_{\theta}-\beta}{\kappa \gamma S} \frac{n_{m}-2}{n_{m}-1}
\end{aligned}
\end{aligned}
$$


for $n_{m} \leq n_{S}$. Thus,

$$
E_{0}\left(V_{m}\right)=\kappa S\left[\frac{\beta}{2}+\frac{\mu_{\theta} z(0)}{\kappa S}+\left(\mu_{\theta}-\beta\right) \frac{\bar{s}_{m}}{S}\left(\frac{2}{3}-\frac{1}{4} \frac{\bar{s}_{m}}{S}\right)\right] n_{m}
$$

for $n_{m} \leq n_{S}$. It is easy to show that $\frac{\bar{s}_{m}}{S}\left(\frac{2}{3}-\frac{1}{4} \frac{\bar{s}_{m}}{S}\right)$ is increasing in $\frac{\bar{s}_{m}}{S}$ for any $\frac{\bar{s}_{m}}{S} \in[0,1]$. We also know from Proposition 3 that $\bar{s}_{m}$ is increasing in $n_{m}$. Therefore, $\frac{d E_{0}\left(V_{m}\right)}{d n_{m}}>0$ for $n_{m} \leq n_{S}$.

Turn now to total welfare. Ignore the integered nature of investors for the moment. There are $N$ investors, each getting the expected payoff $E_{0}\left(V_{m}^{i}\right)$ in Eq. (18). There are also $\frac{N}{n_{m}}$ active intermediaries, each getting the expected payoff $E_{0}\left(V_{m}\right)$ in Eq. (14). Inactive intermediaries receive a payoff of zero. Total (expected) welfare at date $t=0$ is then:

$$
\mathcal{W}=N \times E_{0}\left(V_{m}^{i}\right)+\frac{N}{n_{m}} \times E_{0}\left(V_{m}\right)
$$

where $\frac{1}{n_{m}} \times E_{0}\left(V_{m}\right)$ is the expected, per-capita payoff of an active intermediary.

Substituting in Eq. (14) and (18):

$$
\mathcal{W}=N\left(\beta E_{1}(Z)+\left(\mu_{\theta}-\beta\right) E_{1}\left(W_{m}\right)+\frac{\sigma_{\theta}^{2}}{2 \gamma} \frac{n_{m}-2}{n_{m}-1} \frac{\left[E_{1}\left(W_{m}\right)\right]^{2}}{\mathcal{V}_{1}\left(W_{m}\right)}-\frac{\gamma}{2} \mathcal{V}_{1}\left(W_{m}\right)\right)
$$

Notice that the utility investors receive from the risk premium (i.e., compensation for risk term) is outweighed by the negative effect of variance on the price that the intermediary receives.

The expression for $\mathcal{W}$ is increasing in $n_{m}$ holding constant the security $W_{m}$. Therefore, $\mathcal{W}$ is increasing in $n_{m}$ for $n_{m}>n_{S}$ and it only remains to check that $\mathcal{W}$ is also increasing in $n_{m}$ for $n_{m} \leq n_{S}$ when evaluated at the equilibrium security. Using the expressions for $E_{1}\left(W\left(n_{m}\right)\right)$, $\mathcal{V}_{1}\left(W\left(n_{m}\right)\right)$, and $\bar{s}_{m}$ above, we can write:

$$
\begin{aligned}
\mathcal{W}= & \beta\left(z(0)+\frac{\kappa S}{2}\right) N+z(0)\left[\widehat{\mu}_{\theta}+\frac{\widehat{\sigma}_{\theta}^{2}}{\widehat{\mu}_{\theta}} \frac{2\left(1-\frac{x}{2}\right)+\frac{z(0)}{\kappa S} \frac{1}{x}}{\frac{2}{3}-\frac{x}{2}}\right] \kappa \gamma S N \\
& +\left[\widehat{\mu}_{\theta} x\left(1-\frac{x}{2}\right)+\frac{\widehat{\sigma}_{\theta}^{2}}{\widehat{\mu}_{\theta}} \frac{x\left(1-\frac{x}{2}\right)^{2}}{\frac{2}{3}-\frac{x}{2}}-\frac{x^{3}}{2}\left(\frac{1}{3}-\frac{x}{4}\right)\right] \gamma \kappa^{2} S^{2} N
\end{aligned}
$$


for $n_{m} \leq n_{S}$, where $x \equiv \frac{\bar{s}_{m}}{S}, \widehat{\mu}_{\theta} \equiv \frac{\mu_{\theta}-\beta}{\kappa \gamma S}$, and $\widehat{\sigma}_{\theta} \equiv \frac{\sigma_{\theta}}{\kappa \gamma S}$. Taking derivatives:

$$
\begin{aligned}
\frac{d \mathcal{W}}{d x}= & z(0) \frac{\widehat{\sigma}_{\theta}^{2}}{\widehat{\mu}_{\theta}} \frac{\frac{1}{3}-\frac{z(0)}{\kappa S} \frac{1}{x^{2}}\left(\frac{2}{3}-x\right)}{\left(\frac{2}{3}-\frac{x}{2}\right)^{2}} \kappa \gamma S N \\
& +\left[\frac{\widehat{\sigma}_{\theta}^{2}}{\widehat{\mu}_{\theta}} \frac{\left(1-\frac{x}{2}\right)\left(\frac{2}{3}-x+\frac{x^{2}}{2}\right)}{\left(\frac{2}{3}-\frac{x}{2}\right)^{2}}+\left(\widehat{\mu}_{\theta}-\frac{x^{2}}{2}\right)(1-x)\right] \gamma \kappa^{2} S^{2} N
\end{aligned}
$$

The expression for $\bar{s}_{m}$ rearranges to

$$
\widehat{\mu}_{\theta}=\frac{n_{m}-1}{n_{m}-2} x^{2}>x^{2}
$$

and hence the second line in the expression for $\frac{d \mathcal{W}}{d x}$ is positive. If $z(0)=0$, then it follows immediately that $\frac{d \mathcal{W}}{d x}>0$. If instead $z(0)>0$, then the first line in the expression for $\frac{d \mathcal{W}}{d x}$ is positive if and only if:

$$
\frac{z(0)}{\kappa S}\left(1-\frac{3 x}{2}\right)<\frac{x^{2}}{2}
$$

A sufficient condition is $\frac{z(0)}{\kappa S}<\frac{x^{2}}{2}$ evaluated at $x=\sqrt{\frac{\widehat{\mu}_{\theta}}{2}}$, which is the lowest possible $x$, specifically the $x$ associated with $n_{m}=3$. In other words, $z(0)<\frac{\widehat{\mu}_{\theta} \kappa S}{4}$ is sufficient for $\frac{d \mathcal{W}}{d x}>0$. The (constrained efficient) planner thus chooses $n_{m}=N$ and $W_{m}=Z$ when $z(0)$ is not too large.

Return now to the integered nature of investors. Denote by $\mathcal{W}\left(n_{m}\right)$ the right-hand side of Eq. (A.19), where $W_{m} \equiv W\left(n_{m}\right)$ is the equilibrium security. In a market structure satisfying Eq. (19), aggregate welfare is:

$$
\mathcal{W}=n \times M_{1} \times \frac{\mathcal{W}(n)}{N}+\left(N-n \times M_{1}\right) \times \frac{\mathcal{W}(n+1)}{N} \leq \mathcal{W}(n+1) \leq \mathcal{W}(N)
$$

where the inequalities follow from the fact that $\mathcal{W}(n)$ is increasing in $n$ when $z(0)$ is not too large. Recalling that $\mathcal{W}(N)$ is welfare when all investors trade in one market completes the proof. 


\section{Online Appendices}

\section{Appendix B - Extensions and Robustness}

This appendix considers alternative formulations of our model. We demonstrate that the equilibrium association between market depth and security design uncovered by our model can be supported in all of these formulations. We summarize results that require formal proofs into Remarks, with proofs collected in Section B.5.

\section{B.1 Costly Supply}

Up to this point, we have assumed that each intermediary $m$ backs each unit of the security $W_{m}$ with exactly one unit of $Z$. This assumption allowed us to abstract from mechanical effects that would arise from having a fixed supply of $Z$ and a supply of $W_{m}$ that scales with the number of investors in each market. In particular, $\alpha_{m}$ in constraint (1) would decrease with $n_{m}$. This reflects that the intermediary has to design more units of the security using a given amount of the underlying asset. Accordingly, the security he can design is mechanically worse in the sense that the maximum payoff to any investor is lower in any state $s$. All else constant, the price that the intermediary can get for such a security is lower. In response, he will choose a higher $\bar{s}_{m}$ to boost the expected payoff and get a higher price. Thus, there would be a mechanical association between higher $n_{m}$ and higher $\bar{s}_{m}$, which would reinforce our results but be independent of the price impact that investors have in market $m$.

We can relax the assumption that each unit of $W_{m}$ is backed by one unit of $Z$ and allow the intermediary to choose how many units of $Z$ back each unit of $W_{m}$, subject to a cost of procuring $Z$. In particular, intermediary $m$ incurs a cost $c\left(A_{m}\right)$ to acquire $A_{m}$ units of $Z$ which he then uses to back $n_{m}$ units of $W_{m}$. The cost function satisfies the standard conditions $c(0)=0$ and $c^{\prime}(\cdot)>0$. The intermediary now chooses $W_{m}$ and $A_{m}$ subject to the feasibility constraint (1) where $\alpha_{m}=\frac{A_{m}}{n_{m}}$. This constraint replaces (2). The rest of the model is as before.

Remark 1 The key insights of Propositions 2 and 3 on security design continue to hold. The equilibrium security $W_{m}$ is a debt security with threshold state $\bar{s}_{m} \in[0, S]$. As before, $\bar{s}_{m}$ is increasing in $n_{m}$ so that the face value of $W_{m}$ increases and the security becomes more equity-like as the market size increases. The key insights on market structure also continue to hold. In particular, the compensation for risk term in the investor value function is still decreasing in the size of the 
market, hence investors will choose to trade in many small markets if heterogeneity in investor preference shocks, $\sigma_{\theta}^{2}$, is low. We then know from the security design results that debt will be traded in these markets.

\section{B.2 Alternative Timing}

Another assumption in our set-up relates to the timing of events. Specifically, we have assumed that at date $t=0$ financial intermediaries design securities after investors choose markets. An alternative is that at date $t=0$ investors choose markets after intermediaries design securities. Then, as before, each investor $i$ learns her preference shock $\theta^{i}$ at date $t=1$, after which all markets open and investors in each market trade the security that the corresponding intermediary has designed.

Under this alternative timing, investors still make their market choice before the realization of preference shocks and hence financial intermediaries issue standardized securities. However, intermediaries can now compete for investors through security design. When designing the security first, the intermediary commits to a particular payoff profile before investors choose their markets. In other words, the intermediary designs a security whose payoff profile is independent of the number of investors who show up. Nevertheless, the intermediary is rational so the security design problem will take into account the best responses of investors.

We consider two financial intermediaries under this alternative timing and study the existence of equilibria in which the market structure is symmetric.

Remark 2 The trading equilibrium is still characterized by Proposition 1. Moreover, a symmetric market structure is supported in equilibrium for $\sigma_{\theta}^{2}$ low and the equilibrium security has the same properties as in our main specification. That is, the security that prevails in equilibrium is debt, and the threshold state above which the security delivers a flat payoff is increasing in the number of investors in each intermediary's market.

Thus, even under the alternative timing considered here, a symmetric equilibrium with two large markets will involve the trading of a more equity-like security than a symmetric equilibrium with two small markets, consistent with the results in our main set-up. 


\section{B.3 Market Specialization}

Up to this point, we have assumed that each investor chooses only one market in which to trade. We now consider an extension where some investors can choose more than one market. This allows us to explore conditions under which investors may specialize in markets for bonds or markets for equity rather than participating in multiple markets. As in Babus and Hachem (2021), we assume intermediaries have independent underlying assets $Z$ when allowing for trading in more than one market. None of the results derived so far (i.e., when each investor chooses only one market) hinged on $s$ being an aggregate state rather than an I.I.D. draw by each intermediary, so the insights discussed here are directly comparable. ${ }^{21}$

Consider two groups of investors: X-investors and Y-investors. As in our main set-up, a local market $m$ is associated with each intermediary $m$. We add to this environment an additional market $e$ associated with its own intermediary. X-investors only have access to market $e$ and, for tractability, there is a mass $\eta_{X}$ of $\mathrm{X}$-investors so that trading in market $e$ is perfectly competitive. Thus, $e$ can be interpreted as a centralized market or exchange. Y-investors have the option of trading in the exchange as well as in one local market. In particular, there is a finite number $N_{Y}$ of Y-investors, each of whom can choose to (i) participate only in the centralized market, (ii) participate only in a local market, or (iii) participate in both the centralized market and a local market. ${ }^{22}$ The investor's choice is subject to a per-market participation cost of $K \geq 0$.

The optimal security in each market is characterized by Proposition 2, which in the perfectly competitive exchange delivers $Z$. Furthermore, under Propositions 4 and 5, if the dispersion of preference shocks among Y-investors is not too large, then all local markets are active, and hence the security traded in each local market is debt. The expected payoff of a Y-investor is higher in a local market than in the centralized market at such values of $\sigma_{\theta}^{2}$. Since both expected payoffs are positive, a Y-investor will choose to participate in both markets if $K=0$. However, there exist participation costs $K>0$ where only the local market is profitable for Y-investors to participate in. At these participation costs, we will observe one group (X-investors) trading equity in a centralized market and another group (Y-investors) trading debt in fragmented markets, even though the Yinvestors had the option of trading in both markets. Also notice that debt and equity will coexist

\footnotetext{
${ }^{21}$ The choice of independent $Z$ 's for the exposition of this extension is done for brevity. Even with the same $Z$, investors may realistically choose to trade in one market despite having the opportunity to trade in many markets. For example, Boyarchenko, Costello, and Shachar (2018) provide evidence that the majority of financial institutions participate in either the corporate bond market or the CDS market, depending on the relative transaction costs, even though there exist bonds and CDSs issued on the same entities.

${ }^{22}$ The analysis in Babus and Hachem (2021) informs us that a trading equilibrium exists in (iii).
} 
here in different markets, separately from the asymmetric equilibria discussed in Section 4.

\section{B.4 Multiple Securities}

We close by returning to our main set-up and relaxing the assumption that each intermediary $m$ designs only one security $W_{m}$ for investors. Suppose instead that intermediary $m$ can design two securities, $W_{m}^{0}$ and $W_{m}^{1}$, and that both securities can be traded by investors in market $m$. Denoting by $\phi_{m}$ the relative supply of the additional security,

$$
w_{m}^{0}(s)+\phi_{m} w_{m}^{1}(s) \leq z(s), \forall s \in[0, S]
$$

replaces (2) as the feasibility constraint on the intermediary's security design problem in the main model. The rest of the model is as before.

Remark 3 Proposition 2 now characterizes the aggregate security, $W_{m} \equiv W_{m}^{0}+\phi_{m} W_{m}^{1}$, designed by an intermediary in a market with $n_{m}$ investors. There is a continuum of solutions for the component securities $W_{m}^{0}$ and $W_{m}^{1}$, with each solution aggregating to the payoff profile in Proposition 2.

That the component securities are not uniquely pinned down implies that what matters is the portfolio of securities investors can trade in market $m$. Thus, $W_{m}$ in Proposition 2 can be interpreted as a fund rather than an individual security. The market structure results would then follow as in the main model when investors trade the fund.

\section{B.5 Proofs of Remarks}

\section{Proof of Remark 1 (Costly Supply)}

Given $n_{m}$, intermediary $m$ chooses a security $W_{m}$ to supply in market $m$. He still supplies one unit of $W_{m}$ per capita but now he chooses the number of units $A_{m}$ of the asset $Z$ that back the $n_{m}$ units of $W_{m}$. Previously, we had assumed $A_{m}=n_{m}$. We now let the intermediary choose $A_{m}$ at a cost $c\left(A_{m}\right)$, where $c(0)=0$ and $c^{\prime}(\cdot)>0$. To fix ideas, consider $c\left(A_{m}\right)=\frac{\delta}{2} A_{m}^{2}$.

Intermediary $m$ 's expected payoff at date $t=1$ is:

$$
V_{m}=p_{m} n_{m}+\beta E_{1}\left(A_{m} Z-n_{m} W_{m}\right)-\frac{\delta}{2} A_{m}^{2}
$$


The equilibrium price $p_{m}$ is still given by Eq. (13) so:

$$
E_{0}\left(V_{m}\right)=\left[\left(\mu_{\theta}-\beta\right) E_{1}\left(W_{m}\right)-\frac{n_{m}-1}{n_{m}-2} \gamma \mathcal{V}_{1}\left(W_{m}\right)\right] n_{m}+\beta E_{1}(Z) A_{m}-\frac{\delta}{2} A_{m}^{2}
$$

The Lagrangian for the intermediary's problem can then be written as:

$$
\begin{aligned}
\mathcal{L}= & \left(\mu_{\theta}-\beta\right) n_{m} \int_{0}^{S} w_{m}(s) d F(s) \\
& -\frac{\gamma n_{m}\left(n_{m}-1\right)}{n_{m}-2}\left[\int_{0}^{S}\left(w_{m}(s)\right)^{2} d F(s)-\left(\int_{0}^{S} w_{m}(s) d F(s)\right)^{2}\right] \\
& +\beta E_{1}(Z) A_{m}-\frac{\delta}{2} A_{m}^{2}+\int_{0}^{S} v(s)\left[A_{m} z(s)-n_{m} w_{m}(s)\right] d F(s)+v_{A} A_{m}
\end{aligned}
$$

where $v(s) \geq 0$ is the Lagrange multiplier on the feasibility constraint for state $s$, and $v_{A} \geq 0$ is the multiplier on $A_{m} \geq 0$.

The first order condition for $w_{m}(s)$ is:

$$
v(s)=\mu_{\theta}-\beta-2 \gamma \frac{n_{m}-1}{n_{m}-2}\left[w_{m}(s)-E_{1}\left(W_{m}\right)\right]
$$

where $v(s) \geq 0$ and $A_{m} z(s) \geq n_{m} w_{m}(s)$ hold with complementary slackness. This implies that the equilibrium security, conditional on $n_{m}$, has payoffs:

$$
w_{m}(s)=\left\{\begin{array}{lll}
\frac{A_{m}}{n_{m}} z(s) & \text { if } \quad s<\bar{s}_{m} \\
\frac{A_{m}}{n_{m}} z\left(\bar{s}_{m}\right) & \text { if } \quad s \geq \bar{s}_{m}
\end{array}\right.
$$

where:

$$
\bar{s}_{m}=\arg \min _{k \in[0, S]}\left|z(k)-\frac{n_{m}}{A_{m}}\left(E_{1}\left(W_{m}\right)+\frac{\mu_{\theta}-\beta}{2 \gamma} \frac{n_{m}-2}{n_{m}-1}\right)\right|
$$

and:

$$
E_{1}\left(W_{m}\right)=\frac{A_{m}}{n_{m}}\left(z\left(\bar{s}_{m}\right)-\int_{0}^{\bar{s}_{m}}\left[z\left(\bar{s}_{m}\right)-z(s)\right] d F(s)\right)
$$

The first order condition for $A_{m}$ is:

$$
\delta A_{m}=\beta E_{1}(Z)+\int_{0}^{S} v(s) z(s) d F(s)+v_{A}
$$


Using Eq. (B.2) with $E_{1}\left(W_{m}\right)$ as defined in Eq. (B.4), we can rewrite Eq. (B.5) as:

$$
\begin{aligned}
\delta A_{m}= & \mu_{\theta} E_{1}(Z)+v_{A} \\
& -2 \gamma \frac{n_{m}-1}{n_{m}-2} \frac{A_{m}}{n_{m}}\left[E_{1}(Z) \int_{0}^{\bar{s}_{m}}\left[z\left(\bar{s}_{m}\right)-z(s)\right] d F(s)-\int_{0}^{\bar{s}_{m}} z(s)\left[z\left(\bar{s}_{m}\right)-z(s)\right] d F(s)\right]
\end{aligned}
$$

Consider $A_{m}>0$ so that $v_{A}=0$ :

1. If $\bar{s}_{m}=S$, then Eq. (B.6) reduces to:

$$
A_{m}=\frac{\mu_{\theta} E_{1}(Z)}{\delta+2 \gamma \frac{n_{m}-1}{n_{m}\left(n_{m}-2\right)} \mathcal{V}_{1}(Z)}
$$

which confirms $A_{m}>0$. To confirm that Eq. (B.3) delivers $\bar{s}_{m}=S$, we need:

$$
z(S)-E_{1}(Z)<\frac{\mu_{\theta}-\beta}{2 \gamma} \frac{n_{m}}{A_{m}} \frac{n_{m}-2}{n_{m}-1}
$$

Substituting in the solution for $A_{m}$, the condition for $\bar{s}_{m}=S$ simplifies to:

$$
\frac{n_{m}\left(n_{m}-2\right)}{n_{m}-1}>\frac{2 \gamma}{\delta} \frac{\mu_{\theta}\left[E_{1}(Z) z(S)-E_{1}\left(Z^{2}\right)\right]+\beta \mathcal{V}_{1}(Z)}{\mu_{\theta}-\beta}
$$

The left-hand side of (B.7) is increasing in $n_{m}$ and the right-hand side is positive. Therefore, $\bar{s}_{m}=S$ if $n_{m}$ is above some threshold.

2. If the solution to Eq. (B.3) is interior, then $\bar{s}_{m}$ is defined by:

$$
\int_{0}^{\bar{s}_{m}}\left[z\left(\bar{s}_{m}\right)-z(s)\right] d F(s) \equiv \frac{\mu_{\theta}-\beta}{2 \gamma} \frac{n_{m}}{A_{m}} \frac{n_{m}-2}{n_{m}-1}
$$

and we can use Eq. (B.8) to simplify Eq. (B.6) to:

$$
A_{m}\left(\delta-2 \gamma \frac{n_{m}-1}{n_{m}\left(n_{m}-2\right)} \int_{0}^{\bar{s}_{m}} z(s)\left[z\left(\bar{s}_{m}\right)-z(s)\right] d F(s)\right)=\beta E_{1}(Z)
$$

Using Eq. (B.9) to substitute $A_{m}$ out of Eq. (B.8), we can then rewrite Eq. (B.8) as:

$$
\frac{\beta E_{1}(Z)}{\mu_{\theta}-\beta} \int_{0}^{\bar{s}_{m}}\left[z\left(\bar{s}_{m}\right)-z(s)\right] d F(s)+\int_{0}^{\bar{s}_{m}} z(s)\left[z\left(\bar{s}_{m}\right)-z(s)\right] d F(s)=\frac{\delta}{2 \gamma} \frac{n_{m}\left(n_{m}-2\right)}{n_{m}-1}
$$

which implies $\frac{\partial \bar{s}_{m}}{\partial n_{m}}>0$. Notice from Eq. (B.8) that $A_{m}>0$ and, to confirm $\bar{s}_{m}<S$, we 
need $n_{m}$ below the threshold that delivered $\bar{s}_{m}=S$ in the previous bullet, i.e., the opposite condition of (B.7).

We have now shown that the key insights of Propositions 2 and 3 continue to hold. If small markets are stable, then debt will be traded in that market structure. If large markets are stable, then equity will be traded in that market structure.

Next, we show that small markets are stable if heterogeneity in investor preference shocks, $\sigma_{\theta}^{2}$, is sufficiently low. The investor's expected profit is still given by Eq. (18) so the key is to show that the compensation for risk term is decreasing in $n_{m}$. This amounts to showing $\frac{d \mathcal{V}_{1}\left(W_{m}\right)}{d n_{m}}<\frac{2 \mathcal{V}_{1}\left(W_{m}\right)}{n_{m}\left(n_{m}-2\right)}$ for any $n_{m}$.

The variance of the equilibrium security derived above is:

$$
\mathcal{V}_{1}\left(W_{m}\right)=\left(\frac{A_{m}}{n_{m}}\right)^{2}\left[\int_{0}^{\bar{s}_{m}}\left[z\left(\bar{s}_{m}\right)-z(s)\right]^{2} d F(s)-\left(\int_{0}^{\bar{s}_{m}}\left[z\left(\bar{s}_{m}\right)-z(s)\right] d F(s)\right)^{2}\right]
$$

Consider first any $n_{m}$ where the equilibrium security is $W_{m} \neq Z$. Then, $A_{m}$ depends on $\bar{s}_{m}$ and $n_{m}$ as per Eq. (B.8) and $\bar{s}_{m}$ depends on $n_{m}$ as per Eq. (B.10). Therefore:

$$
\frac{d \mathcal{V}_{1}\left(W_{m}\right)}{d n_{m}}=\frac{2 \mathcal{V}_{1}\left(W_{m}\right)}{A_{m}}\left(\frac{d A_{m}}{d n_{m}}-\frac{A_{m}}{n_{m}}\right)+\frac{2 A_{m}^{2}}{n_{m}^{2}}\left[1-F\left(\bar{s}_{m}\right)\right] z^{\prime}\left(\bar{s}_{m}\right) \frac{d \bar{s}_{m}}{d n_{m}} \int_{0}^{\bar{s}_{m}}\left[z\left(\bar{s}_{m}\right)-z(s)\right] d F(s)
$$

where:

$$
z^{\prime}\left(\bar{s}_{m}\right) \frac{d \bar{s}_{m}}{d n_{m}}=\frac{\frac{\delta}{2 \gamma} \frac{n_{m}^{2}-2 n_{m}+2}{\left(n_{m}-1\right)^{2}}}{\frac{\beta E_{1}(Z)}{\mu_{\theta}-\beta} F\left(\bar{s}_{m}\right)+\int_{0}^{\bar{s}_{m}} z(s) d F(s)}
$$

and:

$$
\frac{d A_{m}}{d n_{m}}=\frac{A_{m}}{n_{m}} \frac{n_{m}^{2}-2 n_{m}+2}{\left(n_{m}-1\right)\left(n_{m}-2\right)}\left(1-\frac{\delta \frac{A_{m}}{\mu_{\theta}-\beta} F\left(\bar{s}_{m}\right)}{\frac{\beta E_{1}(Z)}{\mu_{\theta}-\beta} F\left(\bar{s}_{m}\right)+\int_{0}^{\bar{s}_{m}} z(s) d F(s)}\right)
$$

The condition we want to check, $\frac{d \mathcal{V}_{1}\left(W_{m}\right)}{d n_{m}}<\frac{2 \mathcal{V}_{1}\left(W_{m}\right)}{n_{m}\left(n_{m}-2\right)}$, simplifies to:

$$
\begin{aligned}
& {\left[1-F\left(\bar{s}_{m}\right)\right] z^{\prime}\left(\bar{s}_{m}\right) \frac{d \bar{s}_{m}}{d n_{m}} \int_{0}^{\bar{s}_{m}}\left[z\left(\bar{s}_{m}\right)-z(s)\right] d F(s) } \\
< & \frac{1}{n_{m}}\left[\frac{n_{m}-1}{n_{m}-2}-\frac{n_{m}}{A_{m}} \frac{d A_{m}}{d n_{m}}\right]\left[\int_{0}^{\bar{s}_{m}}\left[z\left(\bar{s}_{m}\right)-z(s)\right]^{2} d F(s)-\left(\int_{0}^{\bar{s}_{m}}\left[z\left(\bar{s}_{m}\right)-z(s)\right] d F(s)\right)^{2}\right]
\end{aligned}
$$




$$
1+\left[1-F\left(\bar{s}_{m}\right)\right] \frac{\left[z\left(\bar{s}_{m}\right)-E_{1}\left(Z \mid s \leq \bar{s}_{m}\right)\right]^{2}}{\mathcal{V}_{1}\left(Z \mid s \leq \bar{s}_{m}\right)}<\frac{\frac{\delta}{2 \gamma} \frac{n_{m}\left(n_{m}-2\right)}{n_{m}-1} \frac{1}{F\left(\bar{s}_{m}\right)}\left(n_{m}^{2}-2 n_{m}+2\right)}{\left[\frac{\beta E_{1}(Z)}{\mu_{\theta}-\beta}+E_{1}\left(Z \mid s \leq \bar{s}_{m}\right)\right]\left[z\left(\bar{s}_{m}\right)-E_{1}\left(Z \mid s \leq \bar{s}_{m}\right)\right]}
$$$$
\Leftrightarrow
$$

$$
\frac{\left[1-F\left(\bar{s}_{m}\right)\right]}{\left(n_{m}-1\right)^{2}} \frac{\left[z\left(\bar{s}_{m}\right)-E_{1}\left(Z \mid s \leq \bar{s}_{m}\right)\right]^{2}}{\mathcal{V}_{1}\left(Z \mid s \leq \bar{s}_{m}\right)}<1-\frac{\frac{n_{m}^{2}-2 n_{m}+2}{\left(n_{m}-1\right)^{2}} \mathcal{V}_{1}\left(Z \mid s \leq \bar{s}_{m}\right)}{\left[\frac{\beta E_{1}(Z)}{\mu_{\theta}-\beta}+E_{1}\left(Z \mid s \leq \bar{s}_{m}\right)\right]\left[z\left(\bar{s}_{m}\right)-E_{1}\left(Z \mid s \leq \bar{s}_{m}\right)\right]}
$$

It follows from $z^{\prime}(\cdot)>0$ that $E_{1}(Z) \geq E_{1}\left(Z \mid s \leq \bar{s}_{m}\right)$ and $\left[z\left(\bar{s}_{m}\right)-E_{1}\left(Z \mid s \leq \bar{s}_{m}\right)\right]>\frac{\mathcal{V}_{1}\left(Z \mid s \leq \bar{s}_{m}\right)}{E_{1}\left(Z \mid s \leq \bar{s}_{m}\right)}$, so a sufficient condition for $\frac{d \mathcal{V}_{1}\left(W_{m}\right)}{d n_{m}}<\frac{2 \mathcal{V}_{1}\left(W_{m}\right)}{n_{m}\left(n_{m}-2\right)}$ is:

$$
\frac{\left[z\left(\bar{s}_{m}\right)-E_{1}\left(Z \mid s \leq \bar{s}_{m}\right)\right]^{2}}{\mathcal{V}_{1}\left(Z \mid s \leq \bar{s}_{m}\right)}<\left(n_{m}^{2}-2 n_{m}+2\right) \frac{\beta}{\mu_{\theta}}-1
$$

The right-hand side is increasing in $n_{m}$ so, with $n_{m} \geq 3$, it will be enough to have:

$$
\frac{z(k)-E_{1}(Z \mid s \leq k)}{\sqrt{\mathcal{V}_{1}(Z \mid s \leq k)}}<\sqrt{\frac{5 \beta}{\mu_{\theta}}-1}, \forall k \in(0, S]
$$

with $\beta>\frac{\mu_{\theta}}{5}$. Now consider any $n_{m}$ where the equilibrium security is $W_{m}=Z$, i.e., any $n_{m}$ satisfying (B.7). Then:

$$
\mathcal{V}_{1}\left(W_{m}\right)=\left(\frac{A_{m}}{n_{m}}\right)^{2} \mathcal{V}_{1}(Z)=\left(\frac{\mu_{\theta} E_{1}(Z)}{\delta n_{m}+2 \gamma \frac{n_{m}-1}{n_{m}-2} \mathcal{V}_{1}(Z)}\right)^{2} \mathcal{V}_{1}(Z)
$$

and:

$$
\frac{d \mathcal{V}_{1}\left(W_{m}\right)}{d n_{m}}=\frac{2\left(\mu_{\theta} E_{1}(Z)\right)^{2} \mathcal{V}_{1}(Z)}{\left(\delta n_{m}+2 \gamma \frac{n_{m}-1}{n_{m}-2} \mathcal{V}_{1}(Z)\right)^{3}}\left(\frac{2 \gamma \mathcal{V}_{1}(Z)}{\left(n_{m}-2\right)^{2}}-\delta\right)
$$

and therefore $\frac{d \mathcal{V}_{1}\left(W_{m}\right)}{d n_{m}}<0$ for $n_{m}$ unboundedly large, which falls in the range of $n_{m}$ defined by (B.7). Accordingly, a sufficient condition for $\frac{d \mathcal{V}_{1}\left(W_{m}\right)}{d n_{m}}<\frac{2 \mathcal{V}_{1}\left(W_{m}\right)}{n_{m}\left(n_{m}-2\right)}$ for all $n_{m}$ is that no value of $n_{m}$ satisfies both $\frac{2 \gamma \mathcal{V}_{1}(Z)}{\left(n_{m}-2\right)^{2}}=\delta$ and (B.7). Rewrite (B.7) as:

$$
\frac{n_{m}\left(n_{m}-2\right)}{n_{m}-1}>\frac{2 \gamma \mathcal{V}_{1}(Z)}{\delta}\left(\frac{1}{1-\frac{\beta}{\mu_{\theta}}} \frac{E_{1}(Z)\left[z(S)-E_{1}(Z)\right]}{\mathcal{V}_{1}(Z)}-1\right)
$$


At any $n_{m}$ where $\frac{2 \gamma \mathcal{V}_{1}(Z)}{\left(n_{m}-2\right)^{2}}=\delta$, this inequality becomes:

$$
\frac{n_{m}}{\left(n_{m}-1\right)\left(n_{m}-2\right)} \stackrel{?}{>} \frac{1}{1-\frac{\beta}{\mu_{\theta}}} \frac{E_{1}(Z)\left[z(S)-E_{1}(Z)\right]}{\mathcal{V}_{1}(Z)}-1
$$

which is eliminated by a lowerbound on $\beta$ relative to $\mu_{\theta} \cdot{ }^{23}$ With $z(s)=s$ and $F(s)=\frac{s}{S}$, for example, this lowerbound is $\beta>-\frac{\mu_{\theta}}{5}$, which is trivially true.

\section{Proof of Remark 2 (Alternative Timing)}

Suppose the timing is such that intermediaries post securities first, then investors choose markets. Market choice is still made before the realization of investor preference shocks, but now intermediaries can compete for investors through security design. By posting securities first, we mean that the intermediary commits to a particular payoff profile before investors choose their markets. The intermediary is rational so his security design problem will take into account the best responses of investors. However, the intermediary cannot post a security whose payoff profile is contingent on the number of investors who show up. That would constitute a customized contract, not a standardized contract. The focus of our paper is on standardized contracts.

Consider two intermediaries, 1 and 2. Intermediary 1 offers a security $W_{1}$ and attracts $n_{1}$ investors. Intermediary 2 offers a security $W_{2}$ and attracts $N-n_{1}$ investors.

The expected value to investor $i$ of trading $W_{m}$ in a market of size $n_{m}$ is still given by $E_{0}\left(V_{m}^{i}\right)$ in Eq. (18). In the extreme case of $\sigma_{\theta}^{2}=0$ :

$$
E_{0}\left(V_{m}^{i}\right)=\frac{\gamma}{2} \frac{n_{m}}{n_{m}-2} \mathcal{V}_{1}\left(W_{m}\right)
$$

By a continuity argument, all results derived under $\sigma_{\theta}^{2}=0$ will extend to $\sigma_{\theta}^{2} \in(0, \overline{\bar{\sigma}})$, where $\overline{\bar{\sigma}}$ is some positive upperbound.

Notice that $\frac{n_{m}}{n_{m}-2}$ in Eq. (B.11) is decreasing in $n_{m}$. Also recall that $W_{m}$ is no longer responsive to $n_{m}$ at the stage where investors choose their markets. Eq. (B.11) says that investors want a more variable security when $\sigma_{\theta}^{2}$ is low. This is because the trading equilibrium delivers a low enough price (or, equivalently, a high enough risk premium) to compensate them for taking the risk. Investors also want to take this risk in very small markets, reflecting the fact that the risk

\footnotetext{
${ }^{23}$ In particular, $\frac{n_{m}}{\left(n_{m}-1\right)\left(n_{m}-2\right)}$ is decreasing in $n_{m}$ for $n_{m} \geq 3$, so a sufficient condition is $\beta>$ $\frac{\mu_{\theta}}{5}\left(5-\frac{2 E_{1}(Z)\left[z(S)-E_{1}(Z)\right]}{\mathcal{V}_{1}(Z)}\right)$.
} 
premium increases with an individual investor's price impact.

Given the securities $W_{1}$ and $W_{2}$, investors will move around until they are indifferent between the two intermediaries. We abstract from the integered nature of investors here to avoid unnecessary algebra. The best response of investors then yields a market structure characterized by $n_{1}^{*}$, where $n_{1}^{*}$ solves:

$$
\frac{n_{1}^{*}}{n_{1}^{*}-2} \mathcal{V}_{1}\left(W_{1}\right)=\frac{N-n_{1}^{*}}{N-n_{1}^{*}-2} \mathcal{V}_{1}\left(W_{2}\right)
$$

Eq. (B.12) defines $n_{1}^{*}$ as a function of $\frac{\mathcal{V}_{1}\left(W_{1}\right)}{\mathcal{V}_{1}\left(W_{2}\right)}$. Differentiate Eq. (B.12) to get:

$$
\frac{d n_{1}^{*}}{d \mathcal{V}_{1}\left(W_{1}\right)}=\frac{n_{1}^{*}}{2} \frac{1}{\frac{1}{n_{1}^{*}-2}+\frac{n_{1}^{*}}{\left(N-n_{1}^{*}-2\right)\left(N-n_{1}^{*}\right)}} \frac{1}{\mathcal{V}_{1}\left(W_{1}\right)}
$$

This derivative is positive. If intermediary 1 posts a more variable security than intermediary 2 , then intermediary 1 will attract more investors.

Each intermediary seeks to maximize his expected profit subject to a state-by-state feasibility constraint on the payoffs of the security he designs. He still offers one unit of the security to each investor in his market and, as in Appendix B.1, pays a cost to procure the assets that back this security. The Lagrangian for intermediary 1's problem is thus given by Eq. (B.1) but with $n_{1}=n_{1}^{*}$, where $n_{1}^{*}$ depends on $W_{1}$ as per Eq. (B.12). The choice variables are the payoffs $w_{1}(s)$ for each state $s \in[0, S]$ and the number of units $A_{1}$ of $Z$ that will back the $n_{1}^{*}$ units of $W_{1}$.

The first order condition for $w_{1}(s)$ is:

$$
\begin{aligned}
v(s)= & \mu_{\theta}-\beta-\frac{\gamma}{n_{1}^{*}-2}\left(2\left(n_{1}^{*}-1\right)+\frac{\left(n_{1}^{*}\right)^{2}-4 n_{1}^{*}+2}{1+\frac{n_{1}^{*}\left(n_{1}^{*}-2\right)}{\left(N-n_{1}^{*}-2\right)\left(N-n_{1}^{*}\right)}}\right)\left[w_{1}(s)-E_{1}\left(W_{1}\right)\right] \\
& +\frac{1}{\frac{1}{n_{1}^{*}-2}+\frac{n_{1}^{*}}{\left(N-n_{1}^{*}-2\right)\left(N-n_{1}^{*}\right)}} \frac{w_{1}(s)-E_{1}\left(W_{1}\right)}{\mathcal{V}_{1}\left(W_{1}\right)}\left[\left(\mu_{\theta}-\beta\right) E_{1}\left(W_{1}\right)-\int_{0}^{S} v(s) w_{1}(s) d F(s)\right]
\end{aligned}
$$

Multiply both sides by $w_{1}(s)$ then integrate over $s \in[0, S]$ to isolate:

$$
\int_{0}^{S} v(s) w_{1}(s) d F(s)=\left(\mu_{\theta}-\beta\right) E_{1}\left(W_{1}\right)-\frac{\gamma}{n_{1}^{*}-2}\left(\frac{2\left(n_{1}^{*}-1\right)+\frac{\left(n_{1}^{*}\right)^{2}-4 n_{1}^{*}+2}{1+\frac{n_{1}^{*}\left(n_{1}^{*}-2\right)}{\left(N-n_{1}^{*}-2\right)\left(N-n_{1}^{*}\right)}}}{1+\frac{1}{\frac{1}{n_{1}^{*}-2}+\frac{n_{1}^{*}}{\left(N-n_{1}^{*}-2\right)\left(N-n_{1}^{*}\right)}}}\right) \mathcal{V}_{1}\left(W_{1}\right)
$$


We can now rewrite the first order condition for $w_{1}(s)$ as:

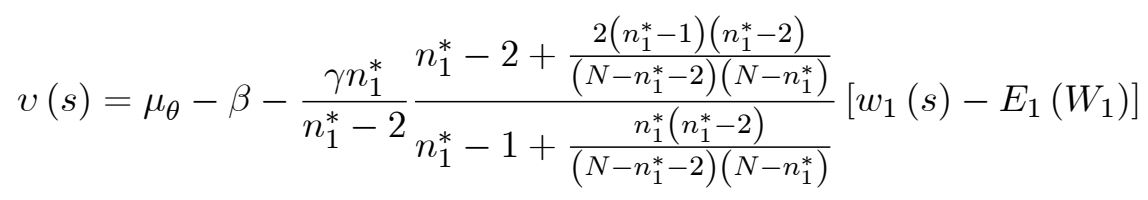

The first order condition for $A_{1}$ still takes the form of (B.5).

In a symmetric equilibrium, both intermediaries offer the same security $W$. Eq. (B.12) implies $n_{1}^{*}=\frac{N}{2}$ which, when substituted into Eq. (B.13), implies:

$$
v(s)=\mu_{\theta}-\beta-\gamma \frac{N^{2}-8}{N(N-4)}\left[w(s)-E_{1}(W)\right]
$$

for each $s \in[0, S]$. Therefore, the security that prevails in a symmetric equilibrium has payoffs:

$$
w(s)= \begin{cases}\frac{2 A}{N} z(s) & \text { if } \quad s<\bar{s} \\ \frac{2 A}{N} z(\bar{s}) & \text { if } \quad s \geq \bar{s}\end{cases}
$$

where the threshold $\bar{s} \in[0, S]$ is defined by:

$$
\bar{s}=\arg \min _{k \in[0, S]}\left|z(k)-\frac{N}{2 A}\left(E_{1}(W)+\frac{\mu_{\theta}-\beta}{\gamma} \frac{N(N-4)}{N^{2}-8}\right)\right|
$$

and $A$ solves:

$$
A=\frac{\beta E_{1}(Z)+\left(\mu_{\theta}-\beta\right) \int_{0}^{\bar{s}} z(s) d F(s)}{\delta+\frac{2 \gamma\left(N^{2}-8\right)}{N^{2}(N-4)}\left[\int_{0}^{\bar{s}}(z(s))^{2} d F(s)-\left(\int_{0}^{\bar{s}} z(s) d F(s)\right)^{2}-\int_{0}^{\bar{s}} z(s) d F(s) \int_{\bar{s}}^{S} z(\bar{s}) d F(s)\right]}
$$

If the solution to Eq. (B.14) is interior, we can combine Eq. (B.14) and (B.15) to get:

$$
\frac{\beta E_{1}(Z)}{\mu_{\theta}-\beta} \int_{0}^{\bar{s}}[z(\bar{s})-z(s)] d F(s)+\int_{0}^{\bar{s}} z(s)[z(\bar{s})-z(s)] d F(s)=\frac{\delta}{2 \gamma} \frac{N^{2}(N-4)}{N^{2}-8}
$$

We then need:

$$
\delta<\frac{2 \gamma}{\mu_{\theta}-\beta}\left[\mu_{\theta}\left[z(S) E_{1}(Z)-E_{1}\left(Z^{2}\right)\right]+\beta \mathcal{V}_{1}(Z)\right] \frac{N^{2}-8}{N^{2}(N-4)}
$$


for the solution to indeed be interior, in which case:

$$
\frac{d \bar{s}}{d N}=\frac{\delta}{2 \gamma} \frac{N\left(N^{3}-24 N+64\right)}{\left(N^{2}-8\right)^{2}} \frac{1}{z^{\prime}(\bar{s}) \int_{0}^{\bar{s}}\left[z(s)+\frac{\beta E_{1}(Z)}{\mu_{\theta}-\beta}\right] d F(s)}>0
$$

where the inequality follows from $N \geq 6$ to ensure $\frac{N}{2} \geq 3$. Therefore, the alternative timing considered here does not change the result that debt would be traded in smaller markets than equity, all else the same.

\section{Proof of Remark 3 (Multiple Securities)}

Consider an intermediary that designs two securities, $W^{0}$ and $W^{1}$, for investors. There are $n$ investors that can trade both securities. The demand functions of investor $i$ are $Q_{0}^{i}\left(p_{0}, p_{1} ; \theta^{i}\right)$ and $Q_{1}^{i}\left(p_{0}, p_{1} ; \theta^{i}\right)$ for the securities $W^{0}$ and $W^{1}$, respectively, and her expected payoff after the realization of $\theta^{i}$ (but before the realization of $s$ ) is:

$$
\begin{aligned}
V^{i}= & {\left[\theta^{i} E_{1}\left(W^{0}\right)-p_{0}\right] q_{0}^{i}+\left[\theta^{i} E_{1}\left(W^{1}\right)-p_{1}\right] q_{1}^{i} } \\
& -\frac{\gamma}{2}\left[\mathcal{V}_{1}\left(W^{0}\right)\left(q_{0}^{i}\right)^{2}+2 \operatorname{Cov}_{1}\left(W^{0}, W^{1}\right) q_{0}^{i} q_{1}^{i}+\mathcal{V}_{1}\left(W^{1}\right)\left(q_{1}^{i}\right)^{2}\right]
\end{aligned}
$$

The first order conditions of an investor $i$ who trades both securities are:

$$
\begin{aligned}
& {\left[\theta^{i} E_{1}\left(W^{0}\right)-p_{0}\right]-\gamma\left[\mathcal{V}_{1}\left(W^{0}\right) q_{0}^{i}+\operatorname{Cov}_{1}\left(W^{0}, W^{1}\right) q_{1}^{i}\right]-\frac{\partial p_{0}}{\partial q_{0}^{i}} q_{0}^{i}-\frac{\partial p_{1}}{\partial q_{0}^{i}} q_{1}^{i}=0} \\
& {\left[\theta^{i} E_{1}\left(W^{1}\right)-p_{1}\right]-\gamma\left[\mathcal{V}_{1}\left(W^{1}\right) q_{1}^{i}+\operatorname{Cov}_{1}\left(W^{0}, W^{1}\right) q_{0}^{i}\right]-\frac{\partial p_{0}}{\partial q_{1}^{i}} q_{0}^{i}-\frac{\partial p_{1}}{\partial q_{1}^{i}} q_{1}^{i}=0}
\end{aligned}
$$

Define $\sigma_{0}^{2} \equiv \mathcal{V}_{1}\left(W^{0}\right), \sigma_{1}^{2} \equiv \mathcal{V}_{1}\left(W^{1}\right)$, and $\sigma_{01} \equiv \operatorname{Cov}_{1}\left(W^{0}, W^{1}\right)$. Also define $\lambda_{0}^{0} \equiv \frac{\partial p_{0}}{\partial q_{0}^{2}}, \lambda_{0}^{1} \equiv \frac{\partial p_{1}}{\partial q_{0}^{2}}$, $\lambda_{1}^{0} \equiv \frac{\partial p_{0}}{\partial q_{1}^{i}}$, and $\lambda_{1}^{1} \equiv \frac{\partial p_{1}}{\partial q_{1}^{i}}$. The investor's first order conditions can then be expressed more compactly as:

$$
\left(\begin{array}{c}
\theta^{i} E_{1}\left(W^{0}\right)-p_{0} \\
\theta^{i} E_{1}\left(W^{1}\right)-p_{1}
\end{array}\right)=\left(\gamma\left(\begin{array}{cc}
\sigma_{0}^{2} & \sigma_{01} \\
\sigma_{01} & \sigma_{1}^{2}
\end{array}\right)+\left(\begin{array}{cc}
\lambda_{0}^{0} & \lambda_{0}^{1} \\
\lambda_{1}^{0} & \lambda_{1}^{1}
\end{array}\right)\right)\left(\begin{array}{l}
q_{0}^{i} \\
q_{1}^{i}
\end{array}\right)
$$

which isolates:

$$
\left(\begin{array}{c}
q_{0}^{i} \\
q_{1}^{i}
\end{array}\right)=\left(\gamma\left(\begin{array}{cc}
\sigma_{0}^{2} & \sigma_{01} \\
\sigma_{01} & \sigma_{1}^{2}
\end{array}\right)+\left(\begin{array}{cc}
\lambda_{0}^{0} & \lambda_{0}^{1} \\
\lambda_{1}^{0} & \lambda_{1}^{1}
\end{array}\right)\right)^{-1}\left(\begin{array}{c}
\theta^{i} E_{1}\left(W^{0}\right)-p_{0} \\
\theta^{i} E_{1}\left(W^{1}\right)-p_{1}
\end{array}\right)
$$


Turn now to market clearing, which requires:

$$
\sum_{i}\left(\begin{array}{c}
q_{0}^{i} \\
q_{1}^{i}
\end{array}\right)=\left(\begin{array}{l}
n \\
\phi n
\end{array}\right)
$$

where $\phi$ denotes the supply of $W^{1}$ relative to $W^{0}$. Rewrite as:

$$
\left(\begin{array}{c}
q_{0}^{j} \\
q_{1}^{j}
\end{array}\right)+\sum_{i \neq j}\left(\begin{array}{l}
q_{0}^{i} \\
q_{1}^{i}
\end{array}\right)=\left(\begin{array}{c}
n \\
\phi n
\end{array}\right)
$$

where:

$$
\begin{aligned}
\sum_{i \neq j}\left(\begin{array}{c}
q_{0}^{i} \\
q_{1}^{i}
\end{array}\right)= & \left(\gamma\left(\begin{array}{cc}
\sigma_{0}^{2} & \sigma_{01} \\
\sigma_{01} & \sigma_{1}^{2}
\end{array}\right)+\left(\begin{array}{cc}
\lambda_{0}^{0} & \lambda_{0}^{1} \\
\lambda_{1}^{0} & \lambda_{1}^{1}
\end{array}\right)\right)^{-1} \sum_{i \neq j}\left(\begin{array}{c}
\theta^{i} E_{1}\left(W^{0}\right) \\
\theta^{i} E_{1}\left(W^{1}\right)
\end{array}\right) \\
& -(n-1)\left(\gamma\left(\begin{array}{cc}
\sigma_{0}^{2} & \sigma_{01} \\
\sigma_{01} & \sigma_{1}^{2}
\end{array}\right)+\left(\begin{array}{cc}
\lambda_{0}^{0} & \lambda_{0}^{1} \\
\lambda_{1}^{0} & \lambda_{1}^{1}
\end{array}\right)\right)^{-1}\left(\begin{array}{l}
p_{0} \\
p_{1}
\end{array}\right)
\end{aligned}
$$

from the first order conditions of investors $i \neq j$. Rearrange the rewritten market clearing equation to isolate:

$$
\left(\begin{array}{c}
p_{0} \\
p_{1}
\end{array}\right)=\frac{\sum_{i \neq j} \theta^{i}}{n-1}\left(\begin{array}{c}
E_{1}\left(W^{0}\right) \\
E_{1}\left(W^{1}\right)
\end{array}\right)+\frac{1}{n-1}\left(\gamma\left(\begin{array}{cc}
\sigma_{0}^{2} & \sigma_{01} \\
\sigma_{01} & \sigma_{1}^{2}
\end{array}\right)+\left(\begin{array}{cc}
\lambda_{0}^{0} & \lambda_{0}^{1} \\
\lambda_{1}^{0} & \lambda_{1}^{1}
\end{array}\right)\right)\left(\left(\begin{array}{c}
q_{0}^{j} \\
q_{1}^{j}
\end{array}\right)-\left(\begin{array}{c}
n \\
\phi n
\end{array}\right)\right)
$$

Thus, the price impacts solve the system:

$$
\left(\begin{array}{cc}
\lambda_{0}^{0} & \lambda_{0}^{1} \\
\lambda_{1}^{0} & \lambda_{1}^{1}
\end{array}\right)=\frac{1}{n-1}\left(\gamma\left(\begin{array}{cc}
\sigma_{0}^{2} & \sigma_{01} \\
\sigma_{01} & \sigma_{1}^{2}
\end{array}\right)+\left(\begin{array}{cc}
\lambda_{0}^{0} & \lambda_{1}^{0} \\
\lambda_{0}^{1} & \lambda_{1}^{1}
\end{array}\right)\right)
$$

which yields:

$$
\begin{gathered}
\lambda_{0}^{0}=\frac{\gamma \sigma_{0}^{2}}{n-2} \\
\lambda_{1}^{0}=\lambda_{0}^{1}=\frac{\gamma \sigma_{01}}{n-2} \\
\lambda_{1}^{1}=\frac{\gamma \sigma_{1}^{2}}{n-2}
\end{gathered}
$$


We can now write the investor demands as:

$$
\left(\begin{array}{c}
q_{0}^{i} \\
q_{1}^{i}
\end{array}\right)=\frac{1}{\gamma} \frac{n-2}{n-1}\left(\begin{array}{cc}
\sigma_{0}^{2} & \sigma_{01} \\
\sigma_{01} & \sigma_{1}^{2}
\end{array}\right)^{-1}\left(\begin{array}{c}
\theta^{i} E_{1}\left(W^{0}\right)-p_{0} \\
\theta^{i} E_{1}\left(W^{1}\right)-p_{1}
\end{array}\right)
$$

which implies the market clearing prices:

$$
\left(\begin{array}{c}
p_{0} \\
p_{1}
\end{array}\right)=\frac{\sum_{i} \theta^{i}}{n}\left(\begin{array}{c}
E_{1}\left(W^{0}\right) \\
E_{1}\left(W^{1}\right)
\end{array}\right)-\gamma \frac{n-1}{n(n-2)}\left(\begin{array}{cc}
\sigma_{0}^{2} & \sigma_{01} \\
\sigma_{01} & \sigma_{1}^{2}
\end{array}\right)\left(\begin{array}{l}
n \\
\phi n
\end{array}\right)
$$

Turn next to the intermediary's security design problem. The intermediary chooses $W^{0}$ and $W^{1}$ to maximize his expected payoff,

$$
E_{0}\left(V_{m}\right)=\left[E_{1}\left(p_{0}\right)+\phi E_{1}\left(p_{1}\right)+\beta E_{1}\left(Z-W^{0}-\phi W^{1}\right)\right] \times n
$$

subject to the feasibility constraint

$$
w^{0}(s)+\phi w^{1}(s) \leq z(s), \forall s \in[0, S]
$$

The Lagrangian for the security design problem is then:

$$
\begin{aligned}
\mathcal{L}= & {\left[E_{1}\left(p_{0}\right)+\phi E_{1}\left(p_{1}\right)+\beta E_{1}\left(Z-W^{0}-\phi W^{1}\right)\right] \times n } \\
& +\int_{0}^{S} v(s)\left[z(s)-w^{0}(s)-\phi w^{1}(s)\right] d F(s)
\end{aligned}
$$

where $v(\cdot) \geq 0$ are Lagrange multipliers. Subbing in the equilibrium prices:

$$
\begin{aligned}
\mathcal{L}= & {\left[\beta E_{1}(Z)+\left(\mu_{\theta}-\beta\right)\left(E_{1}\left(W^{0}\right)+\phi E_{1}\left(W^{1}\right)\right)-\gamma \frac{n-1}{n-2}\left(\sigma_{0}^{2}+2 \phi \sigma_{01}+\phi^{2} \sigma_{1}^{2}\right)\right] \times n } \\
& +\int_{0}^{S} v(s)\left[z(s)-w^{0}(s)-\phi w^{1}(s)\right] d F(s)
\end{aligned}
$$


Subbing in the definitions of the expectations, variances, and covariance:

$$
\begin{aligned}
\mathcal{L}= & {\left[\begin{array}{l}
\beta E_{1}(Z)+\left(\mu_{\theta}-\beta\right) \int_{0}^{S}\left(w^{0}(s)+\phi w^{1}(s)\right) d F(s) \\
-\gamma \frac{n-1}{n-2}\left[\int_{0}^{S}\left(w^{0}(s)\right)^{2} d F(s)-\left(\int_{0}^{S} w^{0}(s) d F(s)\right)^{2}\right] \\
-2 \phi \gamma \frac{n-1}{n-2}\left[\int_{0}^{S} w^{0}(s) w^{1}(s) d F(s)-\int_{0}^{S} w^{0}(s) d F(s) \int_{0}^{S} w^{1}(s) d F(s)\right] \\
-\gamma \frac{n-1}{n-2} \phi^{2}\left[\int_{0}^{S}\left(w^{1}(s)\right)^{2} d F(s)-\left(\int_{0}^{S} w^{1}(s) d F(s)\right)^{2}\right]
\end{array}\right] \times n } \\
& +\int_{0}^{S} v(s)\left[z(s)-w^{0}(s)-\phi w^{1}(s)\right] d F(s)
\end{aligned}
$$

Grouping like terms:

$$
\begin{aligned}
\mathcal{L}= & {\left[\begin{array}{l}
\beta E_{1}(Z)+\left(\mu_{\theta}-\beta\right) \int_{0}^{S}\left(w^{0}(s)+\phi w^{1}(s)\right) d F(s) \\
-\gamma \frac{n-1}{n-2}\left[\int_{0}^{S}\left(w^{0}(s)+\phi w^{1}(s)\right)^{2} d F(s)-\left(\int_{0}^{S}\left(w^{0}(s)+\phi w^{1}(s)\right) d F(s)\right)^{2}\right]
\end{array}\right] \times n } \\
& +\int_{0}^{S} v(s)\left[z(s)-w^{0}(s)-\phi w^{1}(s)\right] d F(s)
\end{aligned}
$$

Thus, the intermediary's problem is entirely a function of $w^{0}(\cdot)+\phi w^{1}(\cdot)$; the individual components $w^{0}(\cdot)$ and $w^{1}(\cdot)$ are not separately defined. The security design problem therefore recovers the one that delivers Proposition 2. 


\section{Appendix C - Derivations for Section 4}

Below we present derivations that support the discussion in Section 4.1 and Section 4.2.

\section{Asymmetric Equilibria with Common Underlying Asset (Section 4.1)}

We consider a variation of our main set-up in which every investor has pre-existing relationships with a subset of intermediaries formed from interactions outside the model. Intermediaries are heterogeneous in the number of investors they have relationships with, with some intermediaries having more and others having less. Each investor chooses an intermediary in whose market to trade from the subset of intermediaries that she has a relationship with. The following lemma illustrates how a setting with pre-existing relationships can support asymmetric equilibria, and specifically asymmetric equilibria where debt and equity co-exist:

Lemma C.1 Consider $N$ investors each having a relationship with two of three intermediaries, $\{A, B, C\}$. Denote by $n_{m m^{\prime}} \geq 3$ the number of investors that have relationships with intermediaries $m$ and $m^{\prime}$, for $m, m^{\prime} \in\{A, B, C\}$ and $m \neq m^{\prime}$, where $n_{A B}+n_{A C}+n_{B C}=N$. Without loss of generality, suppose $n_{A B}>n_{A C}>n_{B C}$. Then the $\ell$-stable equilibrium for $\ell=N$ is as follows:

1. For parameters such that all investors want to be in the largest possible markets, the equilibrium market structure has one market of size $n_{A B}+n_{A C}$ and one market of size $n_{B C}$. If $n_{A B}+n_{A C}>n_{S}>n_{B C}$, then debt is traded in one market and equity is traded in the other.

2. For parameters such that all investors want to be in the smallest possible markets, debt and equity coexist if $n_{A B}>\max \left\{\frac{2 N}{3}, 2 n_{S}, N-n_{S}\right\}$ in the case where the investor value function evaluated at the optimal security is monotonically decreasing.

The second part of Lemma C.1 focuses on a monotonically decreasing investor value function because that is the case where asymmetric equilibria are more difficult to obtain. ${ }^{24}$

\footnotetext{
${ }^{24}$ Consider a value function satisfying $\arg \max _{n \in[3, N]} E_{0}\left(V_{m}^{i}(n)\right)=\{3\}$ and $E_{0}\left(V_{m}^{i}(4)\right)=E_{0}\left(V_{m}^{i}(\widetilde{n})\right)$ for some $\tilde{n}>4$. In words, all investors want to be in the smallest possible markets but the investor value function is not monotonically decreasing (it could be U-shaped, for example). With $N=\widetilde{n}+6$ investors, an asymmetric equilibrium with one market of size $\widetilde{n}$ and two markets each of size 3 is stable even if all three intermediaries in Lemma C.1 have pre-existing relationships with all $N$ investors. If instead the value function were monotonically decreasing, then only the symmetric equilibrium with three markets each of size $\frac{N}{3}$ would be stable if all three intermediaries had pre-existing relationships with all $N$ investors.
} 
Proof of Lemma C.1 With $n_{A B}>n_{A C}>n_{B C}$, intermediary $A$ has relationships with the greatest number of investors. The total number of investors with access to intermediary $A$ is $n_{A B}+n_{A C}$. If investors want to trade in the largest possible markets, then all investors with access to intermediary $A$ end up with $A$ under $\ell$-stability for $\ell=N$ in Definition 1 , forming a market of size $n_{A B}+n_{A C}$. The remaining investors will form a market of size $n_{B C}$ with either intermediary $B$ or $C$, leaving one intermediary inactive.

Now suppose investors want to trade in the smallest possible markets. Under the assumption that the investor value function (evaluated at the optimal security) is monotonically decreasing in market size, we can start with any initial market structure and see how investors will move around to form a stable equilibrium. Consider an initial market structure where intermediary $C$ gets $n_{B C}$ investors (any of whom can move to intermediary $B$ ), intermediary $B$ gets $n_{A B}$ investors (any of whom can move to intermediary $A$ ), and intermediary $A$ gets $n_{A C}$ investors (any of whom can move to intermediary $C$ ). To reduce notation, we abstract from the integered nature of investors in what follows. With $n_{A C}>n_{B C}$, some of the investors with intermediary $A$ will want to move to intermediary $C$. Specifically, $\frac{n_{A C}-n_{B C}}{2}$ investors will move from $A$ to $C$, leaving each of $A$ and $C$ with $\frac{n_{A C}+n_{B C}}{2}$ investors. Note that $n_{A B}>n_{A C}>n_{B C}$ implies $n_{A B}>\frac{n_{A C}+n_{B C}}{2}$. Thus, some of the investors with intermediary $B$ will want to move to intermediary $A$, triggering a further move from $A$ to $C$. Denote by $x$ the number of investors that move from $B$ to $A$. The number of investors that further moves from $A$ to $C$ is then $\min \left\{\frac{x}{2}, \frac{n_{A C}+n_{B C}}{2}\right\}$. This will leave intermediary $m \in\{A, B, C\}$ with $\widetilde{n}_{m}$ investors, where

$$
\begin{gathered}
\tilde{n}_{B}=n_{A B}-x \\
\widetilde{n}_{A}=\frac{n_{A C}+n_{B C}}{2}+x-\min \left\{\frac{x}{2}, \frac{n_{A C}+n_{B C}}{2}\right\} \\
\widetilde{n}_{C}=\frac{n_{A C}+n_{B C}}{2}+\min \left\{\frac{x}{2}, \frac{n_{A C}+n_{B C}}{2}\right\}
\end{gathered}
$$

The movement of investors from $B$ to $A$ will stop when $\widetilde{n}_{B}=\widetilde{n}_{A}$, or equivalently

$$
n_{A B}-x=\frac{n_{A C}+n_{B C}}{2}+x-\min \left\{\frac{x}{2}, \frac{n_{A C}+n_{B C}}{2}\right\}
$$

If $x \leq n_{A C}+n_{B C}$, then Eq. (C.1) simplifies to $x=\frac{2 n_{A B}-n_{A C}-n_{B C}}{3}$ so we would need $n_{A B} \leq$ $2\left(n_{A C}+n_{B C}\right)$ to verify $x \leq n_{A C}+n_{B C}$. If instead $x>n_{A C}+n_{B C}$, then Eq. (C.1) simplifies to $x=\frac{n_{A B}}{2}$ so we would need $n_{A B}>2\left(n_{A C}+n_{B C}\right)$ to verify $x>n_{A C}+n_{B C}$. Using $n_{A B}+n_{A C}+n_{B C} \equiv$ 
$N$, we can summarize the solution to Eq. (C.1) as

$$
x=\left\{\begin{array}{lll}
n_{A B}-\frac{N}{3} & \text { if } & n_{A B} \leq \frac{2 N}{3} \\
\frac{n_{A B}}{2} & \text { if } & n_{A B}>\frac{2 N}{3}
\end{array}\right.
$$

Thus, the equilibrium has three markets each of size $\frac{N}{3}$ if $n_{A B} \leq \frac{2 N}{3}$. Otherwise, if $n_{A B}>\frac{2 N}{3}$, the equilibrium has two markets each of size $\frac{n_{A B}}{2}$ and one market of size $N-n_{A B}$ and hence debt and equity will coexist for $n_{A B}$ sufficiently large, specifically $\frac{n_{A B}}{2}>n_{S}>N-n_{A B}$, making the overall condition for coexistence $n_{A B}>\max \left\{\frac{2 N}{3}, 2 n_{S}, N-n_{S}\right\}$.

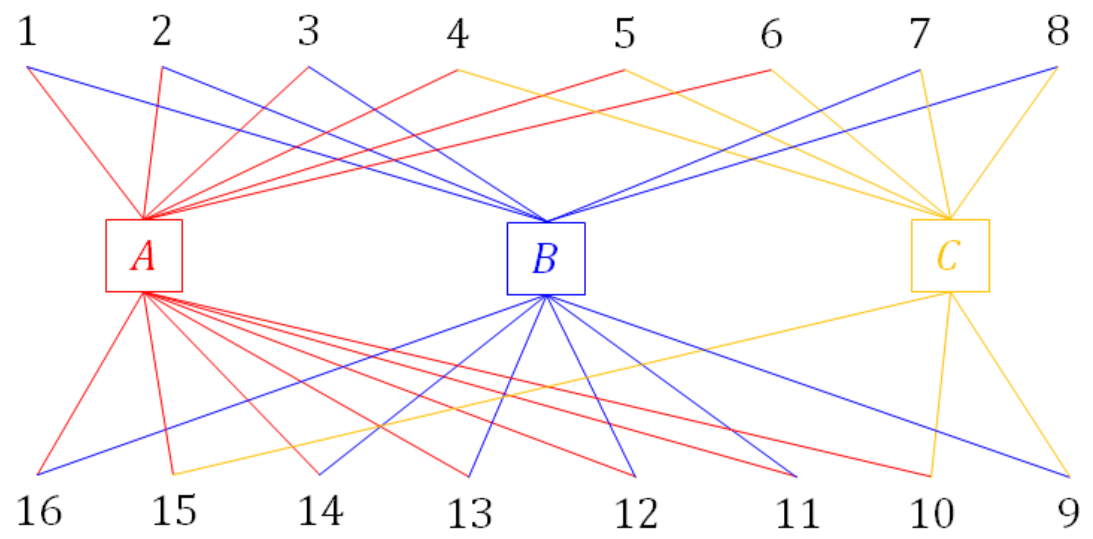

Figure C.1. Relationships example with $M=3$ and $N=16$.

Figure C.1 provides an example of a relationship network with $N=16$, where $n_{A B}=8$, $n_{A C}=5$, and $n_{B C}=3$. Following Lemma C.1, the equilibrium market structure will be asymmetric if investors want to trade in the largest possible markets, with one market of size 13 and one market of size 3 prevailing as the only stable market structure, but it will be (roughly) symmetric if investors want to trade in the smallest possible markets, with two markets of size 5 and one market of size 6 prevailing as the only stable market structure. As the total number of investors $N$ increases, many more examples can be constructed. Consider, for example, $N=65$. If $n_{A B}=30, n_{A C}=20$, and $n_{B C}=15$, then the equilibrium is again (roughly) symmetric if investors want to trade in the smallest possible markets. However, if $n_{A B}=50, n_{A C}=10$, and $n_{B C}=5$, then the equilibrium is asymmetric even if investors want to trade in the smallest possible markets. ${ }^{25}$ The discussion

\footnotetext{
${ }^{25}$ In the first case, the only stable market structure is two markets of size 22 and one market of size 21 . In the second case, the only stable market structure is two markets of size 25 and one market of size 15 .
} 
of asymmetric equilibria here is not meant to be exhaustive about asymmetric equilibria per se. Rather, it is meant to highlight that our model admits equilibria where some intermediaries issue debt securities and others issue equity even when securities are backed by the same underlying asset $Z$. In these equilibria, debt is endogenously traded in smaller markets than equity, for the same reasons we discussed in the analysis of symmetric equilibria.

\section{Asymmetric Equilibria with Different Underlying Assets (Section 4.2)}

Consider $z(s)=\kappa s$ and $f(s)=\frac{1}{S}$. The mean and variance of the underlying asset are then $E_{1}(Z)=\frac{\kappa S}{2}$ and $\mathcal{V}_{1}(Z)=\frac{\kappa^{2} S^{2}}{12}$.

If $n_{m} \leq n_{S}$, then the mean and variance of the asset-backed security are:

$$
\begin{gathered}
E_{1}\left(W\left(n_{m}\right)\right)=\kappa \bar{s}_{m}\left(1-\frac{1}{2} \frac{\bar{s}_{m}}{S}\right) \\
\mathcal{V}_{1}\left(W\left(n_{m}\right)\right)=\kappa^{2} \frac{\bar{s}_{m}^{3}}{S}\left(\frac{1}{3}-\frac{1}{4} \frac{\bar{s}_{m}}{S}\right)
\end{gathered}
$$

where $\bar{s}_{m}$ is characterized by:

$$
\left(\frac{\bar{s}_{m}}{S}\right)^{2}=\frac{\mu_{\theta}-\beta}{\kappa \gamma S} \frac{n_{m}-2}{n_{m}-1}
$$

Thus:

$$
\mathcal{V}_{1}\left(W\left(n_{m}\right)\right)=\left(\frac{\mu_{\theta}-\beta}{\gamma} \frac{n_{m}-2}{n_{m}-1}\right)^{\frac{3}{2}}\left(\frac{\sqrt{\kappa S}}{3}-\frac{1}{4}\left(\frac{\mu_{\theta}-\beta}{\gamma} \frac{n_{m}-2}{n_{m}-1}\right)^{\frac{1}{2}}\right)
$$

so, for a given $n_{m}$, an increase in $\kappa$ will increase the variance $\mathcal{V}_{1}\left(W\left(n_{m}\right)\right)$ of the asset-based security that the intermediary designs.

At any $\kappa$, the condition for the investor's value function to achieve a higher value at $n=n_{\min }$ than at $n \rightarrow \infty$ is:

$$
\left(\frac{\sigma_{\theta}}{\kappa \gamma S}\right)^{2}\left[3-\frac{y_{\min }\left(1-\frac{a}{\sqrt{\kappa}} \frac{y_{\min }}{2}\right)^{2}}{\frac{a}{\sqrt{\kappa}}\left(\frac{1}{3}-\frac{a}{\sqrt{\kappa}} \frac{y_{\min }}{4}\right)}\right]<\left(\frac{a}{\sqrt{\kappa}}\right)^{3} y_{\min }\left(2-y_{\min }^{2}\right)\left(\frac{1}{3}-\frac{a}{\sqrt{\kappa}} \frac{y_{\min }}{4}\right)-\frac{1}{12}
$$

where $a \equiv \sqrt{\frac{\mu_{\theta}-\beta}{\gamma S}}$ and $y_{\min } \equiv \sqrt{\frac{n_{\min }-2}{n_{\min }-1}}$. Note

$$
n_{S}=2+\frac{1}{\left(\frac{a}{\sqrt{\kappa}}\right)^{2}-1}
$$


from Eq. (17) and thus $n_{S} \in(3, \infty)$ requires $\frac{a}{\sqrt{\kappa}} \in(1, \sqrt{2})$. If the number of intermediaries $M$ is such that $n_{\min }=3$, then $y_{\min }=\frac{1}{\sqrt{2}}$ and Eq. (C.2) becomes:

$$
\left(\frac{\sigma_{\theta}}{\kappa \gamma S}\right)^{2}<\frac{\widetilde{a}\left(\frac{\sqrt{2}}{3}-\frac{\widetilde{a}}{4}\right)\left[\frac{\widetilde{a}^{3}}{2 \sqrt{2}}\left(1-\frac{3 \widetilde{a}}{4 \sqrt{2}}\right)-\frac{1}{12}\right]}{\frac{3 \widetilde{a}}{\sqrt{2}}-\frac{7 \widetilde{a}^{2}}{8}-1} \equiv Y(\widetilde{a})
$$

where $\widetilde{a} \equiv \frac{a}{\sqrt{\kappa}} \in(1, \sqrt{2})$. It is straightforward to verify that $Y(\cdot)$ is positive, increasing, and concave over the interval $\widetilde{a} \in(1, \sqrt{2})$. It will then be sufficient to have $\left(\frac{\sigma_{\theta}}{\kappa \gamma S}\right)^{2}<Y(1)$. If the investor's value function has at most one critical point, then the value function will be maximized at $n=n_{\min }$ if $\frac{\sigma_{\theta}}{\kappa \gamma S} \in\left(\frac{1}{3 \sqrt{2}}, \sqrt{Y(1)}\right)$, where the lowerbound is the condition to be in Case 2 or 3 in the environment of the proof of Proposition $5 .{ }^{26}$ Note that this range for $\frac{\sigma_{\theta}}{\kappa \gamma S}$ is non-empty.

The following figure presents an example:

\section{Investor Value Function}

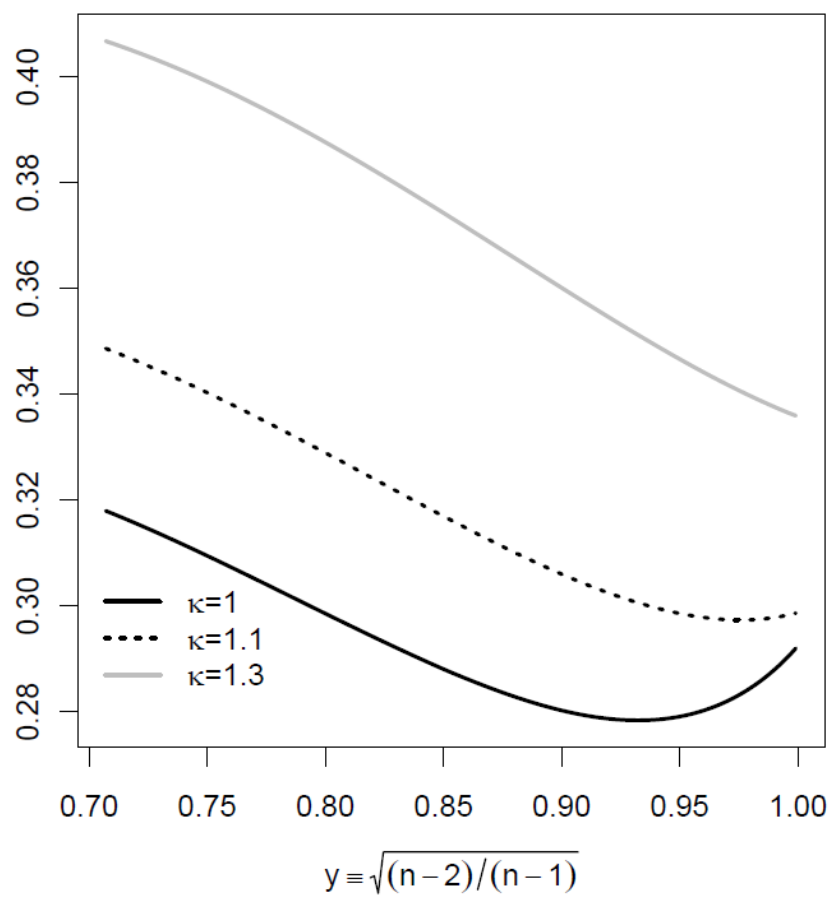

This figure is drawn for $\left(\frac{\sigma_{\theta}}{\gamma S}\right)^{2}=0.065$ and $\sqrt{\frac{\mu_{\theta}-\beta}{\gamma S}}=1.15$, ignoring the scaling factor $\frac{\gamma S^{2}}{2}$.

\footnotetext{
${ }^{26}$ The appeal of these cases is that they permit a direct comparison of the endpoints. Case 1 would require an additional step to show that the value function is maximized at $n=n_{\min }$ rather than $n \in\left(n_{\min }, n_{S}\right)$.
} 
Specifically, we plot

$$
E V(y)=\left(\frac{\sigma_{\theta}}{\gamma S}\right)^{2} \frac{y\left(\sqrt{\kappa}-\frac{a y}{2}\right)^{2}}{a\left(\frac{\sqrt{\kappa}}{3}-\frac{a y}{4}\right)}+a^{3} y\left(2-y^{2}\right)\left(\frac{\sqrt{\kappa}}{3}-\frac{a y}{4}\right)
$$

over the range $y \in\left[\frac{1}{\sqrt{2}}, 1\right]$ for different values of $\kappa$. For all plotted values of $\kappa$, the investor's value function is maximized at the smallest possible market size, $n_{m}=3$, which corresponds to $y=\frac{1}{\sqrt{2}} \cdot{ }^{27}$

Suppose $M^{\prime}$ intermediaries have $\kappa^{\prime}=1$ while the remaining $M^{\prime \prime}$ intermediaries have $\kappa^{\prime \prime}=1.1$. Denote by $E V(n ; \kappa)$ the expected value of an investor in a market of size $n$ when the intermediary has an underlying asset characterized by $\kappa$. We can see from the above figure that $E V(3 ; 1)=$ $E V(n ; 1.1)$ has a solution $n^{*} \in(3, \infty)$. We can also see from the shapes of the value functions for $\kappa=1$ and $\kappa=1.1$ that there is no profitable deviation for investors if all $M^{\prime \prime}$ intermediaries are active and each investor in the economy achieves an expected value of $E V(3 ; 1)$. Thus, a market structure where $M^{\prime \prime}$ intermediaries each get $n^{*}$ investors and $\widetilde{M^{\prime}}$ of the $M^{\prime}$ intermediaries each get 3 investors is stable when the total number of investors in the economy is $N=\widetilde{M^{\prime}} \times 3+M^{\prime \prime} \times n^{*}$ for $\widetilde{M^{\prime}} \in\left[1, M^{\prime}\right]$. The investors in the $M^{\prime \prime}$ markets trade a more variable security than the investors in the $\widetilde{M^{\prime}}$ markets because of both the higher $\kappa$ and the larger market size.

Now suppose $M^{\prime}$ intermediaries have $\kappa^{\prime}=1.1$ while the remaining $M^{\prime \prime}$ intermediaries have $\kappa^{\prime \prime}=1.3$. Also suppose that $N^{\prime}$ investors only have relationships with the $M^{\prime}$ intermediaries while the remaining $N^{\prime \prime}$ investors can choose to trade in any market. From the shapes of the value functions for $\kappa=1.1$ and $\kappa=1.3$ above, we can see that investors are generally better off in smaller markets. For example, if $N^{\prime}=8 \times M^{\prime}$ and $N^{\prime \prime}=4 \times M^{\prime \prime}$, then each of the $M^{\prime}$ intermediaries will get $n^{\prime}=8$ investors while each of the $M^{\prime \prime}$ intermediaries will get $n^{\prime \prime}=4$ investors. The security issued by the $M^{\prime}$ intermediaries then has variance $0.101 \times S^{2}$ while the security issued by the $M^{\prime \prime}$ intermediaries has variance $0.120 \times S^{2}$. In other words, investors in the larger markets trade a less variable security than investors in the smaller markets.

\footnotetext{
${ }^{27}$ For the highest value of $\kappa$ in the figure, the model is in Case 1, which, for the parameterization shown, is also able to deliver the smallest possible market size as the unique symmetric equilibrium.
} 